
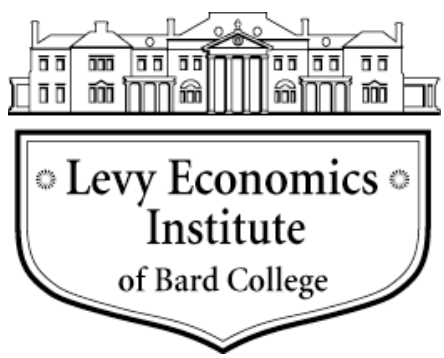

Working Paper No. 680

\title{
The Levy Institute Measure of Economic Well-Being: Estimates for Canada, 1999 and 2005*
}

by

\author{
Andrew Sharpe \\ Alexander Murray \\ Benjamin Evans \\ Elspeth Hazell
}

Centre for the Study of Living Standards, Ottawa

July 2011

\begin{abstract}
* The Levy Institute Measure of Economic Well-Being for Canada was developed as part of the Levy Institute research project "International Comparisons of Economic Well-Being," directed by Edward Wolff and Ajit Zacharias. Andrew Sharpe supervised the construction of the estimates for Canada. We are grateful to the Alfred P. Sloan Foundation for their generous support.
\end{abstract}

The Levy Economics Institute Working Paper Collection presents research in progress by Levy Institute scholars and conference participants. The purpose of the series is to disseminate ideas to and elicit comments from academics and professionals.

Levy Economics Institute of Bard College, founded in 1986, is a nonprofit, nonpartisan, independently funded research organization devoted to public service. Through scholarship and economic research it generates viable, effective public policy responses to important economic problems that profoundly affect the quality of life in the United States and abroad.

Levy Economics Institute P.O. Box 5000

Annandale-on-Hudson, NY 12504-5000

http://www.levyinstitute.org

Copyright (C Levy Economics Institute 2011 All rights reserved 


\begin{abstract}
This report presents estimates of the Levy Institute Measure of Economic Well-Being (LIMEW) for a representative sample of Canadian households in 1999 and 2005. The results indicate that there was only modest growth in the average Canadian household's total command over economic resources in the six years between 1999 and 2005. Although inequality in economic well-being increased slightly over the 1999-2005 period, the LIMEW was more equally distributed across Canadian households than more common income measures (such as after-tax income) in both 1999 and 2005. The median household's economic well-being was lower in Canada than in the United States in both years.
\end{abstract}

Keywords: Well-being, Inequality, Income, Wealth, Government Expenditure, Household Production, LIMEW, (Canada)

JEL Classifications: D13, D31, D63 


\section{The Levy Institute Measure of Economic Well-being: Estimates for Canada, 1999 and $2005^{1}$}

\section{INTRODUCTION}

This report presents estimates of the Levy Institute Measure of Economic Well-being (LIMEW) for a representative sample of Canadian households in 1999 and 2005. The LIMEW is based on a "command over resources" approach to well-being measurement, whereby a household's "economic well-being" refers to its control over, or access to, goods and services.

In recent years, there has been an explosion of interest in the measurement of economic and social well-being. Recognizing that standard measures like per-capita GDP provide an incomplete picture of welfare in a society, researchers have developed a variety of alternative indexes designed to be more comprehensive in their coverage of the factors that affect wellbeing. Examples include the Human Development Index (HDI), ${ }^{2}$ Canadian Index of Well-being $(\mathrm{CIW}),{ }^{3}$ the Genuine Progress Indicator (GPI), ${ }^{4}$ and the Legatum Prosperity Index (LPI). ${ }^{5}$

During over a decade of involvement in this area of research, the Centre for the Study of Living Standards (CSLS) has developed its own Index of Economic Well-being (Osberg and Sharpe 2009a; 2009b), and has participated in the construction of other indexes including the CIW (Sharpe and Arsenault 2009). Our participation in the LIMEW project represents the continuation of a longstanding research program for the CSLS.

The LIMEW, developed by the Levy Institute of Bard College, is a comprehensive household-level measure of command over resources. It consists of four components, as shown in Exhibit 1. The first component is base income, which is the sum of wages, salaries, self-

\footnotetext{
${ }^{1}$ Alexander Murray was an economist at the Centre for the Study of Living Standards (CSLS) and is now in a PhD program at New York University. Benjamin Evans was a research assistant at the CSLS and is currently employed at the Bank of Canada. Elspeth Hazell is an economist at the CSLS. This paper was written under the supervision of Andrew Sharpe of the CSLS. The authors would like to thank Thomas Masterson and Ajit Zacharias of the Levy Institute of Bard College for advice and assistance, and in particular, for carrying out the statistical matching of micro-datasets. In addition, this paper was presented at the 2010 meeting of the Canadian Economics Association in Quebec City, May 28-30, and at the Workshop on International Comparisons in Economic Well-Being among Advanced Industrialized Countries on December 2, 2010. The authors thank Michael Veall for useful comments.

${ }^{2}$ See the HDI web site at http://hdr.undp.org/en.

${ }^{3}$ See the CIW web site at http://www.ciw.ca/en/Home.aspx.

${ }_{5}^{4}$ See the GPI web site at http://www.rprogress.org/index.htm.

${ }^{5}$ See the LPI web site at http://www.prosperity.com.
} 
employment income, fringe benefits and interpersonal transfers (e.g. child support). Income from property (e.g. dividends and rent received) is not included.

The second component is income from wealth, including both the primary residence and non-home assets. The annual "command over resources" arising from the primary residence is estimated by the imputed yearly rent on the residence net of annual mortgage payments.

Household non-home wealth is converted from a stock to a flow using an annuity method.

\section{Exhibit 1: Components of the LIMEW}

\section{Line No. Component}

\begin{tabular}{l|l|}
\hline & \\
1 & Household Earnings \\
3 & Fringe benefits \\
4 & Money income other than earnings \\
5 & Alimony \\
6 & "Other income" \\
7 & Base Income = sum of lines 1-3 \\
8 & Annuity from non-home wealth \\
9 & Net imputed rent on housing \\
10 & Income from wealth = sum of lines 7-8 \\
11 & Government transfers \\
12 & Public consumption \\
13 & Taxes \\
14 & Federal income tax \\
15 & Provincial income tax \\
16 & Payroll tax \\
17 & Consumption tax \\
18 & Property tax \\
19 & Net Government Expenditure = lines $\mathbf{1 0 + 1 1 ~ - ~ 1 2}$ \\
20 & Household production \\
& LIMEW = lines $\mathbf{6 + 9}+\mathbf{1 8}+\mathbf{1 9}$ \\
\hline
\end{tabular}

The third component is net government expenditure, which consists of three subcomponents: government cash transfers to households, taxes paid by households, and public consumption. Public consumption is the value of goods and services consumed by government on behalf of households.

The final component of the LIMEW is household production. The value of household production is evaluated using time-use data and a performance index. The sum of the four 
components-base income, income from wealth, net government expenditure, and household production-is the total LIMEW.

The Levy Institute has constructed LIMEW estimates for a representative sample of households in the United States for a number of benchmark years. The conceptual basis of the LIMEW and findings for 1959, 1972, 1982, 1989, 2000, and 2004 are discussed in Wolff, Zacharias and Masterson (2009). The Centre for the Study of Living Standards (CSLS) was commissioned to produce comparable estimates for Canada, and those estimates are presented in this report. The motivation for this project is twofold. First, the LIMEW provides a comprehensive measure of economic well-being at the household level. This can be used to analyze both the average level of well-being and its distribution within Canada, both at a point in time and over the 1999-2005 period. ${ }^{6}$ Second, the comparability of the Canadian and US LIMEW estimates allows us to draw comparisons between Canada and the United States in terms of economic well-being. We will also be able to compare the LIMEW to other measures of economic welfare. For instance, the United States currently has both a higher GDP per capita and higher income per capita than Canada. ${ }^{7}$ Does the United States also have a higher average household LIMEW than Canada? Has the growth of the LIMEW differed from that of perhousehold GDP?

The remainder of this report is structured as follows. Section II describes the sources of the data underlying the LIMEW and outlines the process by which several surveys were statistically matched to generate a synthetic microdata file. In Section III, we describe how the components of the LIMEW were estimated based on the synthetic microdata file. The empirical results are presented in Section IV, and Section V presents a detailed discussion of two components - income from wealth and household production-that experienced significant changes between 1999 and 2005. Section VI summarizes and concludes.

\footnotetext{
${ }^{6}$ The CSLS planned to produce Canadian LIMEW estimates for 1992, but the necessary data on household wealth were not available. There was a 16-year gap between the last wealth supplement of the Survey of Consumer Finances (SCF) in 1983 and the introduction of the Survey of Financial Security (SFS) in 1999, which leaves us without a wealth survey within the vicinity of the early 1990s. We considered using the 1999 SFS for the wealth component in a LIMEW for 1992 and adjusting the wealth variables by either the rates of return or the aggregate levels of the National Balance Sheet Accounts for the household and non-profit sector. Both of these approaches were deemed inadequate as there were significant changes between 1992 and 1999 not only in the level of household wealth but also in its distribution.

${ }^{7}$ Ross and Murray (2010) provide per-capita estimates of eight different national income measures: gross domestic product, net domestic product, gross national product, net national product, gross domestic income, net domestic income, gross national income, and net national income. They show that the US values exceed the Canadian values for all eight measures in per-capita terms.
} 


\section{DATA SOURCES AND STATISTICAL MATCHING}

The LIMEW is a household-level measure and most of its components are based on microdata from surveys. The exception is the public consumption component, which is based on aggregate public expenditure data and distributed across households according to various criteria. This section describes how the data underlying the LIMEW were collected and prepared for use. As in the case of the United States, the microdata necessary to calculate the income, wealth, and household production components of the LIMEW are not found in any single survey. Thus multiple datasets had to be statistically matched by households or individuals.

\section{A. Data Sources}

Exhibit 2 outlines the data sources used in the construction of the Canadian LIMEW estimates. The microdata are drawn from Statistics Canada surveys. The primary sources for demographic information and income variables are the 1999 and 2005 iterations of the Survey of Labor and Income Dynamics (SLID). Data on household assets and debts are drawn from the Survey of Financial Security (SFS) for 1999 and 2005. The General Social Survey (GSS) focused on time use in 1992, 1998, and 2005; the 1998 and 2005 GSS will be our source for information on time spent on household production. 
Line No. Component

\begin{tabular}{|c|c|c|}
\hline 1 & Household Earnings & SLID \\
\hline 2 & Fringe benefits & Unpublished Statistics Canada data \\
\hline 3 & $\begin{array}{l}\text { Money income other than } \\
\text { earnings }\end{array}$ & \multirow[t]{3}{*}{ SLID } \\
\hline 4 & Alimony & \\
\hline 5 & "Other income" & \\
\hline 6 & Base Income = sum of lines 1-3 & \\
\hline 7 & Annuity from non-home wealth & Statistical matching of SLID and SFS \\
\hline 8 & Net imputed rent on housing & $\begin{array}{l}\text { Statistical matching of SLID and SFS; aligned } \\
\text { with SNA aggregate }\end{array}$ \\
\hline 9 & $\begin{array}{l}\text { Income from wealth = sum of lines } \\
8-9\end{array}$ & \\
\hline 10 & Government transfers & SLID data aligned with SNA aggregate \\
\hline 11 & Public consumption & SNA and others; see Section III \\
\hline 12 & Taxes & \\
\hline 13 & Federal income tax & \multirow{3}{*}{$\begin{array}{l}\text { SLID data aligned with SNA aggregates } \\
\text { SLID }\end{array}$} \\
\hline 14 & Provincial income tax & \\
\hline 15 & Payroll tax & \\
\hline 16 & Consumption tax & $\begin{array}{l}\text { Statistics Canada Input-Output Commodity Tax } \\
\text { Model }\end{array}$ \\
\hline 17 & Property tax & Tax rates from SHS; home ownership from SLID \\
\hline 18 & $\begin{array}{l}\text { Net Government Expenditure = } \\
\text { lines } 11+12-13\end{array}$ & \\
\hline 19 & Household production & Statistical matching of SLID and GSS \\
\hline 20 & Household production = line 19 & \\
\hline 21 & LIMEW $=$ lines $6+9+18+20$ & \\
\hline
\end{tabular}

Notes:

SLID = Survey of Labour and Income Dynamics, SNA = System of National Accounts

SFS = Survey of Financial Security, GSS = General Social Survey

SHS = Survey of Household Spending

\section{B. Statistical Matching}

In both years for which we are estimating the LIMEW for Canada, the SLID is considered the base or "recipient" database, while the SFS and GSS serve as "donor" files that augment the recipient file. For each year, two matching processes must be completed: one to match the SLID to the SFS at the household level, and one to match the SLID to the GSS at the individual level. A detailed discussion of matching procedure and the quality of statistical matches can be found in Masterson (2010). 
The variables used to align the datasets are chosen for analytic and distributional importance. The variables across which we are most interested in drawing average LIMEW comparisons should be matched so our comparisons are accurate. For example, in the United States researchers are concerned about the relative well-being of races, so race is a key variable. If race were not carefully matched, it would be impossible to accurately compare the difference in the average LIMEW of races. Variables that will be used to distribute LIMEW components across households should be matched so that we do not misallocate LIMEW components across households.

The SLID public use microdata file (PUMF) is actually several files: a census family file, an economic family file, a person file for individuals 16 and older, and a key file for persons of all ages. We mainly used the person file and the key file as data sources, but the economic family file was also used for statistical matching. Most variables of interest are coded at the individual level rather than the household level, but it is easy to generate household-level data by aggregating across individuals within households. Unlike the SLID, the SFS does not collect information on individuals. The 2005 SFS has variables containing characteristics of entire economic families, such as size, number of earners, and total income, as well as key characteristics of the major income recipient, namely age, sex, and education level. ${ }^{8}$

\section{i. Matching the SLID and the SFS}

We analyzed the distribution of the variables in the SLID and SFS microdata files to assess the potential for statistical matching. The SFS purposely oversamples affluent families, so only the weighted distributions of variables are expected to have similar distributions to the SLID. Household size, number of earners, region, total income, home ownership status, household type, sex, age and the education level of the major income earner were all aligned for matching. A description of the process for alignment of those variables follows.

In the 2005 SLID household size is top-coded at seven people, but the SFS is top-coded at five. Thus, the SLID household size variable is truncated at five for the purposes of matching with the SFS, but is un-truncated when used to generate an equivalence scale (to adjust for household size). In a manner similar to the household size variable, the variable on the number

\footnotetext{
${ }^{8}$ Note that "household" and "economic family" are not synonymous; a household may contain multiple economic families. The SFS is an economic family-level survey. It was matched to the SLID economic family file, and then data were aggregated across economic families within households.
} 
of earners in a household is also top-coded at different levels for each survey. In the SLID the number of earners is top-coded at seven, but the number of earners is top-coded as three in the SFS. Thus, the number of earners variable in the SLID is truncated at three for the purpose of matching.

The public-use 2005 SFS suppresses the province of the household, only giving the region of the household. Therefore, we can only match on a regional basis rather than a provincial basis. The five regions are Quebec; Ontario; and British Columbia; the Atlantic region, composed of the provinces of Newfoundland and Labrador, Nova Scotia, New Brunswick, and Prince Edward Island; and the Prairie region, composed of the provinces of Manitoba, Saskatchewan and Alberta. Due to the lack of a provincial variable in the 2005 SFS, the region will be our primary geographic variable. ${ }^{9}$

The one proxy variable for wealth found in the SLID is homeownership, which can be matched with the homeownership variable in the SFS. Unfortunately, using both weighted and un-weighted statistics, the SFS understates homeownership relative to the SLID. The reason for this is unclear, but may be related to the exact wording of the questions or to sampling error. The most reliable estimate for homeownership is the census, which in 2006 was 68.5 per cent of economic families. The 2005 SLID estimated homeownership at 67.1 per cent, whereas the 2005 SFS estimated homeownership at only 61.9 per cent.

The families are matched by family type according to the following categories: unattached individual, couples living without children under 18, couples living with children under 18, lone parents, and other family types. The SLID contains a more detailed breakdown of family type; although this detailed variable does not exist in the SFS, it is possible to construct it using other variables containing information about the composition of the economic family. These family types are broken down into subtypes. Unattached individuals may be male or female, elderly or non-elderly. A couple can be elderly or non-elderly; it is classified as elderly if the major income earner is 65 years of age or older, and non-elderly otherwise. Elderly couples are classified either as without children or other relatives at home or as part of the "other families" category.

\footnotetext{
${ }^{9}$ While it is still possible to analyze the difference in LIMEW between provinces in the same region, the differences may be understated do to a miss-matching of wealth. For example, since we will match on a regional rather than provincial basis, it is possible that the income file of an Albertan family will be matched with the wealth file of a Manitoban family. If Alberta and Manitoba have a different distribution of wealth with respect to income and other matching variables, then the comparison may understate the differences in economic well-being.
} 
Since the SLID does not classify one individual within a family as the head or the major income earner in the economic family file, we needed to use the person-level microdata file to identify the major income earner in order to match the SLID with the SFS. This was done by arranging the data by economic families. Within each family we found the individual with the greatest earnings, and in the case of a tie we designated the male as the head.

The characteristics of sex, age and education of the major income earner were checked for similar distributions in the SLID and SFS. The education of the head-of-household variable in the SFS is not as detailed as the one that can be constructed using individual- and family-level SLID data. Only four categories are given: less than high school, a high school diploma, nonuniversity post-secondary certificate, and a university degree or certificate. Thus, the education categories in the SLID have to be aligned with those found in the SFS. When we reduced the number of education categories in the SLID they were found to have a similar distribution to those in the SFS.

\section{ii. Matching the SLID and the GSS}

The GSS has been used for its time use variables. The GSS only collects detailed information about time use (for one particular day) for the individual survey respondent, rather than for the time use patterns of the entire household or family. Thus, the GSS is matched to the personlevel SLID file. The matched variables can then be aggregated to the household level. As a practical matter, this means that individuals from different households are statistically matched to be in the same SLID household, albeit households with similar characteristics.

The person-level SLID and the GSS are matched according to individual characteristics—educational attainment, total individual income, and age—as well as some nonindividual characteristics that are also available in the GSS, such as family type, region of residence, and total household income.

To facilitate matching, the distribution of the variables in the 2005 GSS was compared with the person-level file from the 2005 SLID. Total income of the respondent, total income of the household, age, sex, and marital status of the respondent, region, household size, home ownership, and education level and main activity of the respondent were all found to have similar distributions using person-level weighting. 


\section{Summary}

The process for constructing the synthetic microdata file can be summarized as follows. The economic family SLID file is augmented by the person-level characteristics of families' major income earners, drawn from the SLID key file and person file. This augmented economic family file is then matched with the SFS file, giving families wealth characteristics. These are converted to household-level characteristics by aggregating across economic families within households.

The person-level SLID file is matched to the GSS file, giving those persons time use characteristics. These characteristics are then converted to household characteristics by aggregating across individuals within SLID households. Combining the two synthetic household-level files yields one synthetic microdata file of households with variables on income, wealth, and time use.

A final note: the 1999 SFS does not contain the gender decompositions of the head of the household, which is unfortunate because it reduces our analytic ability to measure distinctions between the economic well-being of men and women. This is because in the process of statistically matching the 1999 SLID and SFS datasets, we may attribute the wealth of maleheaded SFS families to female-headed SLID families and vice-versa. (This is not an issue for 2005 , since the 2005 SFS does indicate the sex of the major income earner.) Of course, we will still be matching for other characteristics including income and home value, but considering the importance of gender differences in command over economic resources, it should be kept in mind that our estimates may understate them.

\section{ESTIMATING THE LIMEW AND ITS COMPONENTS}

This section provides a detailed description of the process by which the components of the LIMEW are estimated using the synthetic microdata files and data from other sources.

\section{A. Base Income}

In the construction of the LIMEW, the first element is base income, defined as the sum of earnings, interpersonal transfers, and in-kind compensation from work, which includes employer contributions for health insurance. Earnings and alimony are found in the SLID. However, in-kind compensation, or fringe benefits, are not included in the SLID. The 1999 and 
2005 SLID questionnaire does ask its respondents if their employer offered them supplementary medical insurance, dental insurance, or life/disability insurance. However, these data are not included in the public use microdata files. Sharpe et al. (2008) used special request data from Statistics Canada on the value of supplementary labor income in the form of employers' contributions to accident and sickness insurance plans, group term life insurance plans, administrative service contracts (non-insurance benefits (e.g. for health) that are paid by employers and administered by insurance companies), premiums to provincial health plans in Alberta and British Columbia, and non-profit health plans. These totaled \$13,147 million in 1999 and \$20,956 million in 2005 (in current dollars). We will use this data for the aggregate amount of supplementary income.

We attribute benefits to persons based on the size of their workplace and whether they are covered by a collective agreement. The probability of receiving fringe benefits is estimated by workplace size and collective agreement coverage status based on the Workplace and Employee Survey. Benefits are then assigned to SLID workers on the basis of these probabilities. Each worker assigned benefits receives the same value of benefits, and nonworkers and those not assigned benefits receive zero benefits.

\section{B. Government Transfers}

Cash transfers from the government, such as Social Assistance, Old Age Security, Canada Pension Plan benefits, and Employment Insurance benefits, are identified in the SLID. However, we do not use these numbers directly. We obtain the aggregate value of government transfers to persons from CANSIM and allocate them across SLID individuals according to their shares of total transfer income as reported in the SLID. This ensures that the value of government transfers in our estimates is equal to the total from the national accounts.

Canada has no significant non-cash transfer programs like the Supplemental Nutrition Assistance Program (food stamps program) in the United States. However, a large portion of government health expenditure is considered part of non-cash government transfers in order to be comparable to the U.S. LIMEW.

Given the dramatically different structures of the Canadian and American healthcare systems, the distributional effects of the Canadian national healthcare system are of great interest. However, measuring the distributional effect of Medicare is difficult. Work has been done to estimate the distribution of government spending on healthcare (Gillespie 1980; Manga 
1978). Nevertheless, one well-documented healthcare cost pattern is the concentration of expenditures during late-life and end-of-life care.

Health Canada (2001) shows the distribution of government expenditure on healthcare by several expenditure categories and by age and sex. The report divides healthcare expenditure into seven categories: hospitals, other institutions, physicians, other professionals (mainly dentists), drugs, home care services, and other expenditures. We used the proportions of these seven categories in 2000-1 to allocated and distribute health care expenditures in both 1999 and 2005.

Expenditures in the categories of other institutions, home care services and "other expenditures" are considered part of public consumption, and will be discussed in that section. The remaining expenditure categories-hospitals, physicians, other professionals, and drugsare combined into a single expenditure category and are considered part of non-cash transfers. These expenditures are allocated across households on the basis of the number, age and sex of household members, using the spending shares by age and sex from Health Canada (2001). ${ }^{10}$

\section{Taxes}

When constructing the LIMEW, taxes have to be subtracted from base income. Income taxes and the employee portion of payroll taxes are provided in both years of the SLID, but property taxes and consumption taxes are more difficult to calculate. Payroll taxes in Canada take several forms, some of which are paid in part or in entirety by the employer. We ignore those that are paid entirely by the employer (such as workers compensation). Only the taxes actually paid by members of households need to be subtracted from base income. These taxes consist of three components: the employee proportion of employment insurance (EI); Canadian Pension Plan or Quebec Pension Plan (CPP/QPP) (the Canadian equivalent of Social Security); and public health insurance premiums. All three are found in the 1999 and 2005 SLID.

Information on property taxes is drawn from the Survey of Household Spending (SHS), since it is not available in the SLID or the SFS. Although property taxes are set by municipalities, public use microdata do not reveal the municipalities in which households are located. Because the value of the homes is not included in the SHS, we calculated the average

\footnotetext{
${ }^{10}$ For example, Health Canada (2001) reports that males aged 45-54 received 5.3 per cent of total public health expenditures, while females aged 35-44 received 5.9 per cent. A household containing three individuals - two males aged 45-54 and one female aged $35-44$ - would receive $100 *(0.053 *(2 / x)+0.059 *(1 / y))$ per cent of health expenditures in this expenditure category, where $\mathrm{x}$ is the total population of males aged 45-54 and $\mathrm{y}$ is the total population of females aged 35-44.
} 
property tax rate by region in 2005 by dividing the total amount paid in property taxes by households (from the SHS) by the total value of properties (from the SFS) in each region. In 1999, the SFS has a province variable so we calculated average property tax rates the same way, but by province instead of region.

We define consumption taxes as total commodity taxes, both direct and indirect, at the federal and provincial levels. Federal commodity taxes include custom import duties, excise taxes and duties, and the Goods and Services Tax (GST). Provincial commodity taxes include liquor taxes, profits on liquor commissions, gasoline taxes, amusement taxes, tobacco taxes, and retail sales taxes.

Consumption taxes are not included in any of the surveys. In order to estimate consumption tax rates we requested Statistics Canada to calculate the proportion of income spent on consumption taxes by provinces and disposable income deciles. Statistics Canada calculated this by using the Input-Output Commodity Tax Model associated with their Social Policy Simulation Database and Model (SPSD/M), a microsimulation model used for policy analysis (Statistics Canada 2009a). The commodity tax model calculates the amount households spend on commodity taxes by first calculating the effective tax rate for each tax type and then multiplying the effective tax rate by the amount spent on the category in the database (SPSD).

As noted above, our definition of consumption taxes includes both direct and indirect taxes. Direct taxes are paid during the final purchase of the good and services, whereas indirect taxes are paid at some point in the production process. The commodity tax model assumes all indirect taxes are fully passed on to the consumer.

Using these assumptions Statistics Canada calculated for us the average amount economic families spent on commodities taxes in 1999 and 2005, by disposable income (i.e. after income tax) decile and by province. We then divided these amounts by the average disposable income by deciles and provinces to get the ratio of average tax spent over average income. Then for each household, we multiplied this ratio of average tax spent (in their province and income decile) over average income (in their province and income decile) by household disposable income to obtain the total consumption tax paid by the household.

\section{Income from Wealth}

The LIMEW includes two categories of income from wealth: home wealth and non-home wealth. Income from home wealth is the imputed annual rent on the household's primary 
residence, net of the annuitized value of mortgage debt. Income from non-home wealth is an annuity based on the household's holdings of wealth other than the primary residence. (It may include non-primary housing, if the household owns multiple homes.) We outline how these values are computed, beginning with non-home wealth.

\section{i. Non-Home Wealth}

In the LIMEW, non-home wealth, which is a stock, is converted into a flow by calculating a lifetime annuity - the annual payment that would exhaust the value of the asset over the expected remaining lifetime of the asset owner. For a given asset, the lifetime annuity depends on three factors: the current value of the asset, the number of years over which the asset is to be wholly converted to income and the expected annual rate of return on the asset over that time period. We address each of these in turn.

\section{a. Assets and debts: Financial and non-financial non-home wealth is divided into four} categories of assets and one category of debts. The asset categories are real estate and business assets, liquid assets, financial assets, and pension assets. Real estate and business assets include all real estate other than the primary residence, as well as business equity. Liquid assets include the value of savings accounts, checking accounts, and term deposits, but exclude liquids assets which are part of registered retirement savings plans (RRSPs). Financial assets include mutual funds, other investment funds, income trusts, domestic and foreign stocks, domestic and foreign shares in companies, saving bonds and other types of bonds, and other types of financial investments. Financial assets that are part of RRSPs are not included.

Pension assets are the sum of registered pension plans, non-registered pensions, and other specialized retirement savings plans. The latter category includes RRSPs, which are analogous to Investment Retirement Accounts (IRAs) in the United States. At 71 or earlier, Canadians must withdraw all funds from their RRSP, convert it to an annuity or convert it to a Registered Retirement Income fund (RRIF). RRIFs are also included in pension assets. Nonregistered pension plans include deferred profit sharing plans, executive and foreign pension plans, and annuities.

There are two primary categories of registered pensions: defined benefit and defined contribution. In defined benefit plans, employees pay in a certain amount of their pay into the scheme and the payout they receive after retirement is based on the average salary of a certain 
number of the last years they work multiplied by the number of years they work. It is not directly related to the amount they have paid in. Furthermore, as the payout is not based on the returns to investment, the employer bears all the risk. In defined contribution plans, the payouts in retirement are based on the value of payments and interest the payments have accrued. Thus the employee bears the risk. Because defined contribution plans have worth that can be exchanged in the market, they are fungible or marketable wealth. Defined benefit plans do not have the same quality and are thus excluded from the LIMEW definition of wealth. This may understate the level of economic well-being of Canadians relative to Americans. As of January 1, 2006, only 15.7 per cent of Canadians with employer pensions were covered by defined contribution plans (Statistics Canada 2007). This is contrasted with the United States, where defined contribution plans are the norm. It is not possible to identify which households have defined benefit plans and which have defined contributions plans in the SFS. ${ }^{11}$ In order for our Canadian LIMEW estimates to be fully comparable to the US estimates, a US LIMEW must be calculated to include the value of defined benefit plans.

The debt category is "other debts." It includes all debts other than the mortgage on the primary residence.

The values of all assets and debts are taken directly from the SFS.

b. Number of years: The annuity is computed based on the number of years that the household is expected to remain in existence. To estimate this, we take the maximum of the remaining life expectancies of the household's major income earner and his or her spouse (if a spouse exists). The expected number of remaining years of life for an individual is computed using Statistics Canada's life tables (or actuarial tables), which provide life expectancy estimates by age, sex, and province of residence.

\footnotetext{
${ }^{11}$ The SFS uses a complex procedure to estimate the combined value of defined benefit and defined contribution plans. The procedure is documented in Statistics Canada (2001).
} 
c. Expected rates of return: The final factor needed to compute an annuity is the expected real annual rate of return on the asset over the household's remaining lifetime. We estimate nominal rates of return by asset category, based on historical nominal rates. As in the US LIMEW, we base historical returns on average rates of return over the 1960-2009 period, although in some instances historical data on rates of return do not extend that far into the past. Using these nominal rates, real rates of return are calculated by the Fisher equation,

$$
r=\frac{\left(1+r^{n}\right)}{(1+p)}-1,
$$

with $r^{n}$ being the nominal rate of return and $p$ being the compound annual inflation rate (CPIbased) in Canada over the 1960-2009 period. The nominal and real rates of return used are given in Appendix Table 7.

d. Calculating the annuities: Once the asset values, number of years of remaining household life, and expected annual rates of return by asset- (or debt-) type are obtained, the annuities are estimated according to the following formula:

$$
\text { Yearly Payments }=\frac{r \times \text { Asset }}{1-(1+r)^{-\max (\text { LifeExpHead,LifeExpSpouse })}}
$$

Once the annuity for each class of assets and debts is calculated, the sum of the yearly payments received from assets minus the yearly payments due from debts is the yearly flow of income from non-home wealth.

\section{ii. Home Wealth}

The estimation of home wealth is more straightforward. It is the difference between imputed yearly rent on the primary residence and the lifetime annuity of the primary mortgage. The mortgage annuity is computed using the annuity formula described above. Rent is imputed by retrieving the aggregate amount of imputed rent on owner-occupied housing in Canada, available from CANSIM. Aggregate imputed rent is allocated across households according to their shares of the aggregate value of housing (based on the SFS data). 
e. Public consumption: Public consumption by households is the most complex component of the LIMEW. It is estimated in three stages. First, aggregate public consumption is estimated with a detailed breakdown by the function of the spending. Second, expenditures within each functional category are attributed in whole or in part to the household sector. Expenditures attributed to the non-household sector (that is, the business sector or the foreign sector) are not included in the LIMEW. In the final stage, the household sector's shares of government consumption in each functional category are distributed across households according to category-specific criteria. Each of these three stages is discussed below. We provide only the most important details here. More details can be found in Appendix 1.

i. Calculating aggregate government expenditure by function: When we attempted to calculate public consumption by households for Canada using an approach similar to that used in the LIMEW of the United States, four main challenges were encountered:

1. The main dataset for government expenditure categorizes spending according to the financial management system (FMS), which does not contain the necessary detail in expenditure subcategories. Thus, either additional data sources or interpolation was required.

2. The presence of intergovernmental spending within government expenditure functions can lead to double counting if not corrected. The guiding principle used was government expenditure should only be counted at the final stage of purchases (of goods and services) by the government.

3. Transfer payments to individuals are also included within the government expenditure function. Since transfers to individuals are counted as income, they would be double-counted in the LIMEW if our public expenditure functions included these as well. Therefore, government transfers to persons must be removed from government expenditure in order to determine public consumption.

4. The government expenditure in the FMS is calculated on a gross basis; that is, the government expenditure includes expenditure on items which are sold to the non-government sector. The SNA reports government expenditure on a net basis by reducing government expenditure by the amount of sales to other sectors. This must be accounted for in our estimates.

These difficulties would not exist if there were Canadian data comparable to the United States' NIPA Table 3.15.5, in which net government expenditure on consumption and capital is broken down by function. However, the data on Canadian government expenditure is either 
broken down by expenditure type (e.g. on goods on services, fixed capital formation, inventories, transfer payments), as in the case of the National Accounts data, or is described by function (e.g. on national defense, roads, education) as in the Financial Management Systems (FMS) data. The FMS data contains categories similar to those in the American NIPA tables, but does not distinguish between spending on goods and services and transfers to individuals, businesses, or other levels of government.

We use the FMS data as our primary source. The categories and subcategories of government expenditure from the FMS form the structure of our functional breakdown of government expenditure. It contains variables on categories of government expenditure for multiple levels of government: consolidated government, Federal-Province-Local, Provincial and Local, Provincial, and Canadian Pension Plan/Quebec Pension Plan. However, the data on provincial and local government expenditure was insufficiently detailed for our purposes. It was augmented with additional data for expenditure on policing, firefighting, and transportation from other series in CANSIM (see Appendix 1).

There exist significant transfers of funds between the different levels of government within Canada. Merely removing the spending category of general inter-governmental transfers would be insufficient because many federal government programs include transfers to lower levels of government, so the presences of these specific-use transfers means double counting would still occur. This is evident by the fact that the sum of total federal expenditure and total provincial and local expenditure exceeds total consolidated government expenditure (by $\$ 52.1$ billion in 2005, according to the FMS data.) By taking the difference between consolidated government expenditure and consolidated provincial and local we derived federal government expenditure minus transfers to provincial and local governments.

Another problem we needed to address was the existence of transfer payments to persons. Unfortunately, data on the amounts of transfer payments on a basis fully compatible with the government expenditure data (by function) are not available. The best we could do was use transfers to persons on a provincial economic accounts basis. Unfortunately, this creates an inconsistency as the provincial economic accounts are on a calendar year basis whereas the FMS are on a financial year basis (April 1 to March 31). However, since three out of four quarters are the same it was assumed the level of transfers to persons was the same in the calendar year as in the fiscal year. It was assumed that transfer payments to persons fall entirely within the social services category of government spending. 
Finally, the CANSIM data represent gross government expenditures. In order for our estimates to be consistent with the US estimates, we must subtract government sales of goods and services to generate net government expenditure data. Since CANSIM does not provide estimates of government sales by expenditure category, we allocate the aggregate sales across the expenditure categories on the basis of the categories' shares of government spending net of intergovernmental and personal transfers. In 2005, sales of goods and services amounted to 4.0 per cent of gross federal government expenditures (net of all transfers) and 12.5 per cent of gross provincial and local government expenditures (net of all transfers). ${ }^{12}$

\begin{tabular}{|c|c|c|}
\hline \multirow[t]{2}{*}{ Expenditure Category } & \multicolumn{2}{|c|}{ Share (Per Cent) } \\
\hline & 1999 & 2005 \\
\hline Education & 21.0 & 20.1 \\
\hline Health & 19.5 & 23.7 \\
\hline Protection of Persons and Property & 10.2 & 10.8 \\
\hline Social Services & 7.5 & 6.8 \\
\hline Transportation and Communication & 5.5 & 5.9 \\
\hline
\end{tabular}

After correcting these problems, we derived estimates for combined federal and CPP/QPP government expenditure on goods and services and combined provincial and local government expenditure on goods and services. Throughout the rest of the report, federal expenditure will refer to both federal expenditure and CPP/QPP expenditure on goods and services and provincial expenditure will refer to both provincial and local expenditure on goods and services.

Appendix Tables 1 and 2 present the estimates of aggregate public consumption by expenditure category for 1999 and 2005. In terms of combined federal, provincial and local

\footnotetext{
${ }^{12}$ Government sales of goods and services include such things as water charges; rents on buildings; sales of used buildings, machines or equipment; airport landing fees; tolls on transportation infrastructure; tuitions; court fees; and fees for government documents (e.g. passports, all licenses other than licenses to operate vehicles or to hunt wildlife). Intergovernmental sales are in principle eliminated through data consolidation in the FMS (Statistics Canada, 2009b). Since we allocate aggregate government sales across spending categories before distributing net government expenditure between the household and non-household sectors, we implicitly assume that the distribution of government sales between the sectors is the same as that of government expenditures. This may be a problematic assumption, but it is unavoidable in the absence of direct information on the distribution of government sales.
} 
spending, the largest expenditure categories are education, health, protection of persons and property, social services, and transportation and communication (Exhibit 3). Education accounted for about 20 per cent of aggregate public consumption in both 1999 and 2005. Health's share was 19.5 per cent in 1999 and 23.7 per cent in 2005. No other category is more than half as large as these two.

\section{ii. Allocating government expenditures to the household sector: Not all government expenditure} on goods and services directly benefits households. Some of the benefits of public consumption accrue to the business sector. ${ }^{13}$ In order to isolate the spending that directly benefits households, government expenditure on goods and services is allocated to the household and non-household (i.e. business) sectors.

When deciding how to allocate public consumption, our main goal is consistency with previously established LIMEW estimates for the United States. Each category or subcategory was allocated using a method similar to that used in the equivalent category in the United States LIMEW as found in Appendix Table 3. The allocation method for the Canadian estimates is outlined in Appendix Table 4.

The most important expenditure categories are education, health, transportation and communication, and protection of persons and property. Government consumption in health and education are entirely allocated to the household sector (with the exception of a small proportion of health expenditures going to residential care facilities; see below). The allocation of expenditures in transportation and communication and protection of persons and property differs by subcategory. Appendix 1 provides further details on this, as well as on the allocation of the smaller expenditure categories.

\footnotetext{
${ }^{13}$ One might argue that public consumption in the business sector indirectly benefits the household sector because households own the businesses. However, these benefits - to the extent that they exist - should enter the LIMEW through increases in household wealth. The inclusion of the public consumption that benefits the business sector would therefore double-count the indirect benefits to the household sector.
} 
iii. Distributing government expenditures across households: We are concerned with not only the level of the benefit of government expenditure to households, but also the distribution of these benefits among households. Thus, public expenditure needs to be distributed across households in the most detailed manner possible with available data. Once again, the CSLS used a procedure similar to that used for the United States LIMEW. We have not explicitly distributed federal government spending by provinces. Federal government spending was distributed within Canada, while provincial governments' spending was distributed within their respective provinces. This means that if an expenditure category is distributed by population, then the distribution of federal spending by provinces is on a per capita basis.

As noted above, education and health are the largest categories of public consumption. We address those two categories here. Look to Appendix 1 for a discussion of the distribution of the remaining spending categories.

In order to be compatible with the U.S. LIMEW, a large portion of government expenditure on health is included in government non-cash transfers. The only components included in public consumption are expenditure on institutions other than hospitals, home care services and "other expenditures." We allocated the share of healthcare spending on "other institutions" to the non-household sector because this represents healthcare spending on individuals in residential care facilities who are not covered in our microdata. Expenditures on home care services are allocated on a per-person basis to the household sector, but only among those aged 65 and over. Finally, we allocated "other expenditures" on a per capita basis to the household sector on the assumption that they represent expenditures on public health.

Only a small proportion of Canadians aged 5 to 18 are not in public school. Those not enrolled in public school are either enrolled in private school, are being home schooled, or have dropped out. For distribution purposes we identified 5,506,812 and 5,491,466 children and adults in elementary and secondary school in 1999 and 2005 respectively in the SLID. (Those aged 5 to 15 are assumed to be in school and those aged 16 to 19 are considered in high school if they reported they were in high school during their reference year.) Administrative data suggests 5,372,733 and 5,212,533 in 1999/2000 respectively 2005/2006 (Statistics Canada, 2008b). Given the figures, we attributed public spending on elementary and secondary school to 97.6 (in 1999) and 94.9 (in 2005) per cent of families with school-aged children based on the number of school-aged children they have. (Children in the remaining households-selected stochastically_are assumed to be either in private school or not in school.) 
Government expenditure on post-secondary education expenditure was allocated to economic families by the number of members who have attended a post-secondary institution within that year. Unlike the United States almost all universities within Canada are publically funded. The province of Quebec has its own system of community college-like institutions known as CEGEPs, which are meant to be a bridge between high school and university. They are almost entirely publically funded. There are also private colleges (vocational or technical) as well as public colleges (vocational or technical), but the datasets we use do not contain the variables necessary to distinguish attendance at public or private college. ${ }^{14}$

F. Household Production: Economists have not reached a consensus about the correct method for valuing household production. Since it is individuals, not households, who spend time, household production is calculated first on an individual basis and then the value of the production from the individuals within the household is summed to produce the value of the production of the household.

The delineating factor in whether we ought to categorize an activity as household production is whether it can be replaced on the market. Some activities such as cooking and cleaning can obviously be substituted. These activities are known as "core household production." Another category of household production is procurement activities. This includes shopping for groceries and other shopping. These are included because they are necessary for the running of the household and can be substituted by use of professional shoppers. The third category is care, which includes both childcare and eldercare. There is some ambiguity in the availability of market replacement and the bounds of childcare. Developmental psychology has highlighted the importance of play in a child's proper development, as well as bonding between the child and his or her primary caregiver, but there are questions as to whether this can be bought on the market.

\footnotetext{
${ }^{14}$ Another issue is that the permanent residence of an economic family may not be the same province as where a member is receiving an education. As per the Canadian constitution education is in provincial jurisdiction, and thus is funded provincially. So in reality provincial funding may go to a household permanently residing in another province. However, our data do not allow us to identify this, so there is some misallocation of the benefits of postsecondary funding. Anyone attending a post-secondary institution will be assumed to be receiving government funding (even if they are enrolled in a private college) and thus will be allocated government spending of the province in which their economic family resides (even if they are funded by another province). However, the flows of students attending university out of province should largely net out.
} 
Researchers have proposed various ways to value household production. Specific replacement cost, general replacement cost, and replacement wage are the three main approaches found in the literature (Fraumeni 2008). The specific replacement cost approach values the specific activities of household production by the cost that would be required to replace the work by hiring a worker who specializes in that activity. For example, childcare would be evaluated by the cost of hiring a babysitter or nanny, and household cooking would be evaluated by the cost of hiring a cook. Many believe that the use of market wages overstates the value of household production because the household producer is unlikely to be as productive in household production as a specialist worker would be.

Another approach is general replacement cost, which evaluates household production of all categories by the cost of hiring a "general worker" such as a domestic servant. Some believe this understates the value of household production because individuals with a high degree of human capital are more productive over many types of production, including household production.

The third approach is replacement cost. Replacement cost values household production using the implicit wage rate that the worker receives on the formal labor market. This has two problems. First, much of household production is done by those who do not participate in the formal labor market. Second, this ignores the fact that the wage received by individuals in the labor market is what they receive as specialists, and those supposing that people are equally productive in the home may overstate the value of household production.

The compromise used in the LIMEW is the modified general replacement cost approach (Wolff, Zacharias and Masterson 2009). As a base this uses the general replacement cost using the wages of domestic workers in Canada. However, because we realize the different productive capacity of workers, we modify the value of household work by the individual by a performance index. This performance index $(p)$ uses the weighted average of normalized years of schooling, ${ }^{15}$ normalized household income, and the normalized time availability of the individual. ${ }^{16}$ It is defined as:

\footnotetext{
${ }^{15}$ Years of schooling is estimated from the categorical educational attainment variable.

${ }^{16}$ Time availability is calculated by subtracting paid work hours from the total available hours in a week. (Twentyfour hours a day minus eight hours of sleep a night; 168-56 =112)
} 


$$
p=1+\frac{\left(\frac{s-\mu_{s}}{\sigma_{s}}\right)+\left(\frac{y-\mu_{y}}{\sigma_{y}}\right)+\left(\frac{t-\mu_{t}}{\sigma_{t}}\right)}{3}
$$

where $s$ is the (estimated) years of schooling, $y$ is household pre-tax income, and $t$ is the time availability of the individual. $\mu_{s}, \mu_{y}$, and $\mu_{t}$, are the mean of schooling, household income, and time availability, respectively. Similarly, $\sigma_{s}, \sigma_{y}$, and $\sigma_{t}$ are the standard deviation of schooling, income, and time availability respectively. If any of the sub-indices are not calculable due to non-response, that sub-index is assumed to be zero.

The base household production wage rate is based on an estimate of the hourly wage of domestic employees (occupational group G811: visiting homemakers, housekeepers, and related occupations) from the 2006 census. In the 2006 census, average hours worked per week is 36 and average annual weeks worked is 42.5 . So if we multiply these numbers together we obtain an average of 1,530 hours worked a year. We then divide the annual employment income of domestic employees, $\$ 17,944$, by 1,530 hours to obtain a wage rate of $\$ 11.73$ per hour (in 2005 dollars). Similarly, the 2001 census reveals that domestic employees worked on average 41.8 weeks per year and 35 hours per week. Thus, they worked on average 1,463 hours per year. They earned an average of $\$ 16,336$ in employment income in 2000 , which implies an hourly wage rate of $\$ 11.17$ (in 2000 dollars).

These base wage rates are adjusted by the individual's performance index. However, regardless of how low the performance index for an individual is, there is a floor on the implicit wage of household production at the weighted (by share of labor force) average of provincial minimum wages, which was calculated to be $\$ 6.63$ in 1999 and $\$ 7.42$ in 2005 (current dollars).

\section{RESULTS: THE LIMEW IN CANADA}

\section{A. Mean and Median Estimates of the LIMEW}

\section{i. Composition of the LIMEW}

Exhibit 4 provides the mean LIMEW for 1999 and 2005, as well as a breakdown of the mean LIMEW into its components and subcomponents. The mean value of the LIMEW in Canada (in 2000 US dollars) was $\$ 77,074$ in 2005, up 1.08 per cent per year from $\$ 72,254$ in 1999 (Table $\left.1^{17}\right){ }^{18}$ Chart 1 illustrates these means, as well as the corresponding medians for 1999 and 2005.

\footnotetext{
${ }^{17}$ All Tables and Appendix Tables are in the Appendix.
} 
Chart 1: Mean and Median LIMEW, Canada, 1999 and 2005

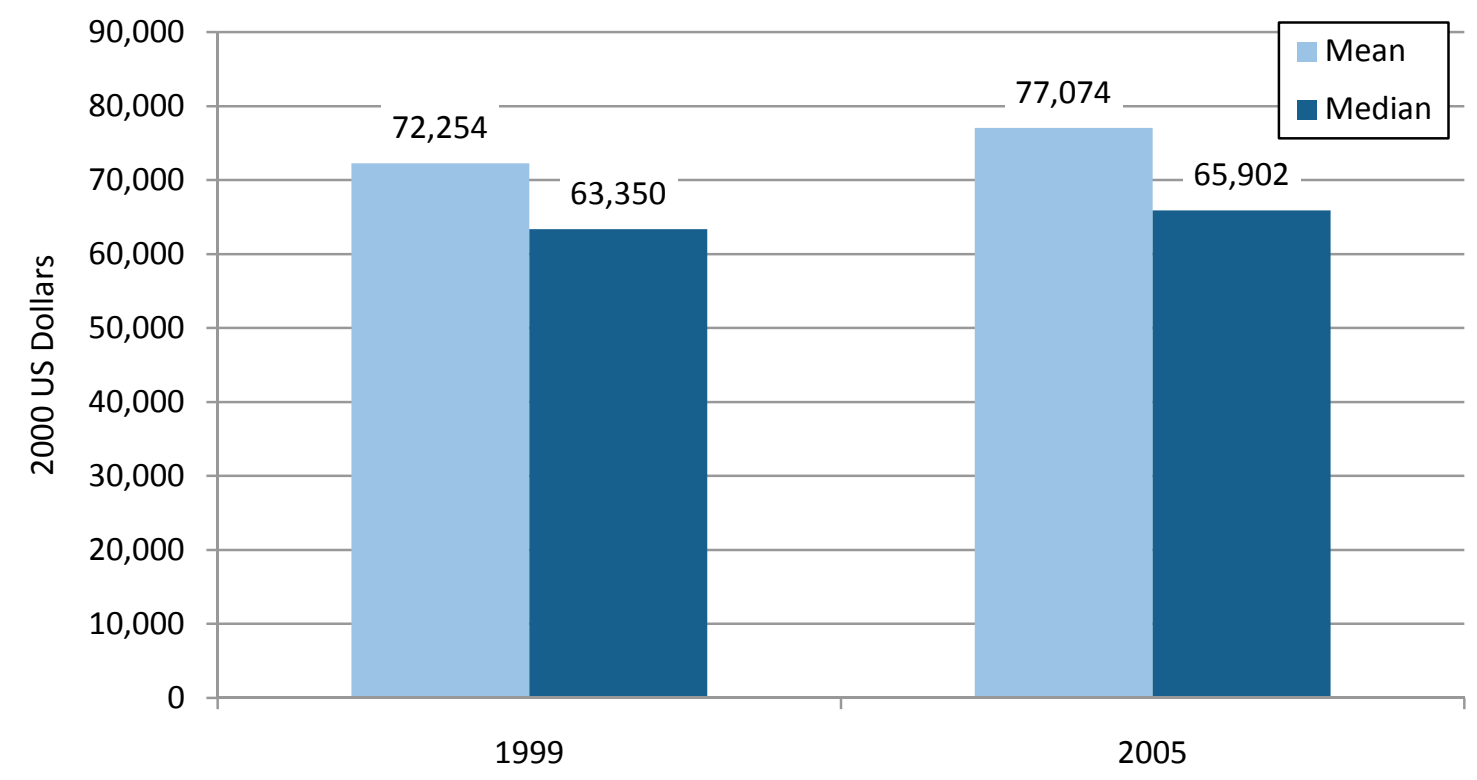

a. Base income: The LIMEW breakdown in Exhibit 4 illustrates the relative importance of each component in overall economic well-being. The largest component is base income. Mean household base income was $\$ 39,984$ in 2005 and accounted for 52 per cent of the total LIMEW. Earnings made up 95 per cent of base income in 1999 and 94 per cent in 2005; the other subcomponents of base income are relatively small (Chart 2).

\footnotetext{
${ }^{18}$ All estimates are in 2000 PPP adjusted US dollars unless otherwise indicated in order to be consistent with the estimates for the United States from the Levy Institute. Current dollar estimates for 1999 and 2005 are converted to 2000 Canadian dollars using the Canadian CPI, then to 2000 US dollars using the 2000 Canada-US personal consumption-based PPP from the OECD (equal to 1.2116).
} 
Exhibit 4: Composition of the Mean LIMEW for Canada, 1999 and 2005

\begin{tabular}{|c|c|c|c|c|}
\hline \multirow[t]{2}{*}{ Line No. } & \multirow[t]{2}{*}{ Component } & \multicolumn{2}{|c|}{ Mean Value (2000 US Dollars) } & \multirow{2}{*}{$\begin{array}{l}\text { Change, } \\
\text { 1999-2005 } \\
\text { (Per Cent } \\
\text { per Year) }\end{array}$} \\
\hline & & 1999 & 2005 & \\
\hline 1 & Household Earnings & 34,450 & 37,620 & 1.48 \\
\hline 2 & Fringe benefits & 953 & 1,228 & 4.32 \\
\hline 3 & Money income other than earnings & 861 & 1,136 & 4.73 \\
\hline 4 & Alimony & 172 & 204 & 2.89 \\
\hline 5 & "Other income" & 689 & 932 & 5.16 \\
\hline 6 & Base Income = sum of lines 1-3 & 36,264 & 39,984 & 1.64 \\
\hline 7 & Annuity from non-home wealth & 6,633 & 8,542 & 4.31 \\
\hline 8 & Net imputed rent on housing & 4,628 & 4,594 & -0.12 \\
\hline 9 & Income from wealth = sum of lines 7-8 & 11,261 & 13,136 & 2.60 \\
\hline 10 & Government transfers & 10,606 & 11,652 & 1.58 \\
\hline 11 & Public consumption & 8,473 & 9,306 & 1.57 \\
\hline 12 & Taxes & $-17,765$ & $-18,401$ & 0.59 \\
\hline 13 & Federal income tax & 5,984 & 6,003 & 0.05 \\
\hline 14 & Provincial income tax & 3,741 & 3,668 & -0.33 \\
\hline 15 & Payroll tax & 1,582 & 1,764 & 1.83 \\
\hline 16 & Consumption tax & 4,105 & 4,390 & 1.13 \\
\hline 17 & Property tax & 2,353 & 30,974 & 53.66 \\
\hline 18 & $\begin{array}{l}\text { Net Government Expenditure }=\text { lines } 10+11 \\
-12\end{array}$ & 1,315 & 2,557 & n.a. \\
\hline 19 & Household production & 23,415 & 21,397 & -1.49 \\
\hline 20 & LIMEW $=$ lines $6+9+18+19$ & 72,254 & \begin{tabular}{|l|}
77,074 \\
\end{tabular} & 1.08 \\
\hline 21 & After-tax Income $=$ lines $6+10-12$ & 24,038 & 27,244 & 2.11 \\
\hline 22 & $C D I=$ lines $20-19-11$ & 40,365 & 46,371 & 2.34 \\
\hline 23 & $\mathrm{PFI}=$ lines $20-19$ & 48,839 & 55,677 & 2.21 \\
\hline
\end{tabular}

Notes:

1. After-tax income is base income plus government transfers net of taxes.

2. CDI is comprehensive disposable income. It is equal to the LIMEW less household production and public consumption.

3. PFI is post-fiscal income. It is equal to the LIMEW less household production. 
Chart 2: Mean Base Income, Canada, 1999 and 2005

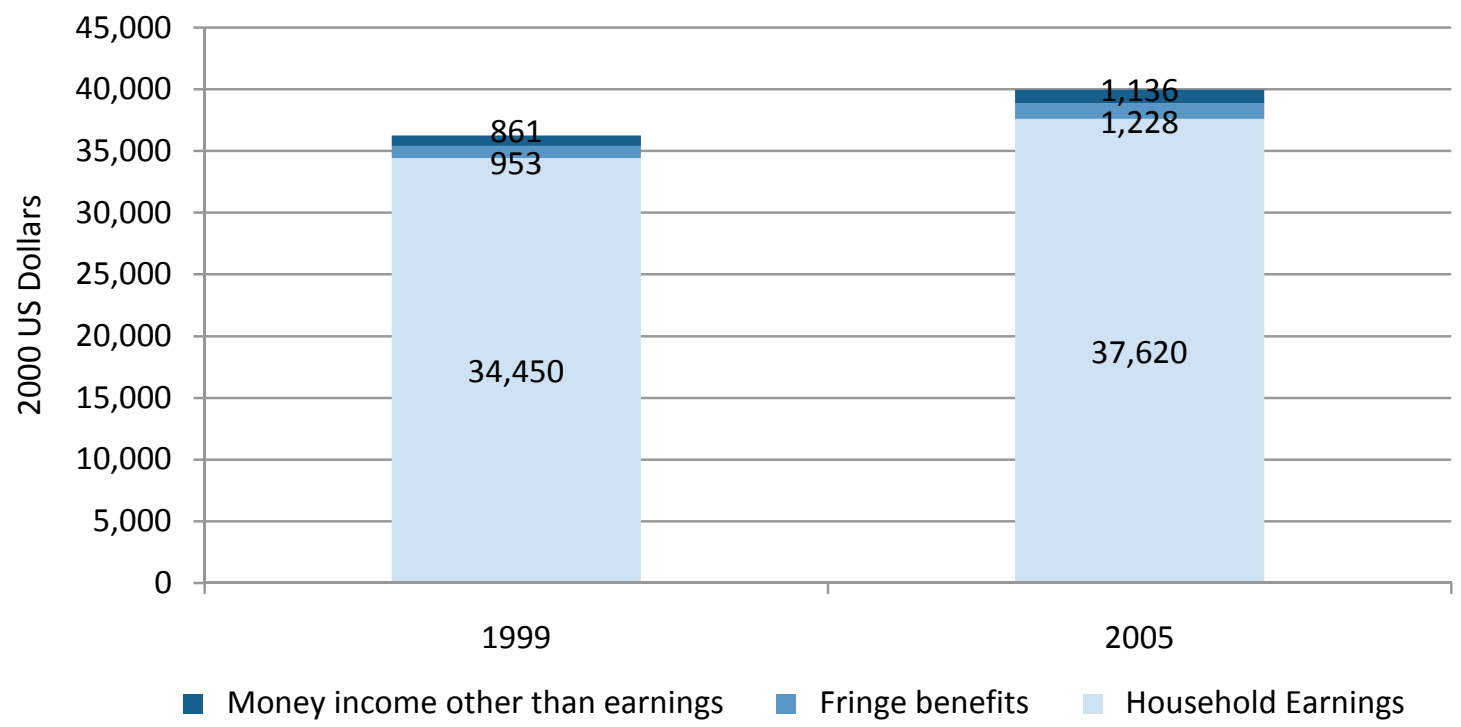

b. Income from wealth: Average imputed income from wealth was $\$ 13,136$ in 2005, up 2.60 per cent per year from $\$ 11,261$ in 1999 (Chart 3). Income from wealth accounted for 17.0 per cent of mean LIMEW in 2005, up from 15.6 per cent in 1999.

Chart 3: Mean Income from Wealth, Canada, 1999 and 2005

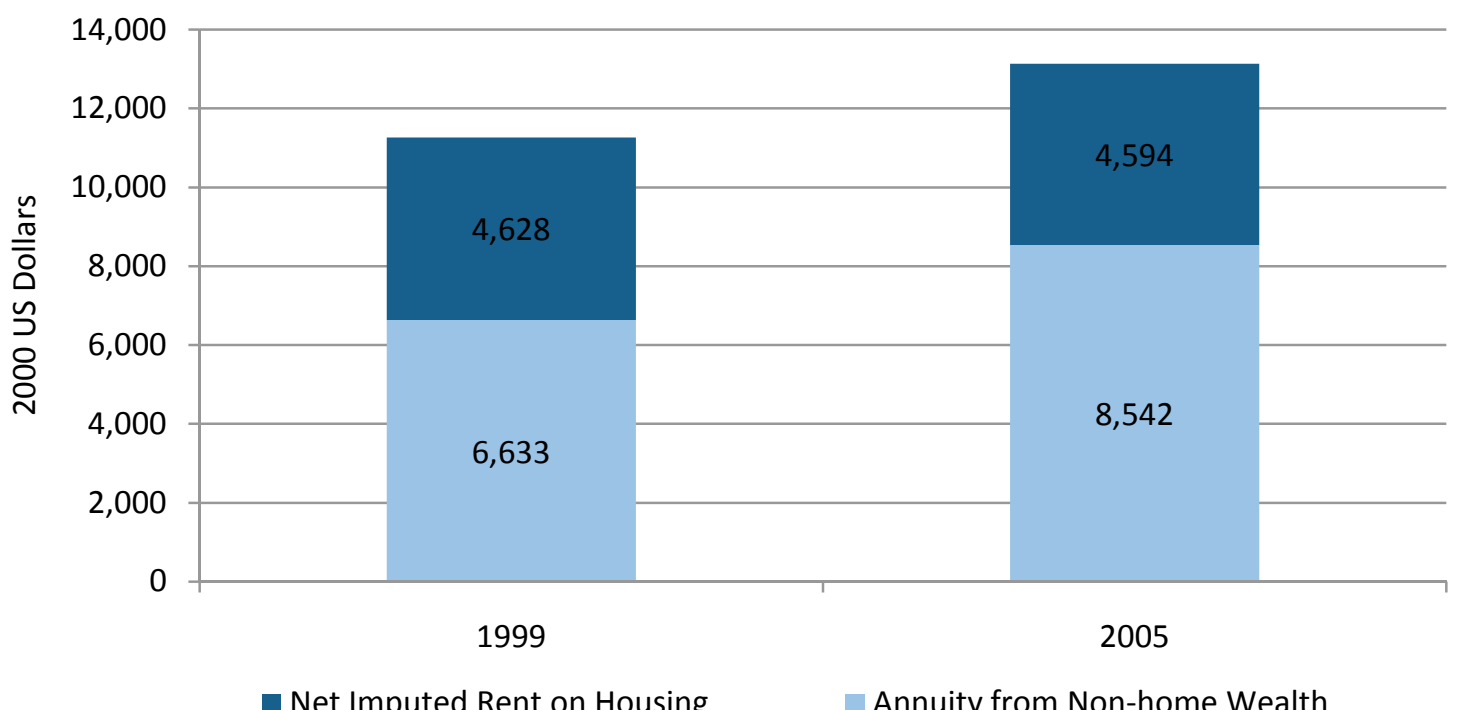

The increase in income from wealth is entirely attributable to the 4.31 per cent annual increase in the non-home wealth annuity from $\$ 6,633$ in 1999 to $\$ 8,542$ in 2005 . Net imputed 
rent on the primary residence remained more or less stable, declining 0.12 per cent per year, over the 1999-2005 period.

c. Net government expenditure: For the average household, net government expenditure was $\$ 2,557$ in 2005, up from $\$ 1,315$ in 1999 . The benefits of government transfers and public consumption amounted to about $\$ 19,079$ in 1999 and $\$ 20,958$ in 2005, but were largely offset by taxes (Chart 4). This average masks significant differences in the impact of government across the income distribution, as we show in Section $\mathrm{C}$ below.

Chart 4: Mean Net Government Expenditure, Canada, 1999 and 2005

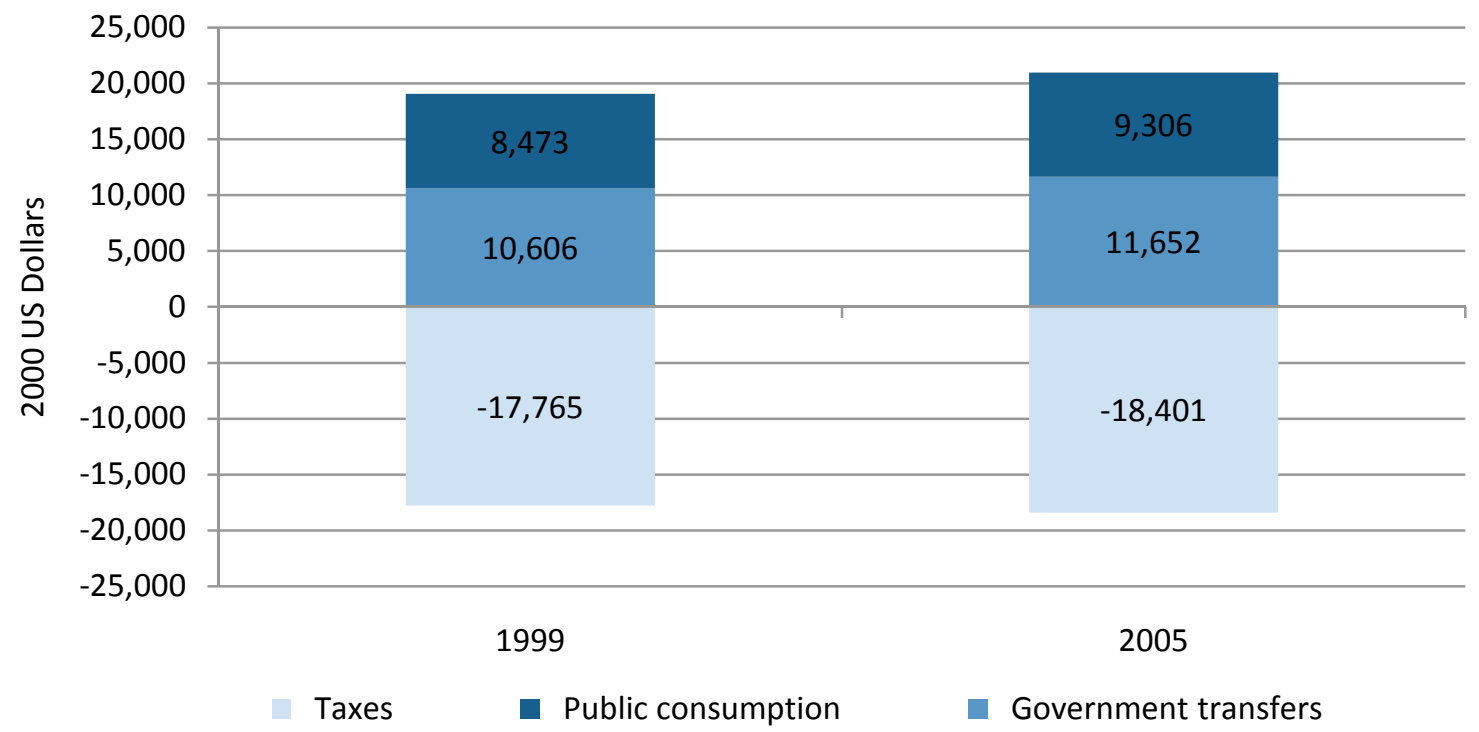

d. Household production: The final component is household production, which was valued at $\$ 21,397$ per household in 2005 (Chart 5). This represented a decrease of 1.49 per cent per year from $\$ 23,415$ in 1999 . The source of this decline is investigated by decomposing household production into the annual number of hours spent on household production by adults, the base replacement wage (the average wage of domestic employees in Canada), and the performance index in section V.B of this report. 
Chart 5: Household Production in Canada, 1999 and 2005

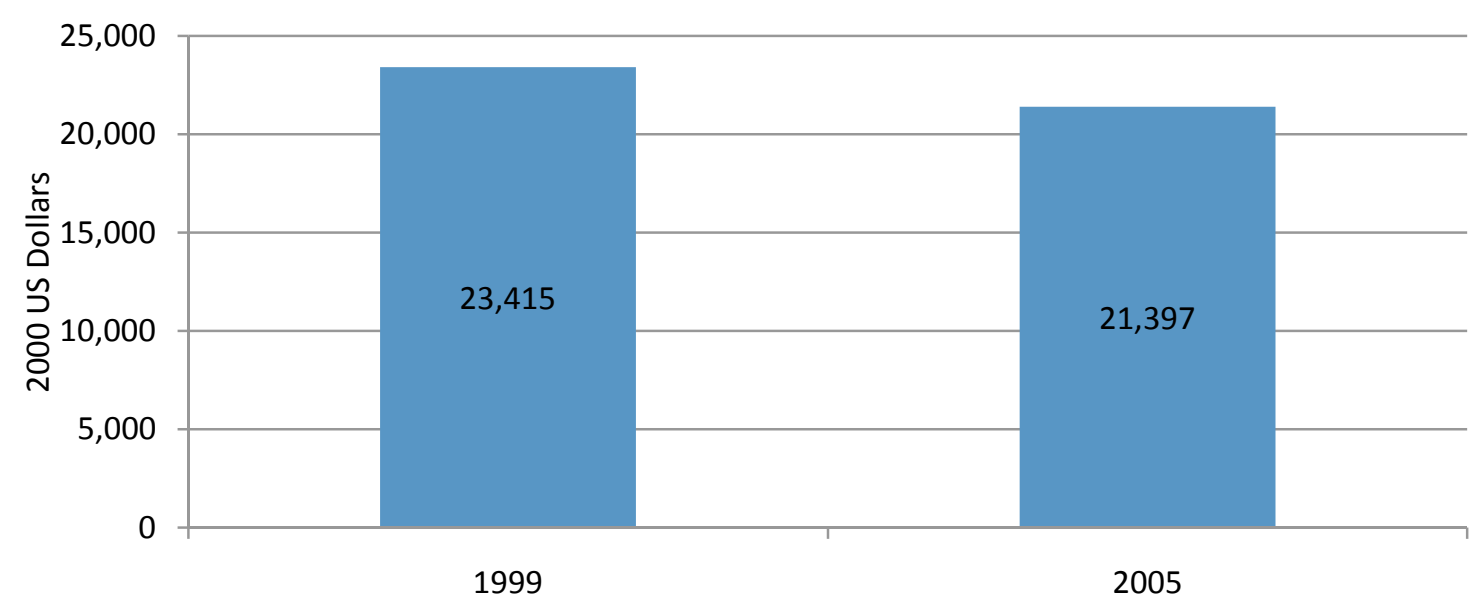

e. Summary: The average household in Canada experienced growth of just over 1 per cent per year in its total command over resources (as measured by the LIMEW) over the 1999-2005 period. Significant growth in base income (1.64 per cent per year) and income from non-home wealth (4.31 per cent per year) was offset by a decline in household production (-1.49 per cent per year) (Chart 6). The net impact of the government on the LIMEW was relatively small compared to the other components for the average household in both 1999 and 2005.

\section{Chart 6: LIMEW by Components, Canada, 1999 and 2005}

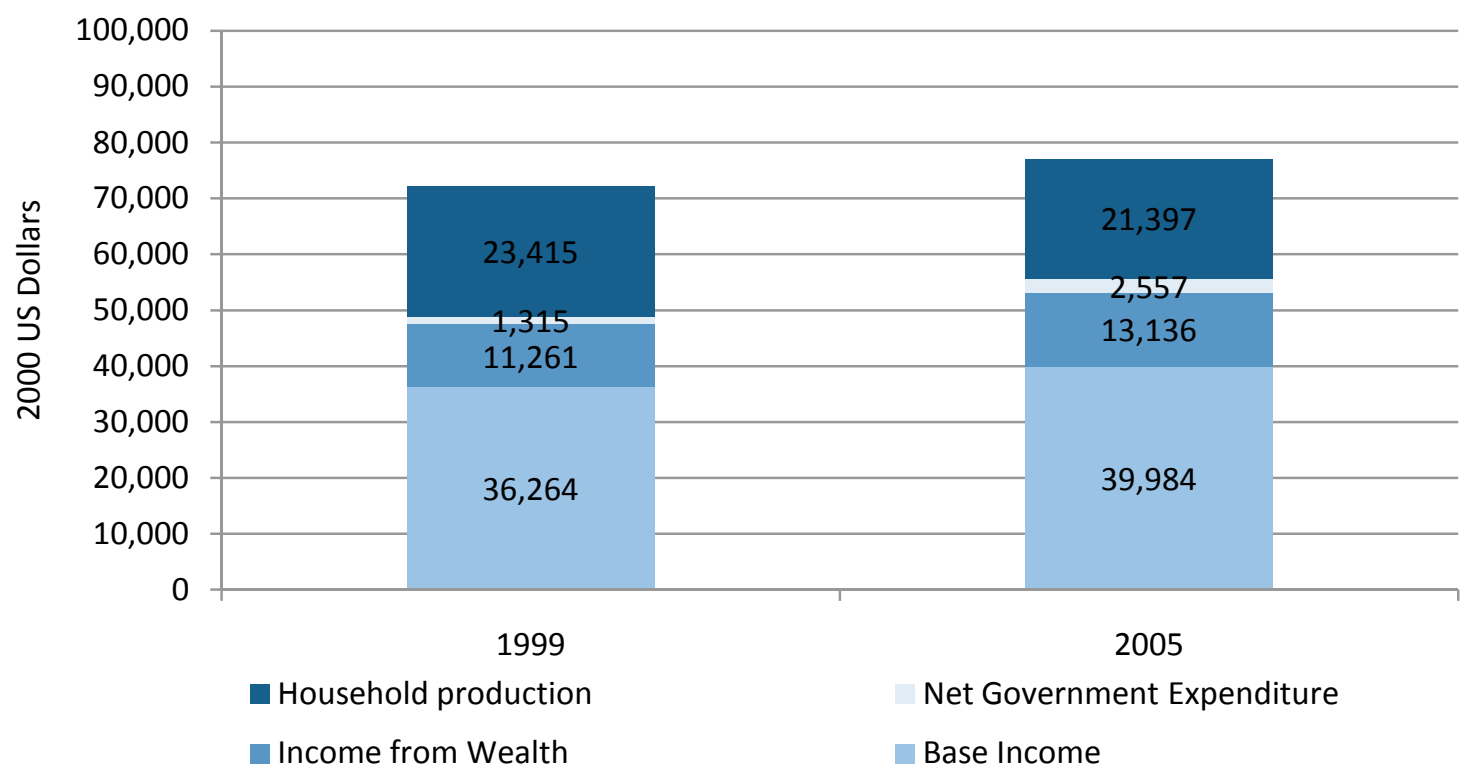


ii. Trends in the LIMEW and Alternative Income Measures: In addition to the LIMEW, Exhibit 4 provides three alternative measures of household income: after-tax income, comprehensive disposable income (CDI), and post-fiscal income (PFI). After-tax income is equal to base income plus government transfers, less taxes. This is a standard household income concept. CDI is equal to the LIMEW less household production and public consumption, while PFI is the LIMEW less household production. Comparing these measures illustrates the impact of different LIMEW components on households' total LIMEW values.

Mean after-tax household income was $\$ 27,244$ in 2005 , up 2.11 per cent per year from $\$ 24,038$ in 1999 . This mainly reflects the strong growth of base income. Adding income from wealth yields CDI, which grew 2.34 per cent per year from \$40,365 in 1999 to $\$ 46,371$ in 2005 . The higher growth rate reflects the increase in income from wealth over the period.

Adding public consumption yields PFI. The growth rate of PFI was 2.21 per cent per year. Growth in public consumption contributed to PFI growth, but the growth rate of PFI was still slightly below that of CDI.

As noted above, the mean LIMEW grew by 1.08 per cent per year over the 1999-2005 period. This was the smallest rate of growth among the four income measures.

The key message that arises from the comparison of these income measures is that the "non-traditional" elements of the LIMEW make a significant difference in how we assess both the level and the growth of households' economic well-being. After-tax income is a common measure of economic well-being, but in 2005, the average household's LIMEW was 283 per cent higher than its after-tax income (Chart 7). By excluding wealth, public consumption and household production, after-tax income drastically understates the level of households' command over resources. After-tax income also overstates the rate of growth of command over resources since household production experienced negative growth. 
Chart 7: LIMEW and Other Income Measures, 1999 and 2005

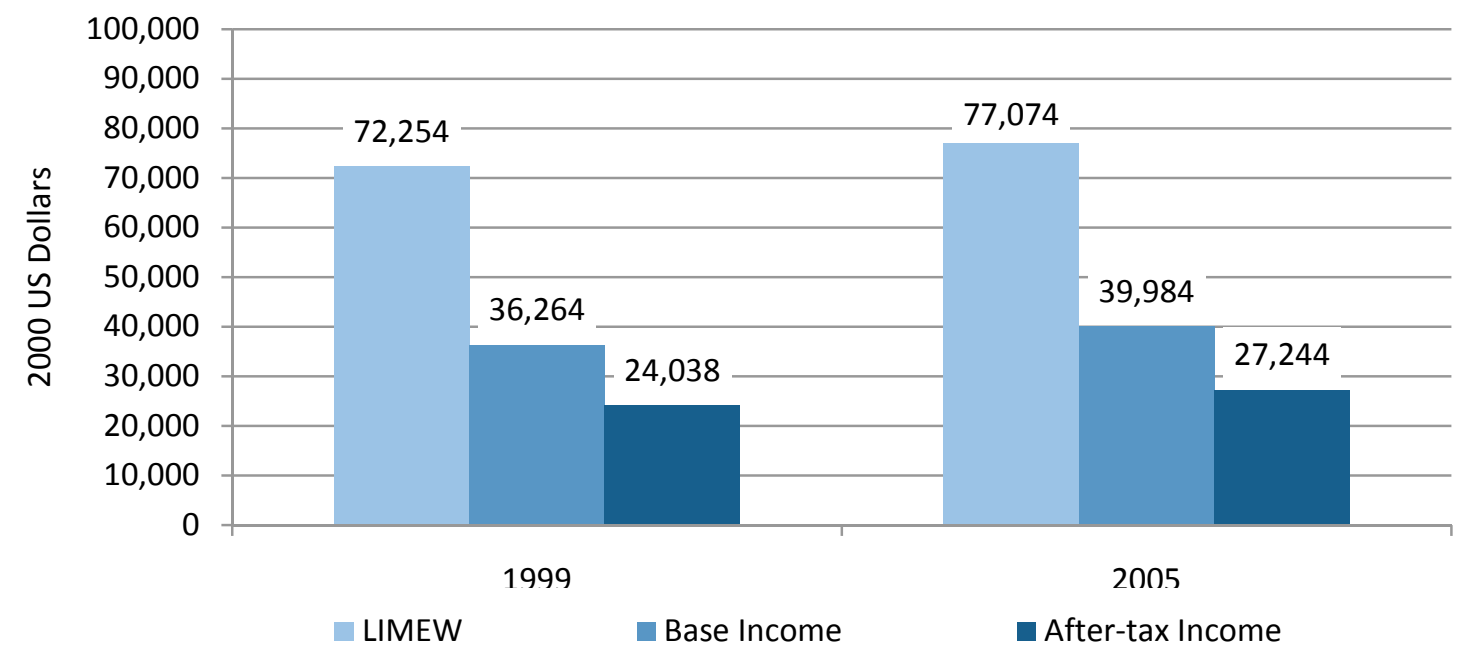

Note: After-tax income = base income + government transfers - taxes

iii. Equivalence scale-adjusted LIMEW: Table 1 also reports the LIMEW and its components in equivalent income terms. ${ }^{19}$ The use of equivalence scale-adjusted estimates does not affect our key conclusions, although the scale affects the magnitudes and the growth rates of the LIMEW and the other income measures. The fact that the growth rates of the equivalent income measures almost all exceed those of the unadjusted measures suggests that there have been substantial changes in the size or composition of Canadian households.

Table 10 provides the average values of the equivalence scale for five household types, along with the proportion of households that falls into each household type. The data show that between 1999 and 2005, there was a shift in the composition of households away from large households (i.e. those with multiple adults and at least one child under 18) and toward smaller households. The proportion of households with multiple adults and at least one child declined from 28.8 per cent in 1999 to 25.7 per cent in 2005. The proportion of single-parent households with children also fell, from 4.7 per cent in 1999 to 4.2 per cent in 2005. Over the same period, the proportion of households with multiple adults and no children increased from 41.0 per cent to 42.9 per cent, and the proportion of households consisting of a lone adult increased from 25.5 per cent to 27.1 per cent.

The household types with declining shares of the population of households are also the types with the larger average equivalence scale values. Since household income is divided by

\footnotetext{
${ }^{19}$ The equivalence scale adjusts household income for household size by taking into account the economies of scale in consumption that arise from sharing household costs among two or more people. See Note 7 of Table 1 for a description of the equivalence scale used.
} 
the equivalence scale to generate equivalent income, the shift in the composition of households (from large to small households) explains the faster growth rates of the equivalent income measures relative to their unadjusted counterparts.

These compositional shifts may reflect the aging of the population. As the "baby boom" generation approaches retirement, the children of that generation are reaching maturity and moving out of their parents' households. This could explain the compositional shift toward smaller household sizes.

\section{B. Comparison of Canada and the United States by LIMEW}

Our Canadian LIMEW estimates were carefully constructed so as to be comparable to the US estimates provided by Wolff et al. (2009a). However, this paper reports the recently revised estimates of mean and median LIMEW for the United States provided by the Levy Institute. Although the US estimates are for 2000 and 2004 rather than 1999 and 2005, the years are close enough for comparisons to be meaningful.

The median LIMEW for the United States was \$69,514 in 2000 (in 2000 US dollars), 9.7 per cent higher than the Canadian median LIMEW of \$63,350 in 1999 (Table 2). The US median LIMEW in 2004 was $\$ 71,599,8.6$ per cent higher than the Canadian median of $\$ 65,902$ in 2005 .

\section{Chart 8: Canadian LIMEW as a Proportion of the US LIMEW}

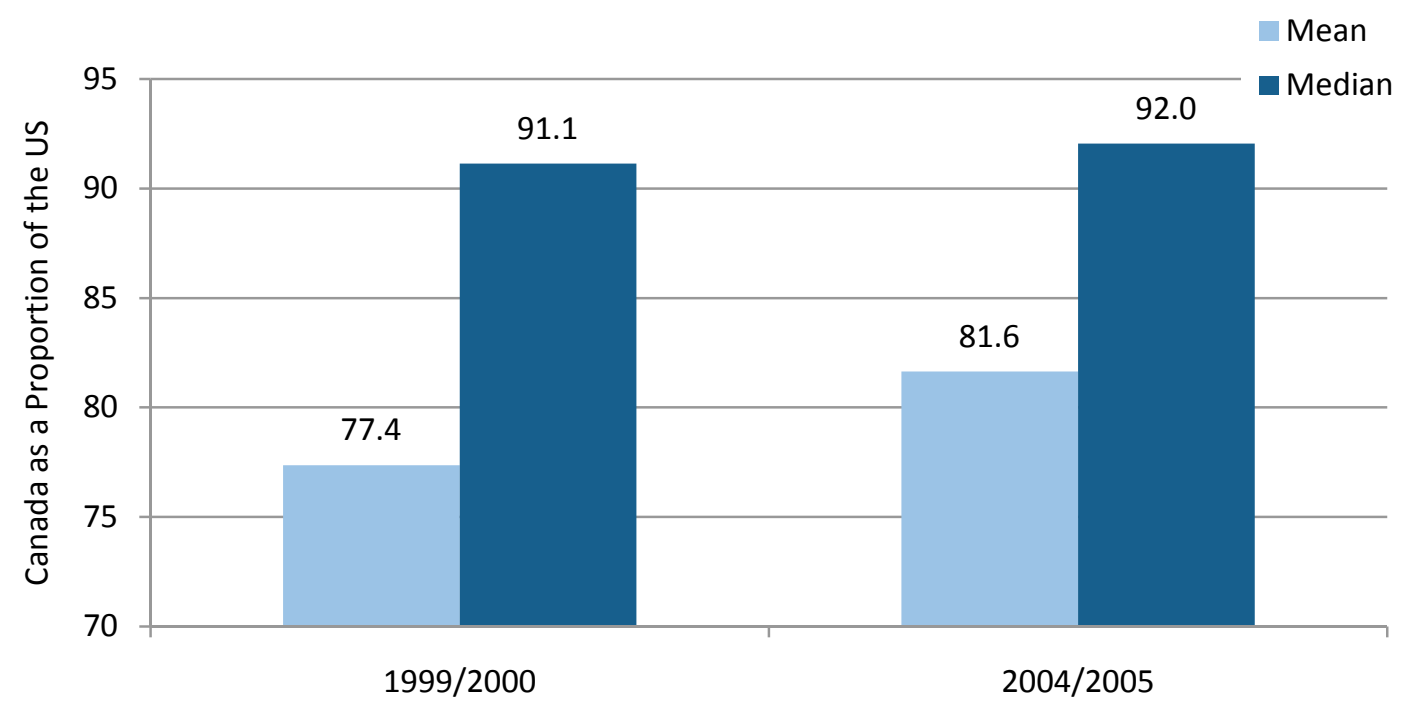

Note: Canadian LIMEW estimates are for 1999 and 2005. US estimates are for 2000 and 2004. 
The United States outperformed Canada in terms of PFI and CDI as well. The USCanada gaps for these two measures were larger in each year than the gap for the LIMEW. The median PFI in the United States exceeded that of Canada by 23.9 per cent in 1999/2000 and by 14.1 per cent in 2004/2005. For CDI, the US median exceeded the Canadian value by 29.5 per cent in 1999/2000 and by 17.5 per cent in 2004/2005. The sizes of these gaps relative to the LIMEW gap reflects the fact that household production forms a larger share of the total LIMEW in Canada (32 per cent in 1999 and 28 per cent in 2005) than it does in the United States (about 21 per cent in both years). It is also clear that part of the US advantage in economic well-being is due to Canada's declining household production; the US-Canada gap closed much more significantly in terms of PFI and CDI than it did for the LIMEW between 1999 and 2005.

\section{Composition of the LIMEW by Income Quintile}

Table 3 shows the mean LIMEW by LIMEW quintile. The mean LIMEW grew in the bottom quintile between 1999 and 2005 by just 0.02 per cent per year, while the second and third quintiles experienced growth of 0.35 and 0.72 per cent per year, respectively. The top two quintiles experienced more substantial growth in their average LIMEW value over the six years, with growth of 1.07 and 1.62 per cent per year for the fourth and fifth quintile, respectively.

Table 3 also provides a breakdown of the mean LIMEW into its four components by LIMEW quintile. Base income accounted for about half of the LIMEW for all five quintiles in both years, and its share increased between 1999 and 2005 in every quintile but the highest, where it almost imperceptibly decreased. Income from wealth forms a greater share of total LIMEW at the top of the distribution than at the bottom, accounting for 9.3-11.3 per cent of the LIMEW in the bottom quintile to 18.8-22.6 per cent in the top quintile. 
Chart 9: Composition of the LIMEW by LIMEW Quintile, Canada, 1999 and 2005
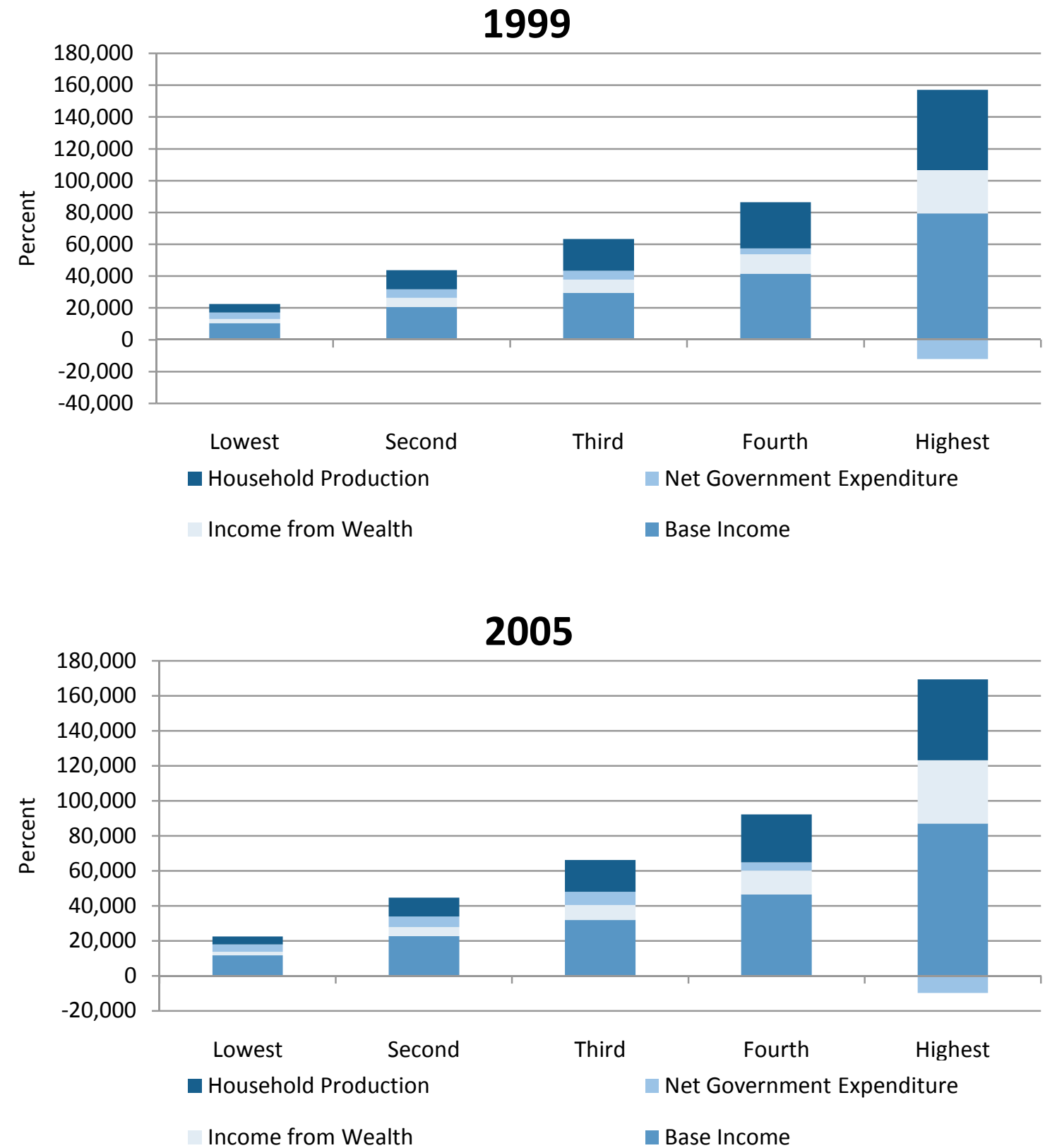

Net government expenditure shows the opposite pattern. The government accounted for 18-19 per cent of the LIMEW for those in the bottom quintile in both 1999 and 2005, while those in the top quintile were net losers from government taxing and spending in both years. This suggests that the fiscal system is, on balance, progressive.

Household production is the second-largest component of the LIMEW after base income, and in general it contributes a larger share of total well-being at the top of the LIMEW 
distribution than at the bottom. This is perhaps a counterintuitive result; one might expect to find a negative correlation between household production and other LIMEW components (base income and income from wealth), since richer people can afford to buy goods and services that poorer people have to produce themselves in the home. We explore our household production estimates in more detail in Section V.B below.

Table 3 a provides the dollar values of each LIMEW component by income quintile. Base income increased between 1999 and 2005 in every quintile, as did net government expenditure. On the other hand, household production declined over the period in every quintile, while income from wealth decreased in the bottom two quintiles and increased in the top three.

\section{LIMEW Inequality}

The most common measure of income inequality is the Gini coefficient. In 1999, the Gini for the LIMEW in Canada was 0.340 (Table 4). It increased by 5.04 per cent to 0.357 in 2005. This indicates that inequality in household command over resources increased slightly over the period. $^{20}$

Zacharias et al. (2009) find that the levels and trends of Gini coefficients for the United States are sensitive to the income measure used. Table 4 shows that the same is true for Canada, but only to a limited degree. Base income is by far the most unequally distributed of the five Canadian income measures in Table 4, with Gini coefficients of 0.546 in 1999 and 0.550 in 2005. The levels of the Gini coefficients for the remaining measures fall between those of the LIMEW and base income, ranging from 0.345 to 0.496 in 1999 and from 0.365 to 0.490 in 2005. The LIMEW and PFI showed the largest increases in inequality between 1999 and 2005, while after-tax income became slightly less unequal.

Using equivalent income measures affects the magnitudes of the Gini coefficients but not the direction of the trends. The Gini for the equivalence scale adjusted LIMEW was 0.266 in 1999, and it increased by 7.01 per cent to 0.285 in 2005 .

Economic well-being is more equally distributed in Canada than in the United States. According to the latest data provided by the Levy Institute, the US Gini coefficients in 2004 were 0.487 for CDI, 0.453 for PFI, and 0.420 for the LIMEW.

\footnotetext{
${ }^{20}$ For each income measure in Table 4 , there is a small proportion of households with negative values. Strictly speaking, the Gini coefficient is not valid when negative values are present in the data, and it may overstate the degree of inequality (Hagerbaumer 1977; Chen et al. 1982). Although the number of households having negative values is relatively small, the Gini coefficients reported in this paper should be interpreted with some caution.
} 
Another indicator of economic inequality is the 90/10 ratio; that is, the ratio of the $90^{\text {th }}$ percentile to the $10^{\text {th }}$ percentile. ${ }^{21}$ Table 5 provides the $90^{\text {th }}$ and $10^{\text {th }}$ percentiles and $90 / 10$ ratios for the LIMEW, its components, and the alternative income measures.

In 1999, the 90/10 ratio for the LIMEW in Canada was 5.43. This was the lowest 90/10 ratio among the four income measures (LIMEW, CDI, PFI and after-tax income). Notably, the highest 90/10 ratio among these measures belonged to after-tax income (29.70).

In 2005, the 90/10 ratio for the LIMEW was 5.89. The 8.47 per cent increase in the LIMEW 90/10 ratio between 1999 and 2005 was the largest increase among the income measures. The largest per cent change in the 90/10 ratio occurred in after-tax income, which decreased 44 per cent between 1999 and 2005, but which also had the highest 90/10 ratios in both years.

A third indicator of economic inequality is the share of aggregate income that accrues to each income quintile. Table 6 illustrates this breakdown for the LIMEW, its components, and the alternative income measures in 1999 and 2005. All four of the income measures exhibit substantial inequality, with each quintile of the distribution having a higher share of total income than the quintile below it. That being said, the more comprehensive measures (CDI, PFI and the LIMEW) are more equally distributed across households than after-tax income, the more conventional measure. In terms of the LIMEW, the top quintile had 41.4 per cent of income in 2005, while the bottom quintile had 5.9 per cent. By comparison, the base income component was much more unequally distributed; 53.7 per cent of aggregate base income accrued to the top quintile of households, while -0.1 per cent went to the bottom quintile. The large difference between the distributions of base income and after-tax income suggests that government transfers play a large role in leveling the income distribution. This point is further emphasized by the difference in the distributions of CDI and PFI, as PFI is equal to CDI plus public consumption and PFI is slightly more equal than CDI in terms of quintiles shares.

The shares of the income aggregates accruing to each quintile did not change significantly between 1999 and 2005.

\footnotetext{
${ }^{21}$ The $90^{\text {th }}\left(10^{\text {th }}\right)$ percentile is the value above (below) which only ten per cent of households lie.
} 


\section{E. LIMEW by Age, Education, and Region}

An important use of the LIMEW is to analyze disparities between different groups in society.

One of the key disparities analyzed by Wolff et al. (2009a) was the white/non-white gap. Although racial and ethnic gaps are of interest and concern in Canada, the data do not permit us to run a comparable analysis. However, we can examine other important disparities. In this section, we analyze intergroup LIMEW differences according to three criteria: the age of the household's major income earner, the educational attainment of the major income earner, and the geographic region in which the household is located.

i. LIMEW by the age of the major income earner: One important finding by Wolff et al. (2009) was the increase in the LIMEW of elderly Americans (defined as those aged 65 and over) relative to the non-elderly. They found that the ratio of median LIMEW of elderly to nonelderly Americans increased from 0.61 in 1959 to a peak of 0.89 in 2000, then declined slightly to 0.86 in 2004. The ratio of mean LIMEW of elderly over non-elderly tells a similar, but more dramatic, story; it increased from 0.79 in 1959 to a peak of 1.09 in 2000 (meaning the elderly were better off than the non-elderly), then fell back to 0.98 in 2004.

\section{Chart 10: Ratio of LIMEWs and After-tax Incomes of Elderly to Non-Elderly Households, Canada, 1999 and 2005}

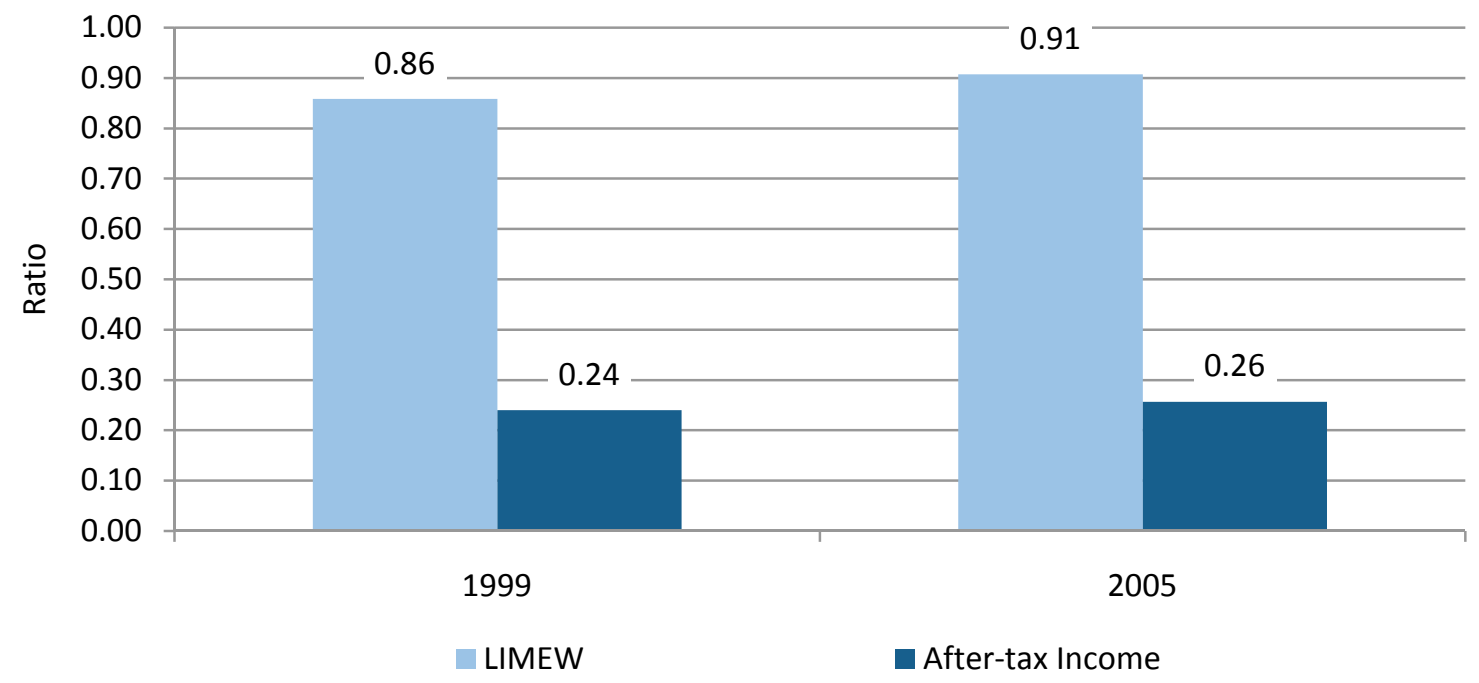

Tables $7 \mathrm{a}$ and $7 \mathrm{~b}$ contain the mean and median estimates of the Canadian LIMEW, its components, and the other income measures for 1999 and 2005 for six age categories (where a household is categorized based on the age of its major income earner). Almost every measure in 
the tables exhibits a similar pattern over the lifecycle. In both years, most measures rise throughout the first fifty years of life, peaking in the 45-54 age category, then decline thereafter. CDI, PFI and LIMEW, however, show a slight increase between ages 55-64 and 65 and older for means and medians in both years, except mean LIMEW in 1999. More striking exceptions to this life cycle pattern are net government expenditure, which shows the opposite pattern, and income from wealth, which is highest among the elderly. These patterns are true whether we use means or medians as our estimates of average well-being.

We do not have a time series dating back as far as the one Wolff et al. created for the United States, so we cannot examine long-term trends in the relative well-being of different age groups. Over the six-year time span available to us, there was not much change in the ratio of average elderly to non-elderly well-being according to any of the six income measures. The mean LIMEW in 1999 was \$63,755 among elderly households and \$74,246 among non-elderly ones, for a ratio of 0.86 . The mean LIMEW in 2005 was $\$ 71,154$ among the elderly and $\$ 78,451$ among the non-elderly, for a ratio of 0.91 . If we use medians instead, the ratios are 0.86 for 1999 and 0.93 for 2005.

The story is very different if we use equivalent income measures. In 1999, the equivalence scale adjusted mean LIMEW was $\$ 104,386$ for the elderly and $\$ 87,610$ for the nonelderly, for a ratio of 1.19 . The mean LIMEW in 2005 was $\$ 115,446$ among the elderly and $\$ 94,301$ among the non-elderly, for a ratio of 1.22 . If we use median equivalent measures, the ratio is 1.19 and 1.23 for 1999 and 2005 respectively. These ratios imply that the elderly had higher mean and median levels of economic well-being than the non-elderly in both 1999 and 2005. Indeed, according to the mean and median equivalent LIMEW values, the elderly are the most well-off age group in Canada; none of the other groups reported in Tables $7 \mathrm{a}$ and $7 \mathrm{~b}$ have higher equivalent mean or median LIMEW values than those aged 65 and above. This reflects the fact that elderly households have fewer members on average than young households.

The large equivalent LIMEW values for elderly households are driven by government and by the "non-traditional" elements of the LIMEW (wealth, public consumption and household production). The average elderly household has only 10 to 11 per cent of the equivalent base income of the average non-elderly household. The taxes-and-transfers system closes the gap considerably, but based on equivalent after-tax income, the elderly are still worse off than every age group. Income from wealth benefits elderly households more than nonelderly ones, while the impact of public consumption and household production slightly favor 
the non-elderly. It is important to note, however, that in terms of net government expendituretransfers plus public consumption less taxes-the elderly are the only group that benefits. These results highlight the importance of using a comprehensive measure of command over resources.

\section{ii. LIMEW by the education of the major income earner: Wolff et al. (2009) also analyzed} the relative well-being of those with different levels of education. They found increasing relative well-being for college graduates and decreasing relative well-being for those with less than a high school diploma, high school graduates, and those who attended college but did not graduate.

Tables $8 \mathrm{a}$ and $8 \mathrm{~b}$ present estimates of the mean and median values of the LIMEW and the alternative income measures for four educational attainment categories in Canada: less than high school, high school diploma, non-university post-secondary certificate, and university certificate or degree. Households are categorized on the basis of the educational attainment of the major income earner. The data indicate that households with more well-educated major income earners tend to have greater average command over resources. This no doubt reflects the well-established fact that higher education leads to higher money income. In 1999, the mean LIMEW among university graduates in Canada was $\$ 98,450$, while the average for high school non-completers was $\$ 58,811$. In 2005, the LIMEW averaged $\$ 98,351$ among university graduates and \$62,971 among high school non-completers.

We find no evidence that the LIMEW gap between the well-educated and the least educated Canadians increased over the 1999-2005 period. In fact, the ratio of the mean LIMEW values of university graduates to high school non-completers decreased slightly from 1.67 in 1999 to 1.56 in 2005 . The mean LIMEW ratio for university graduates to high school graduates was 1.47 in 1999 and 1.36 in 2005. The ratios of the medians were similar to those of the means in both years. 
Chart 11: Ratio of Mean LIMEWs and After-tax Incomes of University Graduate to High School Graduate Headed Households, Canada, 1999 and 2005

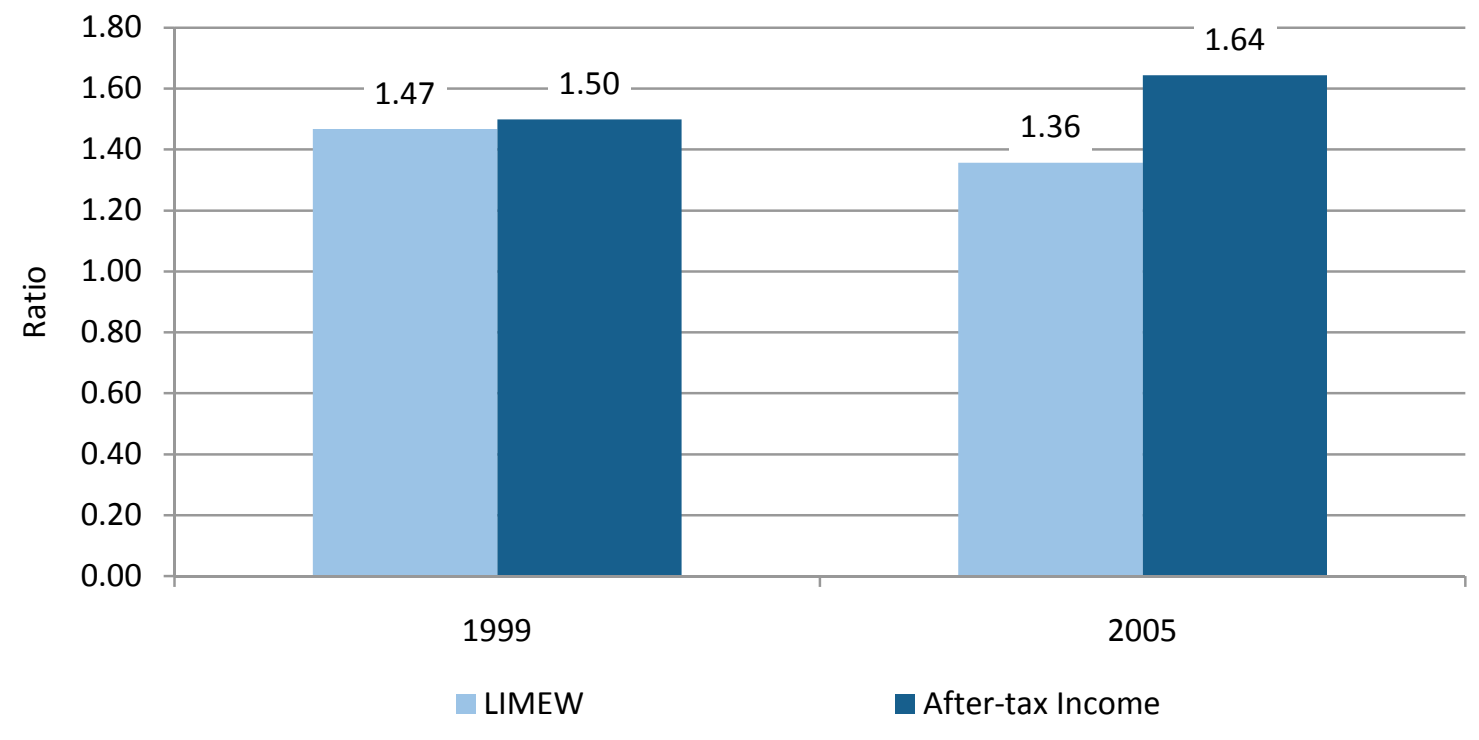

Using equivalence scale adjusted income measures does not alter the story. More welleducated households have higher equivalent LIMEW values than less well-educated ones, and the gap slightly decreased between 1999 and 2005.

Finally, it is worth noting that the comprehensive income measures (CDI, PFI and LIMEW) exhibit smaller gaps between education groups than base income. The mean base income of university graduate households exceeded those of high school non-completers by a factor of 3.8 in 1999 and 3.6 in 2005. As noted above, this reflects the skill premium in the labor market. Moving from base income to after-tax income reduces the gap substantially, which reflects the importance of government transfers in leveling economic well-being across groups.

iiii. LIMEW by region: A key issue in the Canadian context is the degree to which economic well-being varies by region. There are large differences across Canadian regions in terms of economic prowess. The resource-based economy in the Prairie region has boomed in recent years, while the Atlantic region has experienced longstanding economic challenges. It is worth asking how these factors influence economic well-being as measured by the LIMEW. We therefore estimate the mean and median values of the LIMEW, its components, and the alternative income measures for five regions: Atlantic Canada, Quebec, Ontario, the Prairies, and British Columbia. Tables 9a and 9b present the results. 
Ontario ranked first among the regions in terms of mean LIMEW in both 1999 and 2005, with mean LIMEW values of \$79,182 in 1999 and $\$ 84,123$ in 2005. The Prairies ranked second in both years. Quebec had the lowest mean economic well-being in 1999, with a mean LIMEW of $\$ 64,828$, but Atlantic Canada had the lowest LIMEW in 2005 , at $\$ 65,880$.

\section{Chart 12: Mean LIMEW by Region, Canada, 1999 and 2005}

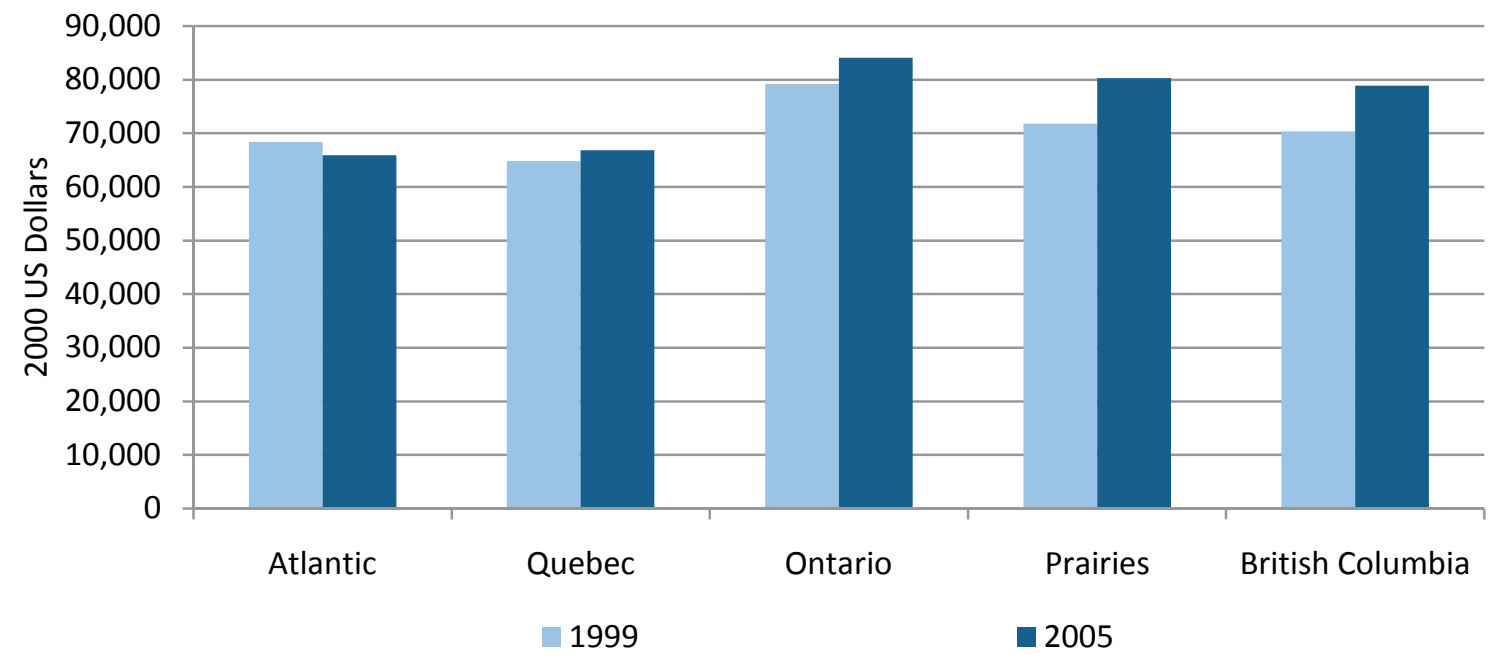

The same pattern emerges in terms of median LIMEW values. Ontario ranked first in both years with \$68,639 in 1999 and \$72,644 in 2005. Quebec had the lowest median LIMEW in 1999 (\$57,091), while the Atlantic region ranked last in $2005(\$ 57,175)$.

British Columbia and the Prairies experienced the fastest mean LIMEW growth over the 1999-2005 period: both showed growth of approximately 1.9 per cent per year. Ontario and Quebec also showed positive annual growth of 1.0 and 0.5 per cent per year, respectively. The mean LIMEW declined over the period in Atlantic Canada by 0.62 per cent per year. The decline in Atlantic Canada was mainly attributable to a large decline in income from wealth (the mean fell from $\$ 11,299$ in 1999 to $\$ 8,254$ in 2005). While the region's mean after-tax income increased slightly over the period, its mean CDI (after-tax income plus income from wealth) fell 0.77 per cent per year from $\$ 38,044$ in 1999 to $\$ 36,330$ in 2005 . No other region experienced a decline in mean CDI over the period.

Our main conclusions do not change if we use the equivalence scale adjusted data. Ontario ranks first among the regions in terms of mean and median economic well-being, while 
Quebec and Atlantic Canada rank last. Average well-being increased fastest in the Prairies over the 1999-2005 period, while it declined in Atlantic Canada.

\section{FURTHER DISCUSSION OF WEALTH AND HOUSEHOLD PRODUCTION}

The key result presented in Section IV is that the average LIMEW among Canadian households only grew modestly during the 1999-2005 period. Base income and income from wealth experienced substantial growth, but it was offset by a decline in household production. In this section, we dig deeper into the income from wealth and household production components in order to explain their changes over this period.

\section{A. Income from Wealth}

Mean income from wealth in Canada grew by 2.60 per cent per year over the 1999-2005 period (Exhibit 4). This was attributable to an increase of 4.31 per cent per year in income from nonhome wealth. Mean imputed rent on housing was relatively stable over the period, decreasing just 0.12 per cent per year. In contrast, median income from wealth decreased 2.35 per cent per year during this period (Table 1). This decrease in median income from wealth is due to decreases in the median of the non-home wealth annuity (2.6 per cent per year) and in the median net imputed rent on housing (4.6 per cent per year) between 1999 and 2005. Thus, although income from wealth increased on average, this hides substantial variation across households.

As discussed in Section III.D, the non-home wealth annuity depends on three factors: the value and composition of households' non-home asset holdings; the real interest rates on the assets; and the expected remaining lifetime of the household. The real interest rates used in our calculations are based on long-term historical averages and are the same for 1999 and 2005, so the increase in the non-home wealth annuity cannot be attributed to a change in interest rates. We therefore investigate only the other two factors.

All else being equal, the mean non-home wealth annuity would increase if the remaining expected lifetime of the average household decreased. A decrease in expected remaining lifetime would require that the household's asset holdings generate an income stream over a smaller number of years, so the annual income payment arising from those assets would increase. Table 11 shows that the mean remaining lifetime expected for a household did 
decrease slightly from 35.7 to 34.8 years between 1999 and 2005. Small decreases in average remaining lifetime were observed for all quintiles of both LIMEW and household income.

It is also worth examining how the size and composition of households' asset holdings contributed to the large increase in the non-home wealth annuity. The average household's nonhome assets (net of non-mortgage debt) increased by 6.30 per cent per year from $\$ 155,159$ in 1999 to $\$ 223,915$ in 2005 (Table 12). Average wealth increased in every non-home asset category, but the largest growth was in real estate and business assets, which grew 10.7 per cent per year, and in non-mortgage debt, which grew 8.73 per cent per year from 1999 to 2005.

\section{B. Household Production}

Mean household production in Canada declined by 1.49 per cent per year over the 1999-2005 period (Exhibit 4). If it had maintained its 1999 value, the mean LIMEW in 2005 would have been $\$ 79,092$, which is $\$ 2,018$ or 2.6 per cent above its actual 2005 value of $\$ 77,074$. LIMEW growth over the 1999-2005 period would have been 1.52 per cent per year, rather than 1.08 per cent per year. We also saw, in Section IV.C, that household production contributes more to the economic well-being of high-LIMEW households than low-income households. Household production's large decline and its "top-heavy" distribution are somewhat surprising results that warrant further investigation.

\section{i. Decline of Household Production Over 1999-2005 Period}

As discussed in Section III.F, the value of household production is based on three factors: the annual number of hours spent on household production by adults (i.e. those aged 18 and over); the base replacement wage, which is the average wage of domestic employees in Canada; and the performance index, which adjusts the base wage to account for productivity differences across individuals. Changes in any of these factors could explain the decline in mean household production over the 1999-2005 period.

Average hours of household production declined by 0.97 per cent per year, from 2,387 hours in 1999 to 2,251 hours in 2005 (Table 13). This was not attributable to a change in household size. Average hours of household production per adult within the household declined from 1,226 hours to 1,162 hours over the period (Table 13a), and the mean number of adults per household was 1.9 in both 1999 and 2005 (Table 14). 
In addition, the imputed hourly value of household production declined from $\$ 9.81$ in 1999 to \$9.51 in 2005 (Table 15) (in 2000 dollars). This was entirely due to a decline in the real value of the base wage from $\$ 9.19$ in 1999 to $\$ 8.78$ in $2005 .^{22}$ The impact of the performance index on growth in the imputed hourly value of household production was positive. The performance index increased the imputed wage of the average household by 6.8 per cent in 1999 and 8.3 per cent in 2005 (Table 15a). ${ }^{23}$

Overall, the decline in household production was driven by declines in both hours of household production and the hourly valuation. Table 16 summarizes the drivers of the 1.49 per cent annual decline in mean household production over the 1999-2005 period. The decline in the real value of the base wage accounted for 0.75 percentage points of the annual decline, while the decline in hours of household production contributed 0.97 percentage points to the decline. The performance index was the only factor that contributed positively to growth of household production over the period (by 0.23 per cent per year).

\section{ii. Inequality in Household Production}

As noted in Section IV.C, household production contributes more to the economic well-being of high-LIMEW households than low-income households (Table 3). There are three factors that could explain this inequality in household production across the LIMEW distribution. The first is the fact that household production is a large component of the LIMEW in Canada (30 per cent) and that we would expect households with high household production to be at the top of the LIMEW distribution and vice versa, all else being equal. Second, average household size may be larger at the top of the LIMEW distribution than at the bottom. This would lead to higher average household production (and base income and income from wealth) for those households because they have more people to engage in production. Finally, the performance index increases the imputed hourly value of household production for high-income and high-

\footnotetext{
${ }^{22}$ These correspond to the 1999 and 2005 current Canadian dollar values of $\$ 10.88$ and $\$ 11.73$ per hour given earlier in the report. Those values were converted to 2000 Canadian dollars using the Canadian CPI, then to 2000 US dollars using the Canada-US personal consumption-based PPP from the OECD. The decline in the real wage reflects the fact that nominal wage growth among Canadian domestic employees did not outpace inflation between 1999 and 2005.

${ }^{23}$ These values are computed by comparing the imputed hourly values in Table 15 with the base wages. As such, they reflect both the performance index itself and the imposition of the lower bounds on the imputed hourly wage (at the value of the labor force-weighted average of provincial minimum wages) after the performance index was applied. See the discussion in Section III.F.
} 
education households. This "builds in" a positive correlation between household production and the other large LIMEW components, base income and income from wealth.

To address these issues, we estimate four versions of mean household production for all households and by LIMEW quintiles. Table 17 presents the results. The baseline estimates are the standard estimates that we have already discussed. They use the performance index and do not adjust for household size. There is significant inequality in the distribution of these baseline household production estimates across the LIMEW quintiles. The ratio of mean baseline household production in the top and bottom LIMEW quintiles (hereafter called the 80/20 ratio) is 9.2 for 1999 and 10.2 for 2005 .

The first alternative measure (Alternative 1) controls for differences in household size by using an equivalence scale (the same scale we have used throughout the report for our equivalent income measures). As expected, the average value of the equivalence scale (which reflects both the size and the composition of households) is larger for high-LIMEW households than for low-LIMEW households (Table 18). As a result, the use of the equivalence scale dramatically reduces inequality in household production. The 80/20 ratio decreases from 9.2 to 5.2 in 1999, and from 10.2 to 5.6 in 2005 (Table 17).

In the second alternative measure (Alternative 2), the performance index is eliminated. Every individual is assigned the same imputed hourly value for his or her household production; namely, the base wage. Alternative 2 does not use an equivalence scale, so comparisons between Alternative 2 and the baseline estimates capture the impact of the performance index on household production inequality. The performance index increases the hourly value of household production in the top LIMEW quintile by 32.3 per cent relative to the base wage in 2005 , but decreases the hourly value for bottom-quintile households by 14.0 per cent in that same year (Table 15a).

The Alternative 2 results show a decline in the 80/20 ratio from 9.2 (the baseline) to 6.0 in 1999 and from 10.2 to 7.0 in 2005 (Table 17). This is a somewhat smaller decrease in inequality than that from the equivalence scale.

The third alternative (Alternative 3) shows the combined impact of the adjustment for household size and the performance index. The performance index is not used, but the equivalence scale is. The two adjustments reduce the 80/20 ratio from 9.2 to 3.5 in 1999 and from 10.2 to 4.0 in 2005. In other words, the two adjustments reduce the inequality of household 
production across the LIMEW distribution (as measured by the $80 / 20$ ratio) by 61 per cent relative to its baseline level in 2005 .

The remaining inequality is partly attributable to the first factor mentioned above. Household production is a substantial component of the LIMEW, and we would expect households with high household production to appear at the top of the LIMEW distribution (and vice versa), all else being equal. We cannot perform a simple adjustment to measure the impact of this selection issue. To provide some idea of its importance, we compute the four household production measures by household pre-tax income quintiles rather than LIMEW quintiles (Table 17a). Since household production is not a component of household pre-tax money income, we would not necessarily expect the inequality of household production across LIMEW quintiles to carry over to household income quintiles. In addition, since PFI is composed of all the same elements as LIMEW except for household production, we also examine inequality of household production across PFI quintiles, in order to more clearly isolate the effect of the selection issue.

Indeed, comparing the baseline estimates from Tables 17 and 17a suggests that the selection issue is a substantial source of observed inequality across the LIMEW distribution. The baseline 80/20 ratio falls from 9.2 to 2.9 in 1999 and from 10.2 to 2.9 in 2005 when we switch to household pre-tax income quintiles. Adjusting for household size and removing the performance index almost entirely eliminates the remainder of the inequality, with Alternative 3 indicating 80/20 ratios of 1.2 in both 1999 and 2005 .

The results across PFI quintiles are almost identical (Table 17b). Switching to PFI quintiles from LIMEW quintiles results in a decrease in the baseline 80/20 ratio from 9.2 to 3.2 in 1999, and from 10.2 to 3.4 in 2005. As with household pre-tax income quintiles, Alternative 3 shows almost no inequality. Indeed, the 80/20 ratio of household production across PFI quintiles falls to 1.3 in 1999 and 1.5 in 2005 for this measure of household production.

In order to put the previous discussion into context, it is also worth examining the inequality of these household production estimates across households. The 80/20 ratios calculated for this purpose show similar inequality patterns across household production quintiles as they do across income quintiles (Table 17c). For example, the 80/20 ratio decreases from 26.1 to 13.1 in 1999 when moving from the baseline estimate to Alternative 3, while in 2005 it falls from 46.0 to 22.7 . 
Furthermore, moving from the baseline estimate to Alternative 1, the Gini index of household production falls from 0.478 to 0.436 in 1999 and 0.511 to 0.474 in 2005 (Table 17c). In contrast to the 80/20 ratio, the Gini index indicates that the performance index has larger effects than the equivalence scale in terms of decreasing inequality in household production, as moving from the baseline to Alternative 2 further lowers the Gini index to 0.420 in 1999 and to 0.456 in 2005 . However, just as in the $80 / 20$ ratio, the reduction in inequality from applying the equivalence scale and removing the performance index is also marked in the Gini index, which falls to 0.383 in 1999 and to 0.424 in 2005 .

Thus, household production shows not only substantially greater inequality across LIMEW quintiles than other income quintiles, but it also demonstrates significant inequality across households. Additionally, in both cases inequality in household production grows between 1999 and 2005 and the performance index increases the inequality of household production.

It is also interesting to see how the alternative method of valuing production affects the inequality of the LIMEW. Table 19 outlines the results of estimating LIMEW with the alternative household production measures. When no equivalence scale is employed, the standard LIMEW (which includes the performance index) has a Gini index of 0.340 in 1999 and 0.357 in 2005, while the alternative LIMEW (which does not use the performance index) has a Gini index of 0.314 in 1999 and 0.338 in 2005. This difference is driven by the lower inequality observed in estimates of household production that do not use the performance index. Examining the LIMEW estimates that also include the equivalence scale yields the same pattern. In addition, all LIMEW estimates show less inequality than the other income measures considered in Table 19, demonstrating the equalizing effect of any measure of household production.

Moreover, alternative LIMEW estimates make it clear that other, more standard measures of income (such as base income and after-tax income) substantially underestimate the growth in inequality between 1999 and 2005. While base income shows an increase in inequality of 0.82 per cent between these years, LIMEW shows an increase of 5.04 per cent and alternative LIMEW shows an increase of 7.67 per cent. Indeed, equivalence scale adjusted alternative LIMEW shows an increase in inequality of 10.67 per cent, while equivalence scale adjusted base income indicates an increase of just 0.77 per cent between these years. Thus, alternative methods of valuing household production demonstrate not only lower inequality than 
the standard LIMEW and other income measures, but also greater growth in inequality between 1999 and 2005.

These results highlight the importance of household size and the performance index. Although cross-household comparisons are sensitive to differences in household size and composition, equivalence scale adjustments are meant to capture economies of scale in consumption, and it is not clear that this same scale can be applied to household production. Therefore, this report has followed Wolff et al. (2009) in focusing on unadjusted measures rather than equivalent measures. In terms of the performance index, this section has demonstrated that it builds a substantial degree of inequality into the household production component of the LIMEW. It is worth reconsidering whether or not this is desirable, especially given the crude nature of the performance index and the lack of direct data on individual productivity in household production.

\section{CONCLUSION}

The Levy Institute Measure of Economic Well-being (LIMEW) is a comprehensive householdlevel measure of command over resources. It consists of several components: money income, including earnings and interpersonal transfers; government transfers net of all taxes; imputed annual income from wealth, including owner-occupied housing and non-home assets; the value of government consumption expenditures undertaken on behalf of households; and the value of household production. The LIMEW is one of a number of measures of economic well-being that have been developed in recent years with the aim of expanding the scope of economic wellbeing beyond the conventional measures such as per-capita GDP.

Our purpose in this report was to produce and present estimates of the LIMEW and its components for a representative sample of Canadian households in the years 1999 and 2005. The estimates were based on several high quality surveys produced by Statistics Canada, augmented by data from other sources (mainly other data produced by Statistics Canada). Care was taken to ensure that the Canadian estimates would be, to the furthest extent possible, comparable with the estimates produced by the Levy Institute for the United States in 2000 and 2004. 
The results indicate that there was only modest growth in the average Canadian household's total command over economic resources over the six years between 1999 and 2005 . The mean value of the LIMEW in Canada was \$72,254 in 1999 (in 2000 US dollars) and $\$ 77,074$ in 2005 . Over the 1999-2005 period, the mean LIMEW increased by 1.08 per cent per year. The median values were $\$ 63,350$ in 1999 and 65,902 in 2005; increasing 0.66 per cent per year over the 1999-2005 period. Measures that fail to account for wealth, public consumption and household production overstate the growth of economic well-being over the period.

Inequality in household command over resources increased slightly over the 1999-2005 period. Nevertheless, in both 1999 and 2005 the total LIMEW was more equally distributed across Canadian households than more common income measures such as after-tax income.

The average household's command over economic resources was lower in Canada than in the United States in both 1999 and 2005. The median LIMEW for the United States was $\$ 69,514$ in 2000 (in 2000 US dollars), 9.7 per cent higher than the Canadian median LIMEW of $\$ 63,350$ in 1999 . The US median LIMEW in 2004 was $\$ 71,599,8.6$ per cent higher than the Canadian median of $\$ 65,902$ in 2005.

There are a number of avenues for future research building on our work. First, a longer Canadian LIMEW time series would be valuable. The fact that we have estimates only for 1999 and 2005 prevents us from using the LIMEW to analyze long-term trends in the economic wellbeing of Canadian households. Estimates for earlier years would be useful even if they were of markedly lower quality than the 1999 and 2005 estimates.

It would also be useful to compare the LIMEW to other comprehensive indicators of economic well-being. The Index of Economic Well-being (IEWB), developed by the CSLS, encompasses many of the same elements as the LIMEW but uses a very different methodology for aggregating across different factors that affect economic welfare. Interesting comparisons could be drawn between the LIMEW and the IEWB in both empirical and theoretical terms. In empirical terms, do the LIMEW and the IEWB produce the same rankings of countries or of regions within Canada? If not, why?

On theoretical grounds, the two indicators differ along a number of dimensions. The relative weights assigned to different domains of economic well-being are explicitly subjective in the IEWB, while the LIMEW (being a dollar-denominated indicator) assigns "marketdetermined" weights to its components. What are the strengths and weaknesses of each approach and what impact does the difference have on the results? The IEWB incorporates 
several non-monetary factors that influence well-being (e.g. unemployment and economic insecurity). These important factors are not explicitly included in the LIMEW. On the other hand, the LIMEW is arguably more effective than the IEWB in approaching economic wellbeing from the perspective of individual households. All these differences could have interesting implications for the measurement of economic well-being and could facilitate the improvement of both indicators.

Finally, there remains room for technical improvements in the LIMEW. If possible, defined benefit pension plans should be excluded from household wealth (in order for the Canadian estimates to be consistent with the US estimates). For both Canada and the United States, it is not clear that the use of long-run historical average interest rates for the rates of return on assets is appropriate given the structural changes that have occurred in recent decades (particularly with respect to monetary policy and inflation). Better data for allocating some categories of public expenditure to the household sector and across households (e.g. public expenditure on air transportation) would be desirable. Finally, the approach to the valuation of household production warrants reconsideration. It would be worthwhile to examine further the issue of whether the valuation method should account for the unobservable efficiency and productivity differences among individuals. Even if such differences were to be taken into account, it is worth investigating alternatives to the admittedly crude performance index that is currently used. 


\section{REFERENCES}

Applied Research Associates, Inc. 2007. Estimation of Road Cost Allocation Between Light Vehicles and Heavy Vehicles in Canada.

Chawla, R. K. and T. Wannell, 2003. "Property Taxes," Perspectives on Labour and Income, pp. 12-19.

Chen, Chau-Nan, Tien-Wang Tsaur and Tong-Shieng Rhai. 1982. "The Gini Coefficient and Negative Income,” Oxford Economic Papers, New Series Vol. 34, No. 3, pp. 473-478.

Fraumeni, B. M. 2008. "Household Production Accounts for Canada, Mexico, and the United States: Methodological Issues, Results, and Recommendations," 30th General Conference of the International Association for Research in Income and Wealth, Portoroz, Slovenia. http://www.iariw.org/papers/2008/fraumeni.pdf

Gillespie, W. I. 1980. The Redistribution of Income in Canada. Ottawa: Gage Publishing Limited.

Hagerbaumer, James B. 1977. "The Gini Concentration Ratio and the Minor Concentration Ratio: A Two-Parameter Index of Inequality," Review of Economics and Statistics, Vol. 59, No. 3, pp. 377-379.

Health Canada 2001. "Health Expenditures in Canada by Age and Sex: 1980-81 to 2000-01," August. http://www.hc-sc.gc.ca/hcs-sss/alt_formats/hpb-dgps/pdf/pubs/2001-exp-dep1980/2001-exp-dep-1980-eng.pdf.

Kum, Hyunsub, and Thomas Masterson. 2008. "Statistical Matching Using Propensity Scores: Theory and Application to the Levy Institute Measure of Economic Well-Being." Working Paper 535. Annandale-on-Hudson, NY: Levy Economics Institute of Bard College. http://www.levyinstitute.org/pubs/wp_535.pdf.

Mackenzie, Hugh, and Richard Shillington 2009. "Canada's Quiet Bargain: The Benefits of Public Spending," Canadian Centre for Policy Alternatives, April. http://www.policyalternatives.ca/sites/default/files/uploads/publications/National_Office _Pubs/2009/Benefits_From_Public_Spending.pdf.

Manga, P. 1978. The Income Distribution Effect of Medical Insurance in Ontario. Toronto: Ontario Economic Council.

Masterson, Thomas 2010. "Quality of Match for Statistical Matches Used in the 1999 and 2005 LIMEW Estimates for Canada.” Working Paper 615. Annandale-on-Hudson, NY: Levy Economics Institute of Bard College. http://www.levyinstitute.org/pubs/wp_615.pdf.

Osberg, Lars, and Andrew Sharpe 2009a."New Estimates of the Index of Economic Wellbeing for Canada and the Provinces, 1981-2008," Centre for the Study of Living Standards Research Report 2009-10, December. http://www.csls.ca/reports/csls200910.pdf. 
Osberg, Lars, and Andrew Sharpe 2009b. "New Estimates of the Index of Economic Wellbeing for Selected OECD Countries, 1980-2007," Centre for the Study of Living Standards Research Report 2009-11, December. http://www.csls.ca/reports/csls200911.pdf.

Ross, Chris, and Alexander Murray (2010) "Aggregate Measures of Income and Output in Canada and the United States: Implications for Productivity and Living Standards," International Productivity Monitor, No. 19, Spring, pp. 20-39.

Sharpe, Andrew, Jean-Francois Arsenault and Peter Harrison 2008. "The Relationship between Labour Productivity and Real Wage Growth in Canada and OECD Countries," Centre for the Study of Living Standards Research Report 2008-8, December. http://www.csls.ca/reports/csls2008-8.pdf.

Sharpe, Andrew, and Jean-Francois Arsenault 2009. "Living Standards Domain of the Canadian Index of Well-being," Centre for the Study of Living Standards Research Report 2009-4, June. http://www.csls.ca/reports/csls2009-4.pdf.

Statistics Canada 1999. "A Comparison of the Results of the Survey of Labour and Income Dynamics (SLID) and the Survey of Consumer Finances (SCF) 1993-1997: Update," Catalogue No. 75F0002MIE-99007. http://www.statcan.gc.ca/pub/75f0002m/75f0002m1999007-eng.pdf.

Statistics Canada 2001. "Survey of Financial Security: Estimating the Value of Employer Pension Plan Benefits-A Discussion Paper," Catalogue No. 13F0026MIE-01002, February. http://www.statcan.gc.ca/pub/13f0026m/13f0026m2001002-eng.pdf.

Statistics Canada 2007. "Pension plans in Canada," The Daily, June 21.

Statistics Canada 2008a. "Workplace and Employee Survey Compendium," Catalogue No. 7 1-585-X. http://www.statcan.gc.ca/pub/71-585-x/71-585-x2008001-eng.pdf.

Statistics Canada 2008b. "Summary Public School Indicators for the Provinces and Territories, 1999/2000 to 2005/2006," Catalogue No. 81-595-M-No. 067. http://www.statcan.gc.ca/pub/81-595-m/81-595-m2008067-eng.pdf.

Statistics Canada 2009a. "SPSD/M: Product Overview," available at: http://www.statcan.gc.ca/microsimulation/pdf/spsdm-bdmsps-overview-vuedensembleeng.pdf.

Statistics Canada 2009b. "Financial Management System (FMS)," Catalogue No. 68F90023X. http://www.statcan.gc.ca/pub/68f0023x/68f0023x2006001-eng.pdf.

Transport Canada 2007a.“Transportation in Canada: An Overview-Addendum.” http://www.tc.gc.ca/media/documents/policy/add2007-e.pdf.

Transport Canada 2007b. "Estimation of Road Cost Allocation between Light Vehicles and Heavy Vehicles in Canada." 
U.S. Census Bureau 2001. "Experimental Poverty Measures: 1999," Current Population Reports, October. http://www.census.gov/prod/2001pubs/p60-216.pdf.

Veldhuis, Niels, and Michael Walker 2006. "Tax Facts 14,” The Fraser Institute. http://www.fraserinstitute.org/commerce.web/product_files/TaxFacts14.pdf.

Wolff, Edward N. 1996. "International Comparisons of Wealth Inequality," Review of Income and Wealth Vol. 42, No. 4, pp. 433-451. http://roiw.org/1996/433.pdf.

Wolff, Edward N., Ajit Zacharias and Thomas Masterson 2009. "Long-Term Trends in the Levy Institute Measure of Economic Well-being (LIMEW), United States, 1959-2004. "Working Paper 556. Annandale-on-Hudson, NY: The Levy Institute of Bard College. http://www.levyinstitute.org/pubs/wp_556.pdf.

Zacharias, Ajit, Edward N. Wolff and Thomas Masterson 2009. "New Estimates of Economic Inequality in America, 1959-2004," Annandale-on-Hudson, NY: The Levy Economic Institute of Bard College. http://www.levyinstitute.org/pubs/lmw_apr_09.pdf. 


\section{Appendix 1: A Detailed Outline of the Estimation of Public Consumption}

Household public consumption is estimated in three stages. First, aggregate public consumption is estimated with a detailed breakdown by the function of the spending. Second, expenditures within each functional category are attributed in whole or in part to the household sector. Expenditures attributed to the non-household sector (that is, the business sector or the foreign sector) are not included in the LIMEW. In the final stage, the household sector's shares of government expenditure in each functional category are distributed across households according

to category-specific criteria. This appendix provides detail about how each of these stages was carried out.

\section{A. Calculating Aggregate Government Expenditure by Function}

As noted in the main text, our main source of data on aggregate public expenditure by function is the FMS, accessed in CANSIM Tables 385-0001 and 385-0002. The breakdown of public expenditure by category and subcategory is in several cases insufficiently detailed for our purposes. We require a highly detailed breakdown because, in order to maximize the comparability of our Canadian estimates with the US LIMEW estimates, the distribution of expenditures between the household and non-household sectors and across households within the household sector must in some cases differ by subcategory. In cases in which we require a more detailed breakdown than that which the FMS data provide, we augmented the FMS data with data from other sources.

\section{i. Additional Data Sources}

As subcategories of spending on protection of persons and property are to be allocated differently between the household sector and non-household sector, a breakdown into subcategories was required. Unfortunately, the consolidated figures do not contain a breakdown of protection of persons and property into its subcategories. In the US LIMEW half of the expenditure on policing and firefighting was allocated to the household sector. Only federal expenditure on policing was reported in 385-0002. We retrieved the series CANSIM Table 2540002, "Trends in police expenditures for Canada." We used this to augment our data on expenditure on police. Expenditure for firefighting is only recorded for local government expenditure in 385-0002, so we assumed that firefighting is paid for at a local level. 
Insufficient detail is available in the key CANSIM tables about the breakdown of government expenditure on transportation. Therefore, this was supplemented with a provincial breakdown of transportation expenditures from Table G7 of Transportation in Canada 2007, available at http://www.tc.gc.ca/policy/anre/menu.htm.

In order to keep the Canadian LIMEW estimates consistent with the American estimates, the allocation of government expenditure on conservation and industry should differ by subcategory. But, provincial and local spending in 385-0001 is not given by subcategory, so the distribution across subcategories was assumed to be the same as that for federal expenditure as found in 385-0002. Similarly, for the environment category the distribution between its subcategories was assumed to be the same as the federal government.

In cases in which alternative data sources could not be found, we generated estimates of expenditures by subcategory by distributing total category expenditures across the subcategories.

This was done in the calculation of expenditures net of intergovernmental transfers. The calculation of federal expenditure minus transfers to lower levels of government (as described in the main text) was insufficiently detailed for our purposes. There exists a more detailed federal expenditure function in CANSIM Table 385-0002. Using this table we assumed the distribution between subcategories of federal government spending minus transfers was same as the distribution between subcategories of federal government spending including transfers.

\section{B. Allocating Government Expenditures to the Household Sector}

As noted in the main text, the two largest expenditure categories-education and health —are allocated almost entirely to the household sector (and much of health expenditure is considered part of non-cash government transfers). This section addresses the allocation of the other spending categories between the household and non-household sectors.

When the data were available, provincial government expenditure was allocated separately by province. For example provincial government expenditure on agriculture was allocated by provinces by the share of net program benefits in that province which went to unincorporated farms. Federal government expenditure is allocated by the weighted average of allocation of provincial government expenditure (if it varies by province). 
Consistent with the allocation of US government expenditure in Appendix Table 3, the government expenditure categories of general government, employment and immigration, and foreign affairs and international assistance were allocated to the non-household sector. The spending categories of labor and regional planning and development were allocated to the household sector, consistent with the allocation of general economic and labor affairs in the US LIMEW. Government expenditure on research is mostly transfers to institutions, so we allocated the spending category of research establishments to the non-household sector. Consistent with the US LIMEW, social services, recreation and culture, and housing are entirely allocated to the household sector. The undefined category of "other expenditures" (not a category in the NIPA tables) was allocated to the non-household sector.

We allocated public expenditure in the "protection of persons and property" category by subcategory. Consistent with LIMEW estimates in the United States, national defense, law courts, and corrections and rehabilitation were allocated to the non-household sector, but both policing and firefighting were allocated half to the household sector and half to the nonhousehold sector. Although there were no equivalent categories in the United States LIMEW, regulatory measures and other protection of persons were also allocated 50:50 because of the allocation of other similar subcategories of protection of persons and property.

Transportation and communication were allocated by subcategory. We have yet to locate appropriate data on passenger versus cargo air travel use, so for preliminary purposes government expenditure on air is allocated a third to the household sector. This is consistent with the US LIMEW. Public expenditure on roads was allocated, by province, by the estimated share of cost of roads that were created by passenger vehicles. This is estimated in Transport Canada (2007b).

Government expenditure on rail was allocated according to the fraction of rail carkilometers which were passenger car-kilometers using CANSIM Tables 404-0014 \& 404-0015. This was to keep the allocation consistent with the LIMEW for the US, which allocated according to share of passenger-car miles in total car-miles.

Consistent with the American LIMEW, government funding of water transportation is entirely allocated to the non-household sector and spending on transit is entirely allocated to the household sector. There are no categories of government spending in the American LIMEW 
equivalent to government expenditure on telecommunication and other transport communication, so we allocated both to the non-household sector.

Resource conservation and industrial development were allocated by subcategory. Trade and industry, tourism and promotion, other resource conservation and industrial development were allocated to the non-household sector. In the LIMEW of the United States, agriculture was allocated by share of family farms in total sales of farm product. However, because government funding may not be proportional to total sales, we allocated (by province) government expenditure on agriculture by the share of net program benefits which went to unincorporated farms (CANSIM Table 200-24 and 200-34). As in the United States, we allocated the categories of forestry and fish and game to the household sector. We allocated public expenditure on mining entirely to the non-household sector. In the US LIMEW, government expenditure on energy was allocated by share of household sector in total energy consumption (39 per cent in 1982). So, we allocated public expenditure on oil and gas and water power according to the share of household sector in energy consumption (22 per cent in Canada in 2005) (CANSIM Table 353-0032).

Public expenditure on the environment was allocated by subcategory. In the United States LIMEW, government funding of water supply facilities was allocated by domestic-use share of total deliveries from the public water supply. The spending category in Canada, water purification and supply, is allocated by household sector water usage.

In the US LIMEW, the government spending subcategory of pollution control and abatement was allocated by the average share of the household sector in the production of four categories of pollution: air pollution, $\mathrm{CO}_{2}$ emissions, water pollution, and municipal solid wastes. Comparable figures do not exist in Canada for the household share of all those forms of pollution. So, we allocated government expenditure on pollution control by the household's sector's share of $\mathrm{CO}_{2}$-equivalent emissions production (CANSIM Table 353-0034). The subcategory of other environmental services was allocated by residential share of waste disposal.

There are some categories of government expenditure which do not need to be allocated between sectors. Payments of debt consist of transfers to individuals, firms or governments and general transfer payments consist entirely of transfer payments to other levels of government. Thus these categories contain no government expenditure on goods and services.

\section{Distributing Government Expenditures across Households}


Policing, firefighting, regulatory measures, other government expenditure on protection of persons and property, labor, fish and game, forestry, mining, and recreation and culture were assumed to be distributed on a per capita basis.

Government expenditure on pollution control, and other environment was distributed by income. Specifically, it is allocated by ecological footprint by income decile. We used estimates from Size Matters: Canada's Ecological Footprint by Income, a 2008 Canadian Centre for Policy Alternatives study. It defines an ecological footprint as “... the biologically productive space in per capita global hectares needed to provide the resources for a nation's total consumption and to absorb the waste that it generates." Government expenditure on the remaining sub-category of environmental spending, water was randomly distributed to those we are attributing municipal water supply usage according to percentage of households in the province who have a municipal water supply as their primary source, using 2007 data. (CANSIM Table 153-0062) Then the amount distributed to those we assume are using municipal water supply is proportional to the amount they spend on water and sewage (from the SHS).

Consumption microdata surveys, the 1999 and 2005 Surveys of Household Spending (SHS) were used to estimate the distribution of some categories of public spending. In energy, recreation and culture, government expenditure was assumed to be proportional to private expenditure by region and income quintile.

Canada does not have a personal transportation survey indicating the kilometers Canadians travel by method of transportation comparable to the National Household Travel Survey (NHTS) for the United States. The NHTS was used to distribute government expenditure on transportation in the United States.

For distributing government expenditure on roads, first we attributed car-ownership to families based on the probability of car-ownership by region and decile in the SHS. Then we distributed government expenditure on roads to those attributed car-ownership in proportion to the average amount spent on gasoline by car-owners in their respective region and income decile.

We distributed government spending on air and rail transportation in a similar manner, but because the public use micro-data for the SHS does not separately report expenditure on rail and air, we used the household expenditure on inter-city transportation for these two categories combined. First we attributed inter-city travel to families according to the proportion of households in the SHS by region and income decile that have positive expenditure on intercity- 
travel. We then distributed government expenditure on rail and air to those families according to the average expenditure on inter-city travel by their respective regions and deciles.

Similarly for energy, the distribution of public expenditure was assumed to be proportional to private expenditure in that category.

Other government expenditures were distributed so that the organizational costs of transfer programs were distributed to those receiving the transfers. Thus the non-transfer expenditures of the CPP/QPP programs (1.6 per cent of the expenditures) were distributed to those receiving benefits. Likewise the organization costs of social services were distributed to those receiving social assistance. Government spending on agriculture was distributed such that it is proportional to household farm income. 
Appendix 2: Tables and Appendix Tables

\section{List of Tables}

Table 1: Mean and Median Estimates of the LIMEW and Other Income Measures, Canada, 2000 US Dollars, 1999 and 2005

Table 2: Comparison of Canada and the United States by Median LIMEW and Other Income Measures, 2000 US Dollars, 1999/2000 and 2004/2005 Table 3: Composition of the LIMEW by LIMEW Quintile, Canada, Per cent, 1999 and 2005

Table 3a: Components of the LIMEW by LIMEW Quintile, Canada, 2000 US Dollars, 1999 and 2005

Table 4: Gini Coefficients for the LIMEW and Other Income Measures, Canada, 1999 and 2005

Table 5: 90/10 Ratios for the LIMEW, it's Components, and Other Income Measures, Canada, 1999 and 05

Table 6: Quintile Shares of Aggregate Income by Income Measure, Canada, Per cent, 1999 and 2005

Table 7a: Mean LIMEW and Other Income Measures by Age of Head of Household, Canada, 2000 US Dollars, 1999 and 2005

Table 7b: Median LIMEW and Other Income Measures by Age of Head of Household, Canada, 2000 US Dollars, 1999 and 2005

Table 8a: Mean LIMEW and Other Income Measures by Educational Attainment of Head of Household, Canada, 2000 US Dollars, 1999 and 2005

Table 8b: Median LIMEW and Other Income Measures by Educational Attainment of Head of Household, Canada, 2000 US Dollars, 1999 and 2005

Table 9a: Mean LIMEW and Other Income Measures by Region, Canada, 2000 US Dollars, 1999 and 2005

Table 9b: Median LIMEW and Other Income Measures by Region, Canada, 2000 US Dollars, 1999 and 2005

Table 10: Composition of Households, 1999 and 2005

Table 11: Remaining Life Expectancy by LIMEW and Household Income Quintiles, Canada, 1999 and 2005

Table 12: Mean household Non-home Assets Holdings by LIMEW and Household Income Quintiles, Canada, 1999 and 2005

Table 12a: Composition of Household Non-home Assets Holdings by LIMEW and Household Income Quintiles, Canada, Per cent, 1999 and 2005

Table 13: Mean Annual Hours of Household Production by LIMEW and Household Income Quintiles, Canada, 1999 and 2005

Table 13a: Mean Annual Hours of Household Production Per Adult by LIMEW and Household Income Quintiles, Canada, 1999 and 2005

Table 14: Mean Number of Adults per Household by LIMEW and Household Income Quintiles, Canada, 1999 and 2005 
Table 15: Mean Hourly Value of Household Production by LIMEW and Household Income Quintile, Canada, 1999 and 2005

Table 15a: Impact of the Performance Index on Hourly Imputed Wage, Canada, Per cent, 1999 and 2005

Table 16: Decomposition of the Change in Household Production over 1999-2005 Period, Canada

Table 17: Alternative Household Production Measures by LIMEW Quintiles, Canada, 1999 and 2005

Table 17a: Alternative Household Production Measures by Household Income Quintiles, Canada, 1999 and 2005

Table 17b: Alternative Household Production Measures by PFI Quintiles, Canada, 1999 and 2005

Table 17c: Alternative Household Production Measures by Household Production Quintiles and Gini Coefficient, Canada, 1999 and 2005

Table 18: Mean Equivalence Scale Value by LIMEW and Household Income Quintile, Canada, 1999 and 2005

Table 19: Gini Coefficients for the Alternate LIMEW Estimates, LIMEW and Other Income Measures, Canada, 1999 and 2005

\section{List of Appendix Tables:}

Appendix Table 1: Net Government Expenditure on Goods and Services, Canada, Millions of Current Dollars, 1999/2000

Appendix Table 2: Net Government Expenditure on Goods and Services, Canada, Millions of Current Dollars, 2005/2006

Appendix Table 3: Allocation and Distribution of Public Consumption, LIMEW for the United States

Appendix Table 4: Allocation and Distribution of Public Consumption, LIMEW for the Canada

Appendix Table 5: Allocation of Government Expenditure to Household and Non-Household Sectors, 1999

Appendix Table 6: Allocation of Government Expenditure to Household and Non-Household Sectors, 2005

Appendix Table 7: Rates of Return for Assets, Canada, Per Cent per Year, 1999 and 2005 
Table 1: Mean and Median Estimates of the LIMEW and Other Income Measures, Canada, 2000 US Dollars, 1999 and 2005

\begin{tabular}{|c|c|c|c|c|c|c|}
\hline \multirow[b]{2}{*}{ Measure } & \multicolumn{2}{|c|}{1999} & \multicolumn{2}{|c|}{2005} & \multicolumn{2}{|c|}{$\begin{array}{c}\text { Growth, 1999- } \\
2005 \text { (Per cent per } \\
\text { year) }\end{array}$} \\
\hline & Mean & Median & Mean & Median & Mean & Median \\
\hline LIMEW & 72,254 & 63,350 & 77,074 & 65,902 & 1.08 & 0.66 \\
\hline Base Income & 36,264 & 27,556 & 39,984 & 29,707 & 1.64 & 1.26 \\
\hline Income from Wealth & 11,261 & 5,264 & 13,136 & 4,563 & 2.60 & -2.35 \\
\hline Net Government Expenditure & 1,315 & 2,134 & 2,557 & 2,771 & 11.73 & 4.45 \\
\hline Household Production & 23,415 & 18,031 & 21,397 & 15,578 & -1.49 & -2.41 \\
\hline After-tax Income & 24,038 & 20,233 & 27,244 & 21,981 & 2.11 & 1.39 \\
\hline CDI & 40,365 & 33,784 & 46,371 & 37,438 & 2.34 & 1.73 \\
\hline PFI & 48,839 & 42,447 & 55,677 & 46,743 & 2.21 & 1.62 \\
\hline
\end{tabular}

\begin{tabular}{|l|r|r|r|r|r|r|}
\multicolumn{9}{c|}{ Equivalence Scale Adjusted: } \\
\hline LIMEW & 90,796 & 81,916 & 98,291 & 87,362 & 1.33 & 1.08 \\
\hline Base Income & 44,341 & 35,160 & 50,080 & 39,494 & 2.05 & 1.96 \\
\hline Income from Wealth & 15,295 & 6,471 & 17,801 & 5,981 & 2.56 & -1.30 \\
\hline Net Government Expenditure & 2,681 & 2,836 & 4,100 & 3,851 & 7.34 & 5.23 \\
\hline Household Production & 28,479 & 23,603 & 26,310 & 20,632 & -1.31 & -2.22 \\
\hline After-tax Income & 29,498 & 25,989 & 34,323 & 29,232 & 2.56 & 1.98 \\
\hline CDI & 51,957 & 44,985 & 60,560 & 50,431 & 2.59 & 1.92 \\
\hline PFI & 62,317 & 55,737 & 71,981 & 62,496 & 2.43 & 1.93 \\
\hline
\end{tabular}

Notes:

1. After-tax income is Base Income plus government cash transfers, less income taxes (federal and provincial), payroll taxes, property taxes, and consumption taxes paid by the household.

2. CDI is comprehensive disposable income. It equals after-tax income plus the value of home and nonhome wealth annuities.

3. PFI is post-fiscal income. It equals CDI plus household public consumption.

4. LIMEW is the complete Levy Institute Measure of Economic Well-being. It is the sum of base income, income from wealth, net government expenditure, and household production. Alternatively, it is equal to PFI plus household production.

5. Equivalent income measures are based on the household equivalence scale used in the U.S. Census Bureau's (2001) experimental poverty measures. The formula for the equivalence scale is as follows: A single adult is given the base value of 1.00, two adults is fixed at 1.41. For families with children the formula is $(\mathrm{A}+0.5 \times \mathrm{C}+0.3 \times \mathrm{S})^{\wedge} 0.7$ Where $\mathrm{A}$ is the number of adults, $\mathrm{C}$ is the number of children and $\mathrm{S}$ is a dummy variable set to 1 if it is a lone parent household and 0 if it is a two-parent household. 
Table 2: Comparison of Canada and the United States by Median LIMEW and Other Income Measures, 2000 US Dollars, 1999/2000 and 2004/2005

\begin{tabular}{|l|c|c|c|c|c|c|}
\cline { 2 - 7 } & \multicolumn{3}{|c|}{$1999 / 2000$} & \multicolumn{3}{c|}{$2004 / 2005$} \\
\cline { 2 - 7 } & Canada & $\begin{array}{c}\text { United } \\
\text { States }\end{array}$ & $\begin{array}{c}\text { US-Canada } \\
\text { Gap (Per } \\
\text { Cent) }\end{array}$ & Canada & $\begin{array}{c}\text { United } \\
\text { States }\end{array}$ & $\begin{array}{c}\text { US-Canada } \\
\text { Gap (Per } \\
\text { Cent) }\end{array}$ \\
\hline LIMEW & 63,350 & 69,514 & 9.7 & 65,902 & 71,599 & 8.6 \\
\hline PFI & 42,447 & 52,597 & 23.9 & 46,743 & 53,332 & 14.1 \\
\hline CDI & 33,784 & 43,754 & 29.5 & 37,438 & 43,971 & 17.5 \\
\hline
\end{tabular}

Notes:

1. The US estimates are provided by the Levy Institute and were developed to be comparable with Canada.

2. Canadian estimates are for 1999 and 2005. US estimates are for 2000 and 2004. 
Table 3: Composition of the LIMEW by LIMEW Quintile, Canada, Per cent, 1999 and 2005

\begin{tabular}{|c|c|c|c|c|c|c|}
\hline Quintile & $\begin{array}{l}\text { Mean LIMEW } \\
\text { (2000 US } \\
\text { Dollars) }\end{array}$ & Total & Base Income & $\begin{array}{l}\text { Income from } \\
\text { Wealth }\end{array}$ & $\begin{array}{l}\text { Net Government } \\
\text { Expenditure }\end{array}$ & $\begin{array}{l}\text { Household } \\
\text { Production }\end{array}$ \\
\hline \multicolumn{7}{|c|}{1999} \\
\hline Lowest & 22,564 & 100 & 46.2 & 11.3 & 18.3 & 24.2 \\
\hline Second & 43,827 & 100 & 46.9 & 13.3 & 12.0 & 27.7 \\
\hline Third & 63,401 & 100 & 46.5 & 13.2 & 8.8 & 31.5 \\
\hline Fourth & 86,503 & 100 & 48.0 & 14.2 & 4.2 & 33.7 \\
\hline Highest & 144,989 & 100 & 54.7 & 18.8 & -8.3 & 34.7 \\
\hline All & 72,254 & 100 & 50 & 16 & 2 & 32 \\
\hline \multicolumn{7}{|c|}{2005} \\
\hline Lowest & 22,590 & 100 & 51.8 & 9.3 & 18.8 & 20.1 \\
\hline Second & 44,753 & 100 & 50.7 & 11.8 & 13.6 & 24.0 \\
\hline Third & 66,172 & 100 & 48.3 & 13.0 & 11.5 & 27.2 \\
\hline Fourth & 92,222 & 100 & 50.4 & 14.8 & 5.1 & 29.7 \\
\hline Highest & 159,635 & 100 & 54.5 & 22.6 & -6.2 & 29.0 \\
\hline All & 77,074 & 100 & 52 & 17 & 3 & 28 \\
\hline
\end{tabular}

Equivalence Scale Adjusted:

\begin{tabular}{|c|c|c|c|c|c|c|}
\hline \multicolumn{7}{|c|}{1999} \\
\hline Lowest & 45,090 & 100 & 46.3 & 11.5 & 18.8 & 23.5 \\
\hline Second & 72,155 & 100 & 46.3 & 14.6 & 11.5 & 27.6 \\
\hline Third & 85,425 & 100 & 45.5 & 14.9 & 8.2 & 31.4 \\
\hline Fourth & 101,607 & 100 & 46.7 & 16.0 & 3.7 & 33.6 \\
\hline Highest & 149,714 & 100 & 54.2 & 21.2 & -9.4 & 34.0 \\
\hline All & 90,796 & 100 & 49 & 17 & 3 & 31 \\
\hline \multicolumn{7}{|c|}{2005} \\
\hline Lowest & 45,613 & 100 & 52.2 & 9.2 & 19.2 & 19.3 \\
\hline Second & 75,160 & 100 & 50.3 & 12.8 & 13.2 & 23.7 \\
\hline Third & 91,092 & 100 & 47.4 & 14.8 & 10.5 & 27.2 \\
\hline Fourth & 110,863 & 100 & 49.6 & 16.7 & 4.1 & 29.6 \\
\hline Highest & 168,731 & 100 & 53.7 & 25.6 & -7.3 & 28.0 \\
\hline All & 98,291 & 100 & 51 & 18 & 4 & 27 \\
\hline
\end{tabular}

\section{Notes:}

1. Base income is the sum of earnings, benefits, interpersonal transfers and other income.

2. Income from wealth is the sum of the annuities from non-home wealth and the imputed yearly rent on owner-occupied housing (net of mortgage and non-home debt annuities).

3. Net government expenditure government transfers plus public consumption, minus all taxes (income, property, payroll and consumption taxes).

4. Household production is the imputed value of household production. 
Table 3a: Components of the LIMEW by LIMEW Quintile, Canada, 2000 US Dollars, 1999 and 2005

\begin{tabular}{|l|r|r|r|r|r|}
\hline \multirow{2}{*}{ Quintile } & $\begin{array}{c}\text { Mean LIMEW } \\
\text { (2000 US } \\
\text { Dollars) }\end{array}$ & $\begin{array}{c}\text { Base } \\
\text { Income }\end{array}$ & $\begin{array}{c}\text { Income } \\
\text { from Wealth }\end{array}$ & $\begin{array}{c}\text { Net } \\
\text { Government } \\
\text { Expenditure }\end{array}$ & $\begin{array}{c}\text { Household } \\
\text { Production }\end{array}$ \\
\cline { 2 - 7 } & A=B+C+D+E & B & C & \multicolumn{1}{c|}{ D } & E \\
\hline Lowest & 22,564 & 10,426 & 2,559 & 4,119 & 5,460 \\
\hline Second & 43,827 & 20,570 & 5,830 & 5,274 & 12,153 \\
\hline Third & 63,401 & 29,477 & 8,357 & 5,590 & 19,977 \\
\hline Fourth & 86,503 & 41,507 & 12,272 & 3,607 & 29,117 \\
\hline Highest & 144,989 & 79,346 & 27,287 & $-12,019$ & 50,375 \\
\hline All & 72,254 & 36,264 & 11,261 & 1,315 & 23,415 \\
\hline \multicolumn{7}{|c|}{} & & 2005 & & 4,539 \\
\hline Lowest & 22,590 & 11,710 & 2,096 & 4,245 & 10,729 \\
\hline Second & 44,753 & 22,694 & 5,265 & 6,065 & 18,026 \\
\hline Third & 66,172 & 31,955 & 8,602 & 7,588 & 27,375 \\
\hline Fourth & 92,222 & 46,486 & 13,654 & 4,707 & 46,318 \\
\hline Highest & 159,635 & 87,076 & 36,062 & $-9,821$ & 21,397 \\
\hline All & 77,074 & 39,984 & 13,136 & 2,557 & \\
\hline
\end{tabular}

Equivalence Scale Adjusted:

\begin{tabular}{|l|r|r|r|r|r|}
\hline \multicolumn{7}{|c|}{1999} \\
\hline Lowest & 45,090 & 20,868 & 5,168 & 8,455 & 10,599 \\
\hline Second & 72,155 & 33,393 & 10,537 & 8,288 & 19,937 \\
\hline Third & 85,425 & 38,905 & 12,702 & 6,993 & 26,825 \\
\hline Fourth & 101,607 & 47,411 & 16,273 & 3,787 & 34,136 \\
\hline Highest & 149,714 & 81,135 & 31,796 & $-14,121$ & 50,904 \\
\hline All & 90,796 & 44,341 & 15,295 & 2,681 & 28,479 \\
\hline \multicolumn{7}{|c|}{} & & 2005 & \\
\hline Lowest & 45,613 & 23,829 & 4,204 & 8,770 & 8,810 \\
\hline Second & 75,160 & 37,838 & 9,624 & 9,896 & 17,802 \\
\hline Third & 91,092 & 43,219 & 13,520 & 9,540 & 24,813 \\
\hline Fourth & 110,863 & 54,972 & 18,507 & 4,540 & 32,844 \\
\hline Highest & 168,731 & 90,542 & 43,152 & $-12,245$ & 47,282 \\
\hline All & 98,291 & 50,080 & 17,801 & 4,100 & 26,310 \\
\hline
\end{tabular}


Table 4: Gini Coefficients for the LIMEW and Other Income Measures, Canada, 1999 and 2005

\begin{tabular}{|l|c|c|c|}
\cline { 2 - 4 } \multicolumn{1}{c|}{} & 1999 & 2005 & Per Cent Change \\
\hline Base Income & 0.546 & 0.550 & 0.82 \\
\hline After-tax Income & 0.496 & 0.490 & -1.19 \\
\hline CDI & 0.382 & 0.399 & 4.48 \\
\hline PFI & 0.345 & 0.365 & 5.80 \\
\hline LIMEW & 0.340 & 0.357 & 5.04 \\
\hline
\end{tabular}

Equivalence Scale Adjusted:

\begin{tabular}{|l|l|l|l|}
\hline Base Income & 0.531 & 0.535 & 0.77 \\
\hline After-tax Income & 0.468 & 0.459 & -2.05 \\
\hline CDI & 0.345 & 0.360 & 4.45 \\
\hline PFI & 0.288 & 0.307 & 6.30 \\
\hline LIMEW & 0.266 & 0.285 & 7.01 \\
\hline
\end{tabular}

Note: For each variable, there is a small proportion of households with negative values. The Gini coefficient may overstate the degree of inequality when negative income values are present in the data (indeed, negative values can lead to Gini coefficients greater than one). Although the number of households having negative values is relatively small, the Gini coefficients reported in this table should be interpreted with some caution. 


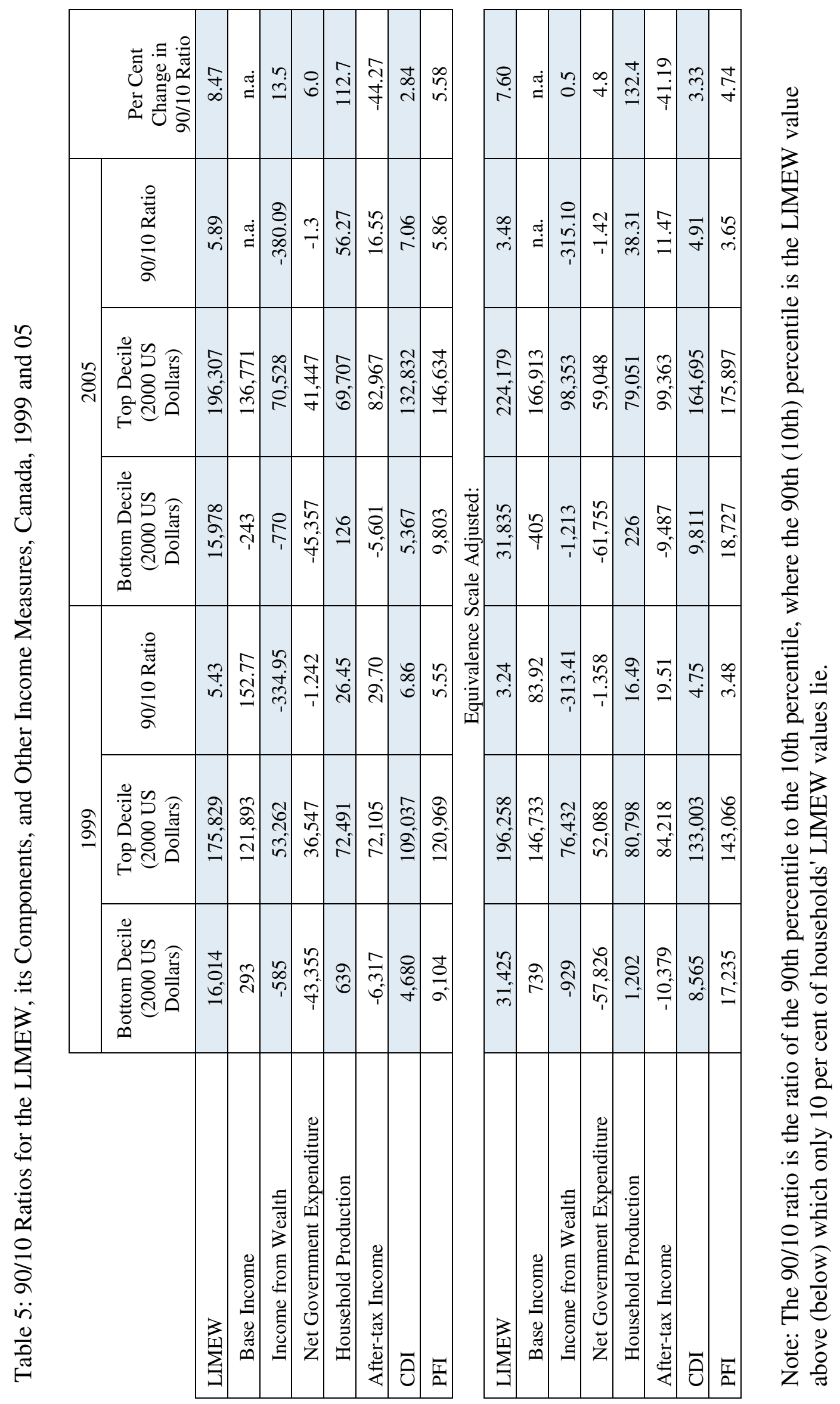




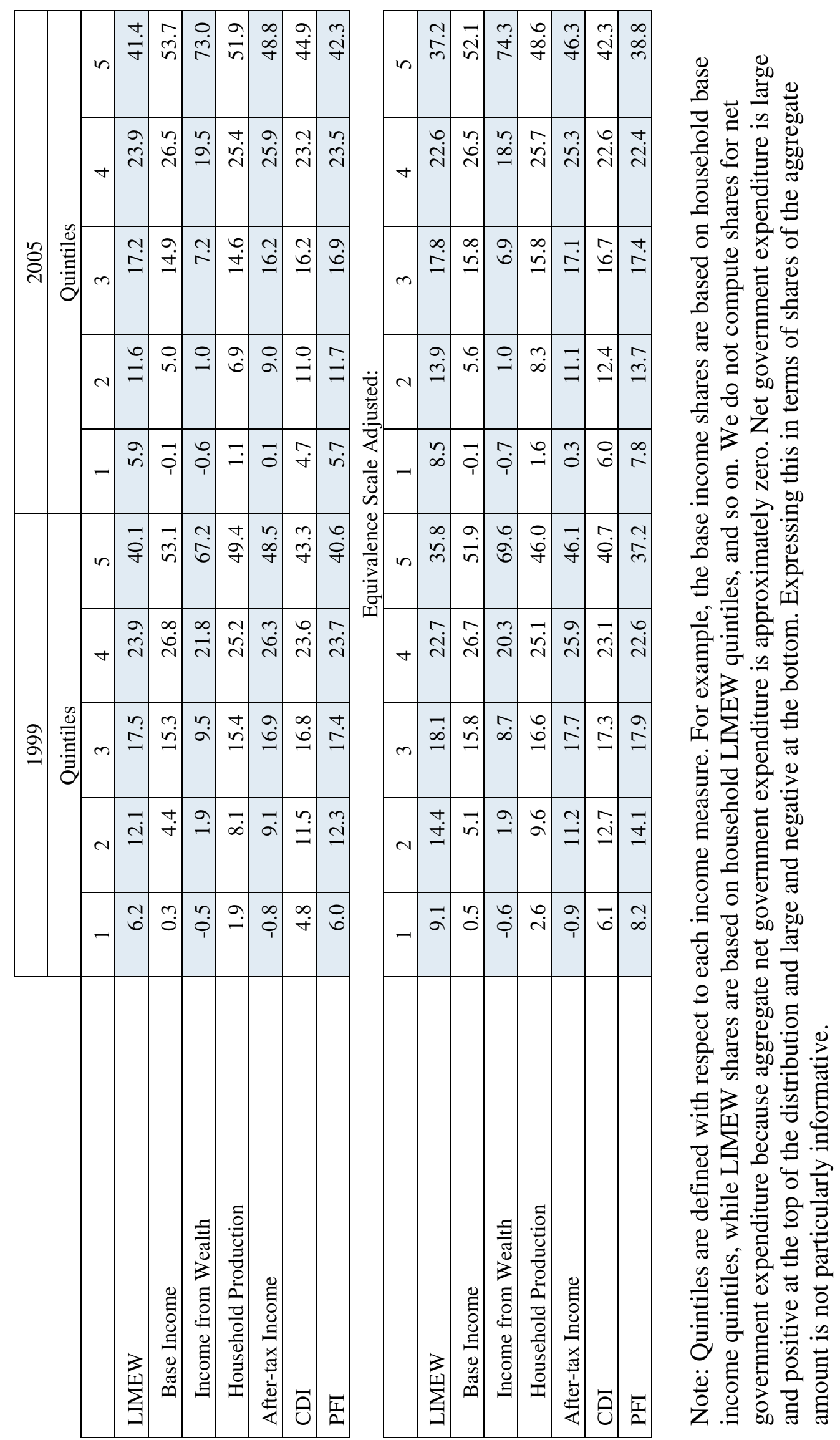




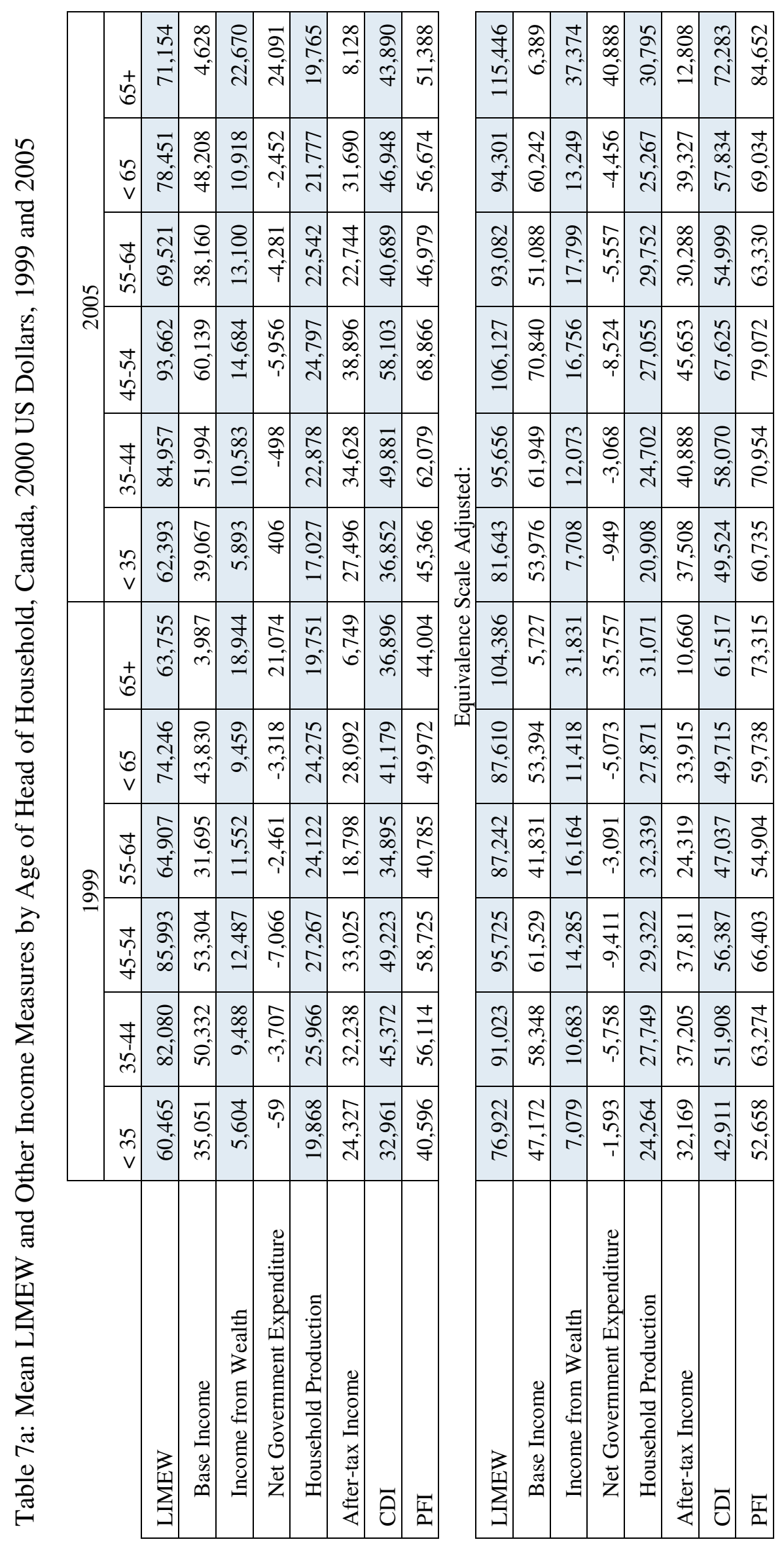




\begin{tabular}{|c|c|c|c|c|c|c|c|c|c|c|c|c|c|c|c|c|c|c|}
\hline & $\begin{array}{c}+ \\
6 \\
b\end{array}$ & 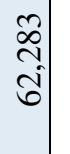 & 0 & $\begin{array}{l}\hat{n} \\
\mathfrak{f} \\
\mathrm{i}\end{array}$ & $\begin{array}{l}\mathfrak{f} \\
\dot{f} \\
+ \\
+\end{array}$ & 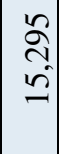 & $\begin{array}{l}\vec{\nabla} \\
\infty \\
\infty\end{array}$ & $\begin{array}{c}R \\
n \\
n \\
n\end{array} \mid$ & 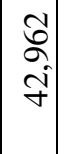 & & $\begin{array}{l}\hat{\sigma} \\
\hat{\sigma} \\
\text { రీ}\end{array}$ & 0 & 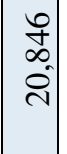 & 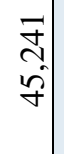 & $\begin{array}{c}2 \\
\forall \\
n \\
v\end{array} \mid$ & $\begin{array}{c}\infty \\
\infty \\
\stackrel{0}{n} \\
\sim\end{array}$ & $\begin{array}{l}\sqrt{ } \\
\infty \\
\infty \\
\infty \\
n\end{array}$ & 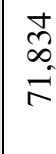 \\
\hline & $\begin{array}{l}n \\
v \\
v\end{array}$ & 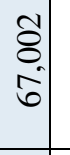 & 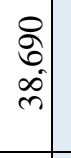 & $\begin{array}{l}m \\
\tilde{\sigma} \\
m\end{array}$ & \begin{tabular}{c}
$a$ \\
$\mathfrak{g}$ \\
\hdashline \\
\hdashline
\end{tabular} & $\mid \begin{array}{c}m \\
f \\
b \\
\vdots \\
0\end{array}$ & 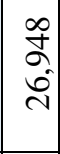 & $\begin{array}{c}\infty \\
\tilde{n} \\
\hat{n}\end{array} \mid$ & 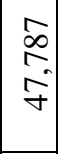 & & \begin{tabular}{c|c}
$\infty$ \\
$\infty$ \\
$\infty$ \\
$\infty$
\end{tabular} & $\begin{array}{l}\stackrel{2}{\hat{n}} \\
\stackrel{0}{n} \\
\bullet\end{array}$ & $\begin{array}{l}\infty \\
i \\
\forall \\
\forall\end{array}$ & 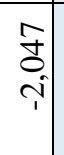 & $\left|\begin{array}{l} \pm \\
\nabla \\
\Xi\end{array}\right|$ & 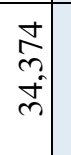 & 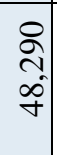 & $\begin{array}{l}\hat{\sigma} \\
\hat{\sigma}\end{array}$ \\
\hline$n$ & 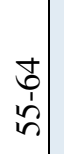 & 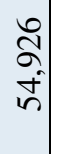 & 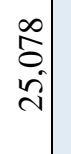 & $\begin{array}{l}8 \\
\stackrel{\infty}{+} \\
+ \\
+\end{array}$ & 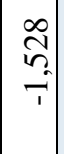 & 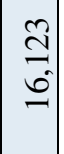 & $\begin{array}{l}8 \\
\infty \\
\infty \\
0 \\
0\end{array}$ & $\begin{array}{l}8 \\
2 \\
2 \\
2\end{array}$ & $\begin{array}{c}n \\
n \\
n\end{array}$ & & $\begin{array}{l}n \\
\infty \\
\infty \\
2\end{array}$ & $\begin{array}{l}\stackrel{p}{R} \\
n \\
n \\
n\end{array}$ & 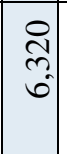 & $\begin{array}{c}\bar{\sigma} \\
\stackrel{1}{i} \\
i\end{array}$ & 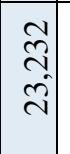 & 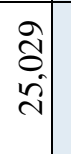 & $\begin{array}{l}\tilde{n} \\
\tilde{n} \\
\tilde{7}\end{array}$ & $\begin{array}{l}\infty \\
\approx \\
\tilde{N} \\
\text { n }\end{array}$ \\
\hline & $\begin{array}{l}\stackrel{v}{r} \\
\dot{r} \\
\dot{y}\end{array}$ & $\begin{array}{l}\stackrel{2}{2} \\
\stackrel{2}{2}\end{array}$ & $\begin{array}{l}\sigma \\
\vec{\sigma} \\
\hat{\sigma}\end{array}$ & 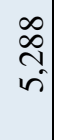 & $\begin{array}{l}8 \\
+ \\
+ \\
+ \\
\end{array}$ & $\mid \begin{array}{c}\hat{\sigma} \\
0 \\
0\end{array}$ & $\begin{array}{c}\stackrel{P}{f} \\
\dot{f} \\
m \\
m\end{array} \mid$ & $\begin{array}{l}0 \\
8 \\
+ \\
0 \\
f\end{array}$ & $\begin{array}{l}m \\
2 \\
i n\end{array}$ & & $\begin{array}{l}\tilde{2} \\
\text { הi } \\
\text {. }\end{array}$ & 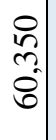 & $\begin{array}{c}\stackrel{\overbrace{}}{f} \\
\stackrel{\leftrightarrow}{0} \\
6\end{array}$ & $\begin{array}{c}\stackrel{+}{\mathrm{f}} \\
\stackrel{1}{1}\end{array}$ & $\begin{array}{l}\vec{\sigma} \\
\overrightarrow{0}\end{array}$ & $\begin{array}{l}\text { పे } \\
\text { } \\
\text { లి }\end{array}$ & $\begin{array}{l}\overline{8} \\
8 \\
i \\
n\end{array}$ & 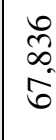 \\
\hline & $\begin{array}{l}7 \\
⿱ \\
⿱ \\
n\end{array} \mid$ & $\begin{array}{l}\infty \\
\stackrel{0}{N} \\
\infty \\
\infty\end{array}$ & $\begin{array}{l}\vec{a} \\
\infty \\
f\end{array}$ & 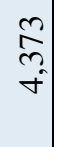 & $\begin{array}{c}\hat{n} \\
\infty \\
1\end{array}$ & $\begin{array}{l}\stackrel{\mathrm{J}}{\mathrm{f}} \\
\mathrm{I}\end{array}$ & $\left|\begin{array}{l}0 \\
\delta \\
\tilde{n} \\
0 \\
\tilde{n}\end{array}\right|$ & $\left|\begin{array}{c}\tilde{b} \\
\dot{f} \\
\tilde{f}\end{array}\right|$ & $\begin{array}{l}0 \\
\infty \\
n \\
n\end{array} \mid$ & $\ddot{\vec{d}}$ & 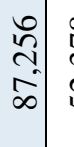 & $\begin{array}{l}\infty \\
\stackrel{\infty}{n} \\
\sim \\
n\end{array}$ & $\frac{\nabla}{n}$ & $\underset{\substack{9 \\
\rightarrow}}{=}$ & 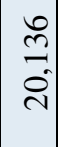 & $\begin{array}{l}\text { oे } \\
\text { nీ }\end{array}$ & $\begin{array}{l}n \\
\tilde{n} \\
\hat{q}\end{array}$ & $\begin{array}{l}\sqrt{\hat{\sigma}} \\
\hat{\sigma}\end{array}$ \\
\hline & $\begin{array}{c}\tilde{m} \\
\vee\end{array}$ & $\begin{array}{l}\text { ț } \\
n \\
\dot{n} \\
n\end{array}$ & $\begin{array}{l}\hat{b} \\
\hat{n} \\
\hat{n}\end{array}$ & $\begin{array}{l}t \\
0 \\
0 \\
-1\end{array}$ & $\because$ & $\begin{array}{l}\stackrel{8}{ \pm} \\
= \\
=\end{array}$ & $\begin{array}{c}\tilde{\infty} \\
0 \\
\vdots \\
\end{array}$ & $\begin{array}{l}\text { ฉ. } \\
\text { m. } \\
\text { m. }\end{array}$ & $\begin{array}{c}\vec{m} \\
f \\
\dot{f}\end{array}$ & 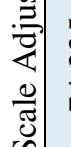 & \begin{tabular}{l}
$\tilde{N}$ \\
\multirow{\tau}{\tau}{} \\
\end{tabular} & \begin{tabular}{l}
8 \\
$\infty$ \\
\multirow{\gamma}{*}{} \\
$\forall$
\end{tabular} & 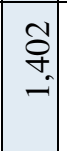 & iి & $\left|\begin{array}{l}\infty \\
\infty \\
n \\
n\end{array}\right|$ & $\begin{array}{l}\vec{n} \\
\hat{n} \\
m\end{array}$ & $\begin{array}{l}\stackrel{\sigma}{\sigma} \\
\dot{\sigma} \\
\dot{f}\end{array}$ & $\begin{array}{c}\stackrel{f}{\sim} \\
\tilde{n} \\
n\end{array}$ \\
\hline & $\begin{array}{l}+ \\
b \\
b\end{array}$ & $\begin{array}{l}0 \\
0 \\
\bullet \\
i\end{array}$ & $\stackrel{0}{0}$ & $\begin{array}{l}m \\
\overrightarrow{0} \\
= \\
=\end{array}$ & $\left|\begin{array}{c}0 \\
\hat{\delta} \\
-i \\
-1\end{array}\right|$ & $\mid \begin{array}{c}7 \\
7 \\
2 \\
2 \\
-2\end{array}$ & $\left|\begin{array}{l}0 \\
\infty \\
2 \\
r\end{array}\right|$ & $\begin{array}{c}\stackrel{m}{+} \\
\infty \\
0 \\
\stackrel{n}{0}\end{array}$ & $\begin{array}{c}\infty \\
n \\
\infty \\
\infty \\
n\end{array} \mid$ & 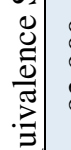 & $\begin{array}{l}8 \\
\text { ळे } \\
\text { ๙ે }\end{array}$ & $\underset{f}{\tilde{d}}$ & $\begin{array}{l}\tilde{a} \\
\tilde{J} \\
\stackrel{-}{ }\end{array}$ & $\begin{array}{l}\infty \\
0 \\
0 \\
\hat{m}\end{array}$ & 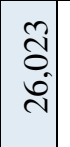 & 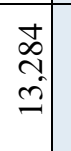 & 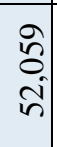 & $\frac{2}{\frac{D}{J}}$ \\
\hline & $\begin{array}{l}n \\
v\end{array}$ & $\begin{array}{l}\tilde{2} \\
\hat{\imath} \\
\hat{6}\end{array}$ & 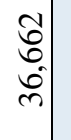 & \begin{tabular}{l}
$\infty$ \\
0 \\
$?$ \\
\multirow{2}{*}{} \\
+
\end{tabular} & $\begin{array}{c}\bar{m} \\
\text { r. } \\
\text { i }\end{array}$ & $\left|\begin{array}{c}\bar{\sigma} \\
\infty \\
\infty\end{array}\right|$ & 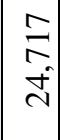 & $\mid \begin{array}{c}\vec{N} \\
\vec{m}\end{array}$ & $\begin{array}{l}n \\
\infty \\
m \\
f\end{array} \mid$ & 工I) & 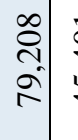 & $\begin{array}{c}\vec{q} \\
q \\
f \\
f\end{array}$ & $\begin{array}{l}n \\
\sim \\
\sim\end{array}$ & $\begin{array}{l}\hat{n} \\
\hat{i} \\
1\end{array}$ & $\begin{array}{l} \pm \\
\tilde{\infty} \\
\text { సे }\end{array}$ & $\begin{array}{l}8 \\
8 \\
0 \\
0 \\
0\end{array}$ & $\begin{array}{l}n \\
\tilde{n} \\
\hat{j} \\
\tilde{f}\end{array}$ & $\begin{array}{l}n \\
\text { nे } \\
\text { ñ }\end{array}$ \\
\hline ஓ & 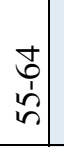 & 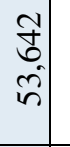 & 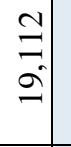 & $\begin{array}{l}\infty \\
\infty \\
\infty \\
+ \\
+\end{array}$ & $\overrightarrow{\widetilde{\sigma}}$ & $\begin{array}{c}\infty \\
\dot{+} \\
n \\
\infty \\
-1\end{array}$ & 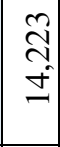 & 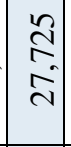 & $\begin{array}{c}\vec{\beth} \\
\text { m. } \\
\text { กे. }\end{array}$ & & \begin{tabular}{l}
\multirow{2}{n}{} \\
\multirow{2}{*}{}
\end{tabular} & 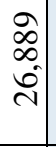 & $\begin{array}{l}\mathfrak{f} \\
\hat{\sigma} \\
6\end{array}$ & 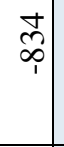 & 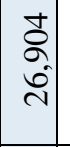 & $\stackrel{\nabla}{\hat{\sigma}}$ & $\begin{array}{l}\tilde{n} \\
\stackrel{n}{m}\end{array}$ & 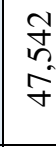 \\
\hline & 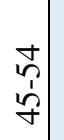 & $\begin{array}{c}n \\
\frac{0}{2} \\
2\end{array}$ & $\begin{array}{l}n \\
=0 \\
6\end{array}$ & 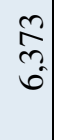 & $\begin{array}{l}\hat{0} \\
\hat{n} \\
\hat{1}\end{array}$ & $\left|\begin{array}{c}0 \\
0 \\
\overline{0} \\
\text { in }\end{array}\right|$ & 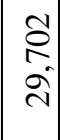 & $\begin{array}{l}\stackrel{+}{ } \\
\underset{\mathbf{f}}{\mathrm{f}} \\
\mathcal{f}\end{array}$ & $\begin{array}{l}t \\
0 \\
-n \\
\tilde{n}\end{array} \mid$ & & $\begin{array}{c}\infty \\
\infty \\
0 \\
\hat{\infty}\end{array}$ & $\begin{array}{l}\hat{\check{n}} \\
\hat{n} \\
\hat{n}\end{array}$ & $\begin{array}{l}0 \\
\text { mे } \\
\text { r. }\end{array}$ & 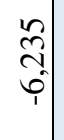 & $\begin{array}{l}\infty \\
0 \\
\infty \\
\dot{J} \\
\text { d. }\end{array}$ & $\begin{array}{l}\overrightarrow{\vec{b}} \\
\vec{d} \\
\dot{m}\end{array}$ & $\begin{array}{l}n \\
\tilde{n} \\
\mathfrak{g}\end{array}$ & $\begin{array}{l}8 \\
8 \\
\text { in }\end{array}$ \\
\hline & $\begin{array}{l}J \\
⿱ \\
\vdots \\
n\end{array}$ & $\begin{array}{l}\stackrel{+}{\sigma} \\
\stackrel{5}{ \pm}\end{array}$ & $\begin{array}{l}\stackrel{0}{f} \\
\underset{f}{f}\end{array}$ & $\begin{array}{l}2 \\
2 \\
n \\
n\end{array}$ & $\mid \begin{array}{c}\infty \\
+ \\
\infty \\
\text { †i } \\
1\end{array}$ & $\begin{array}{l}\hat{m} \\
\hat{n} \\
\hat{n}\end{array} \mid$ & $\left|\begin{array}{c}\hat{0} \\
0 \\
\infty \\
0\end{array}\right|$ & $\begin{array}{l}0 \\
= \\
\stackrel{m}{m}\end{array}$ & $\begin{array}{c}\tilde{c} \\
2 \\
0 \\
n\end{array} \mid$ & & 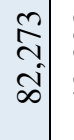 & $\begin{array}{l}\infty \\
\\
g \\
g\end{array}$ & $\begin{array}{l}n \\
2 \\
0 \\
0\end{array}$ & 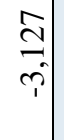 & $\begin{array}{l}\hat{\hat{n}} \\
\tilde{\lambda} \\
\hat{\lambda}\end{array}$ & 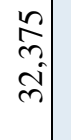 & $\begin{array}{l}\stackrel{N}{f} \\
\underset{f}{f}\end{array}$ & $\begin{array}{l}\stackrel{2}{f} \\
\stackrel{f}{\circ}\end{array}$ \\
\hline & $\begin{array}{c}n \\
\sim \\
\vee\end{array}$ & $\begin{array}{l}\infty \\
0 \\
6 \\
n \\
n \\
n\end{array}$ & $\begin{array}{l}\infty \\
\stackrel{2}{2} \\
\stackrel{\lambda}{2}\end{array}$ & $\stackrel{\infty}{\sim}$ & $\begin{array}{c} \pm \\
\stackrel{1}{1}\end{array}$ & $\begin{array}{l}n \\
\infty \\
\stackrel{0}{n} \\
\pm\end{array}$ & 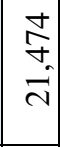 & 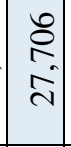 & $\begin{array}{l}n \\
a \\
n \\
n\end{array} \mid$ & & 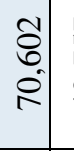 & $\begin{array}{l}\hat{n} \\
\hat{n} \\
\dot{f}\end{array}$ & $\underset{\nabla}{\Xi}$ & $\stackrel{0}{n}$ & $\begin{array}{l}0 \\
\hat{\sigma} \\
\hat{\sigma}\end{array} \mid$ & $\begin{array}{c}\bar{n} \\
\infty \\
\infty \\
0 \\
\end{array}$ & $\begin{array}{c}\hat{n} \\
\hat{n}\end{array}$ & 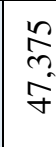 \\
\hline & & 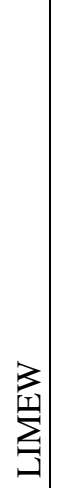 & $\begin{array}{c}\tilde{\Xi} \\
0 \\
0 \\
\Xi \\
0 \\
\tilde{\Xi} \\
\tilde{\Xi} \\
0\end{array}$ & 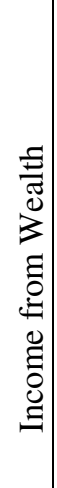 & 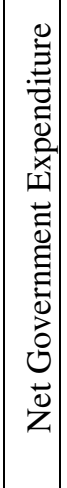 & $\left|\begin{array}{c}0 \\
0 \\
0 \\
0 \\
0 \\
0 \\
0 \\
0 \\
0 \\
\frac{0}{0} \\
0 \\
0 \\
0 \\
0\end{array}\right|$ & 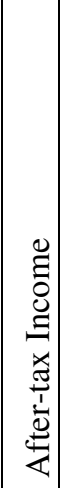 & $\overline{\mathrm{\theta}}$ & $\sqrt{\frac{\pi}{2}}$ & & 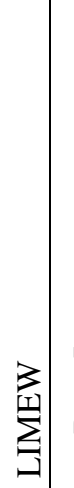 & 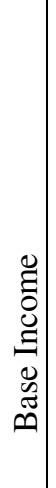 & 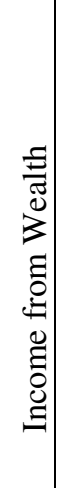 & 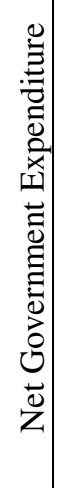 & $\left|\begin{array}{c}0 \\
0 \\
0 \\
0 \\
0 \\
0 \\
0 \\
0 \\
0 \\
0 \\
0 \\
0 \\
0 \\
0 \\
0 \\
0 \\
0\end{array}\right|$ & 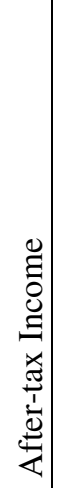 & $\overrightarrow{\mathrm{\theta}}$ & $\underline{\underline{L}}$ \\
\hline
\end{tabular}




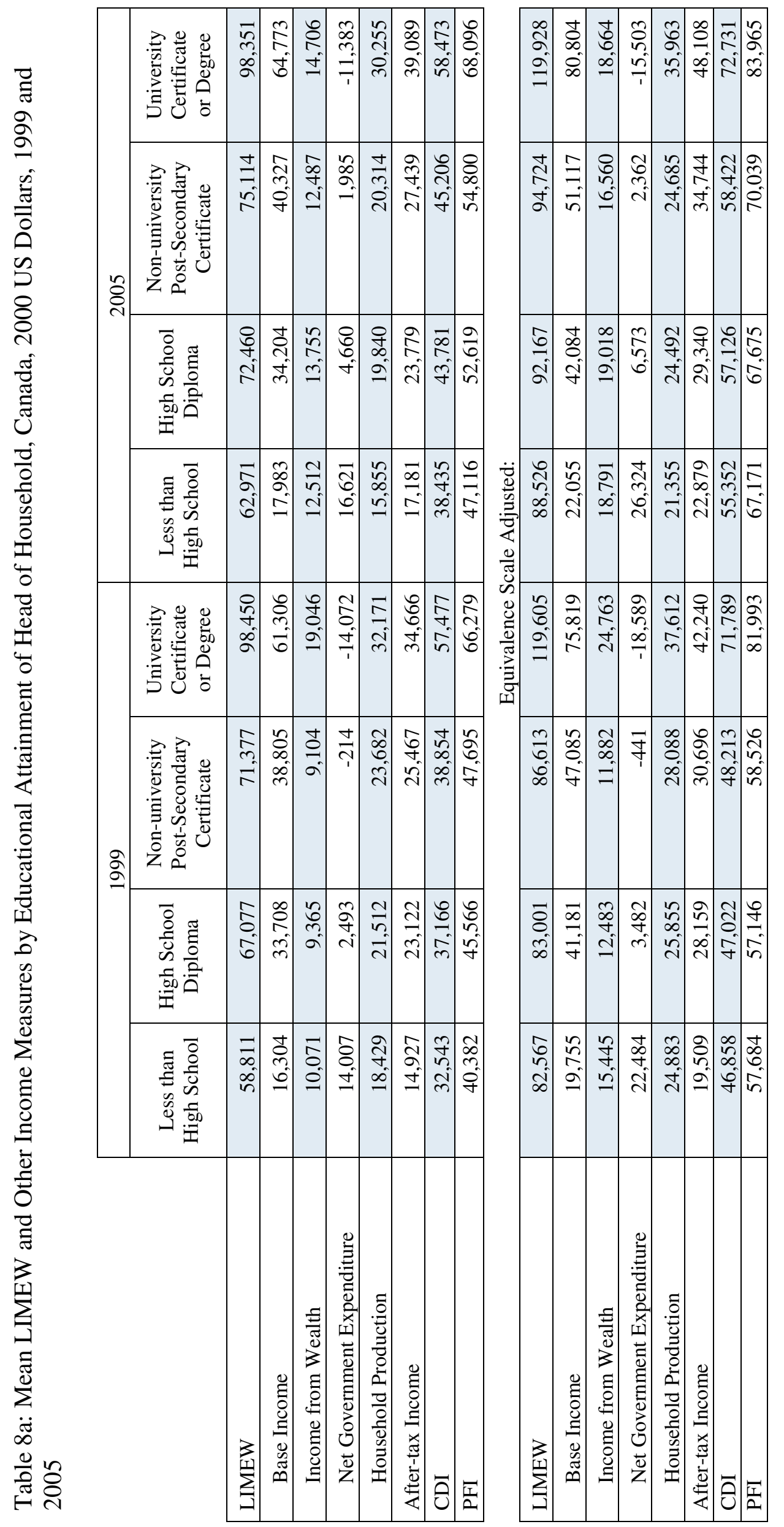




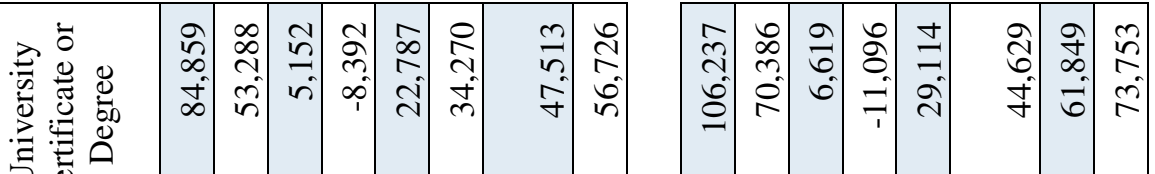

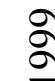

(1)

离

告

ڤั่

ชี

뭉

o

(1)

,

政

标

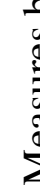

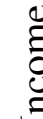

可

สี

3

$\sum_{i=1}^{\infty}$

:

क

衰葛

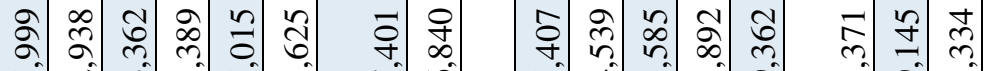

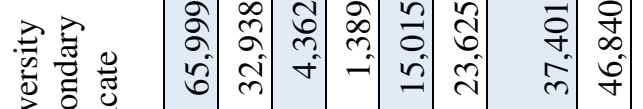

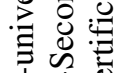

言旁要

:

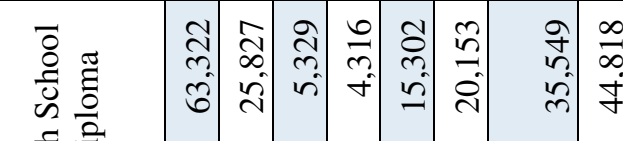

整言

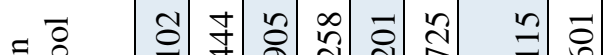

迹就

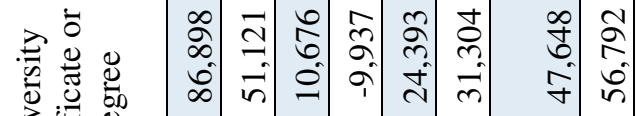

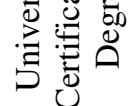

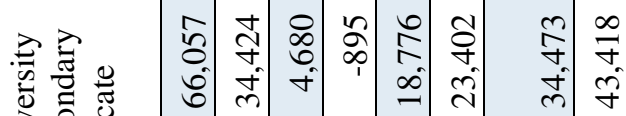

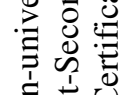

\&. 言悹它

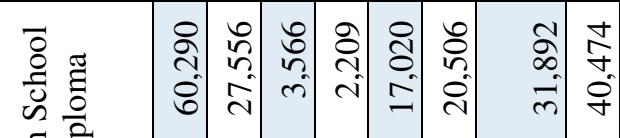

离言

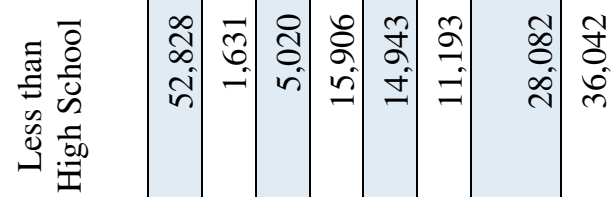

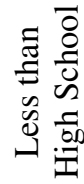

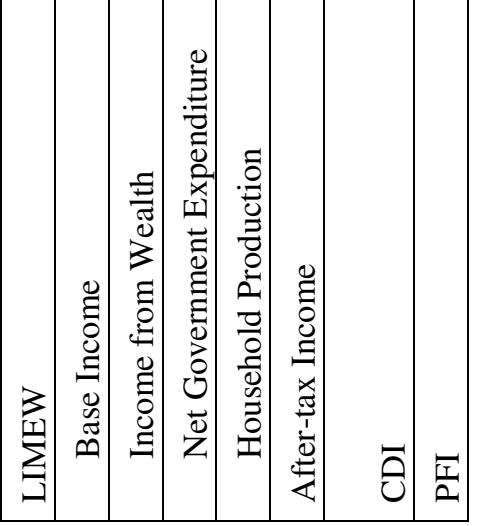

น

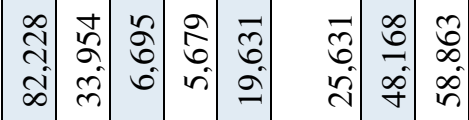

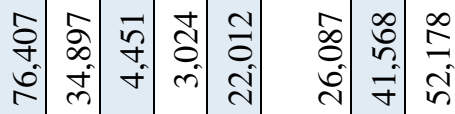

ริ

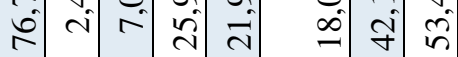

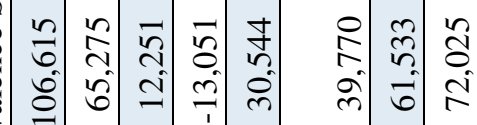




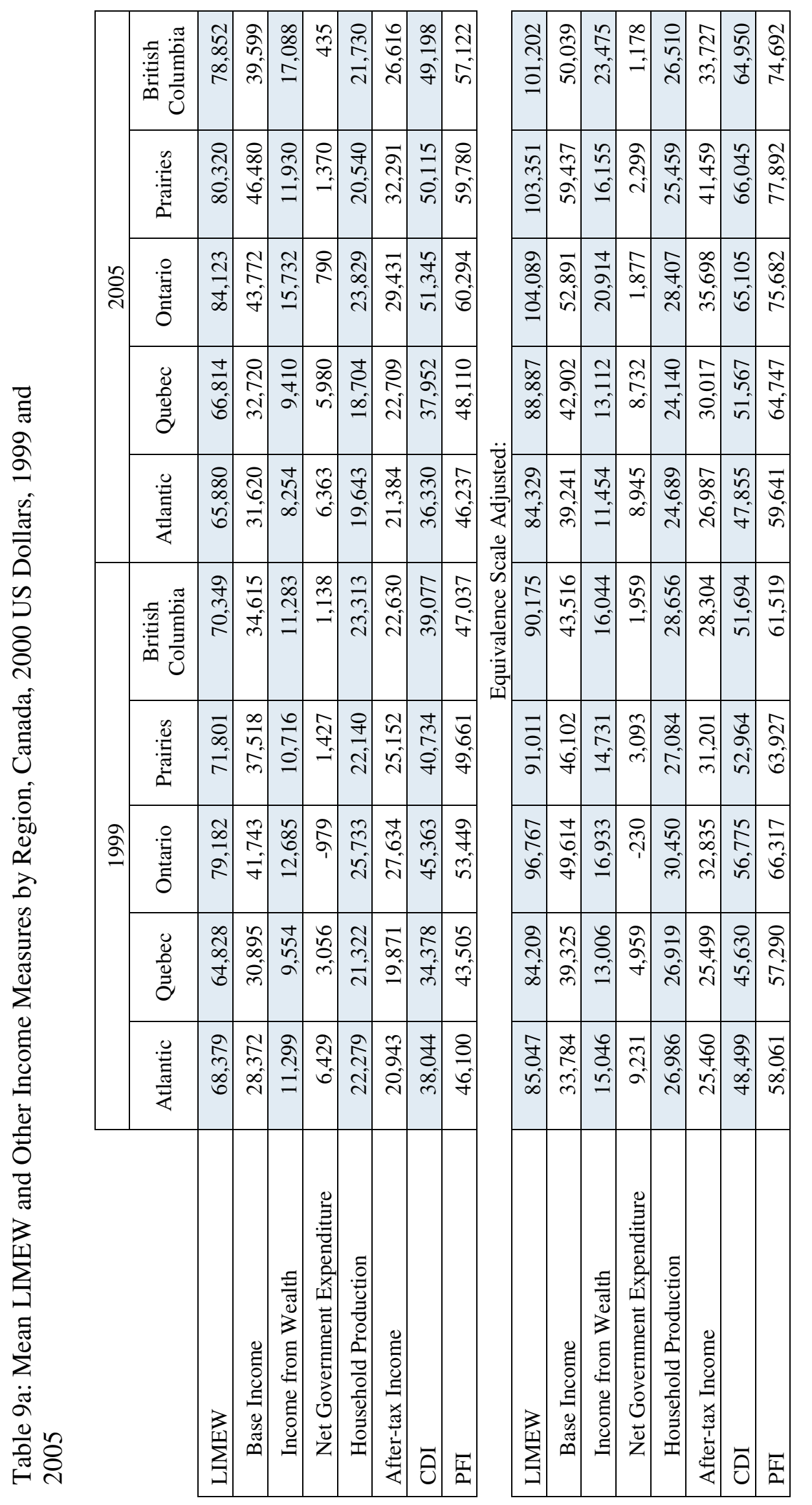

$n$ 


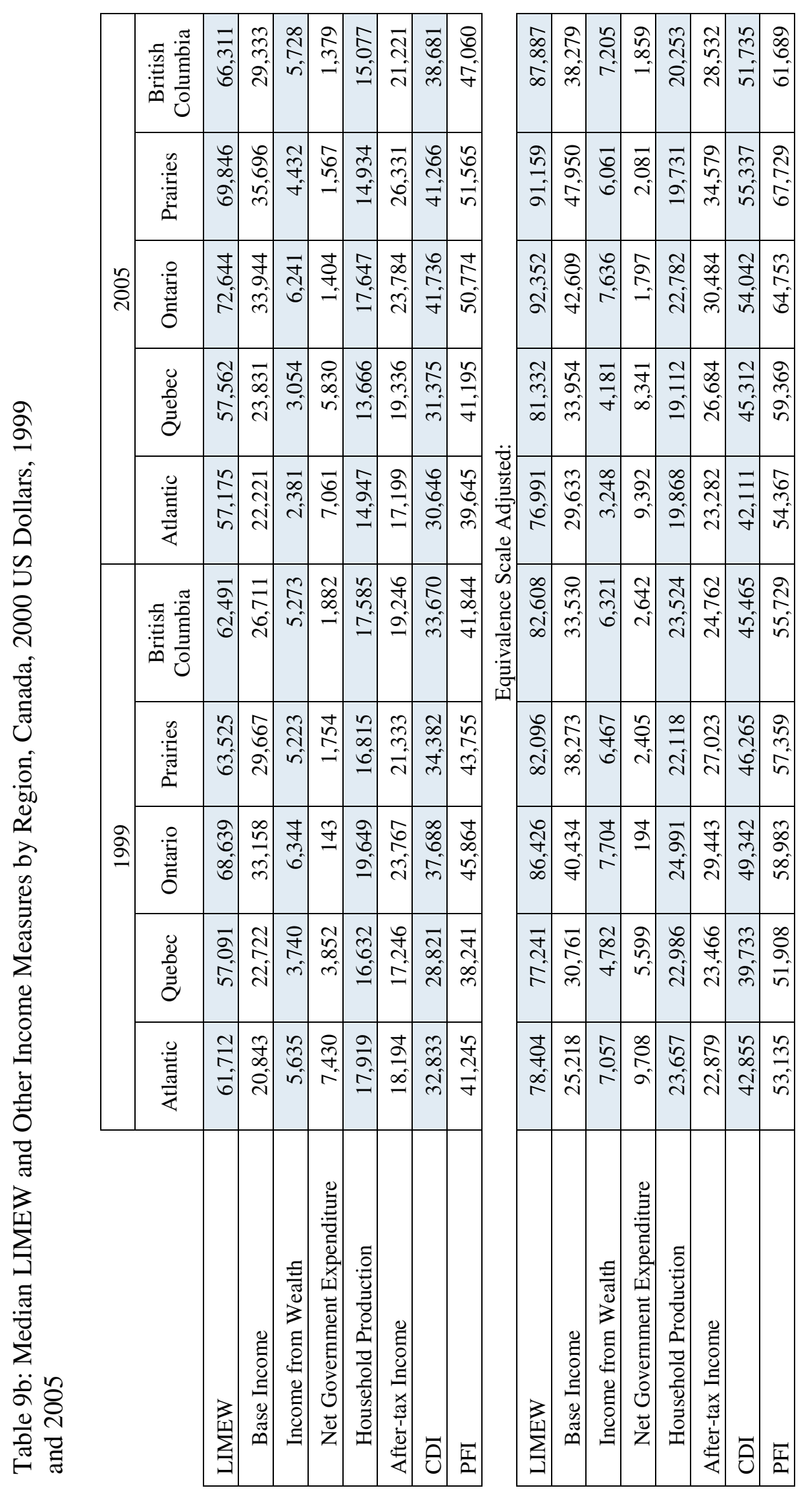

N 


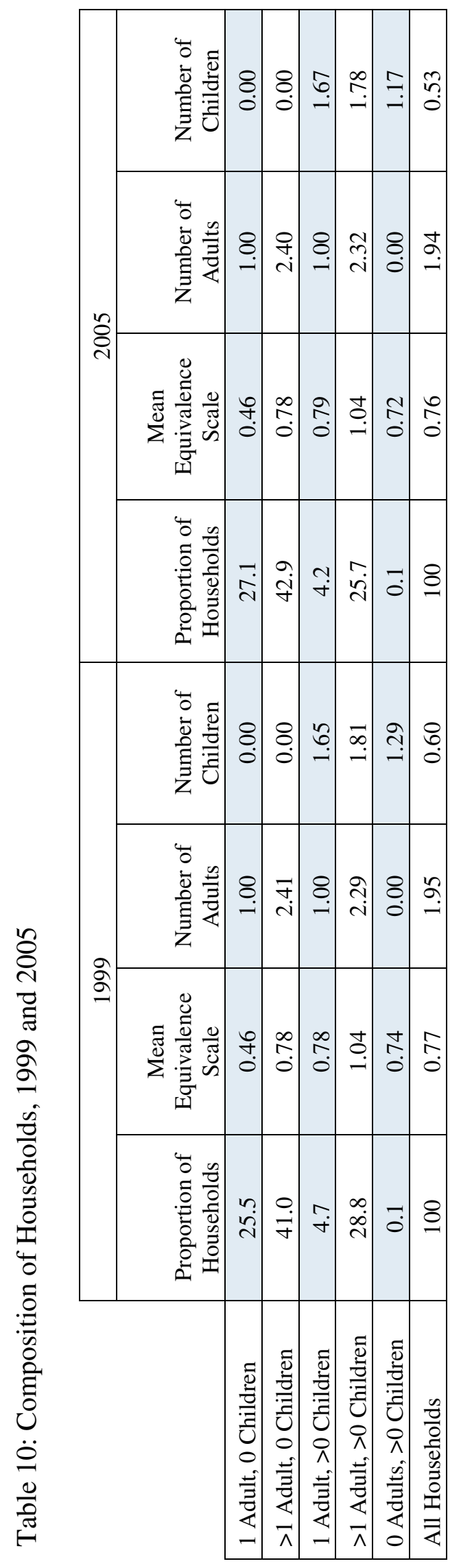

$n$

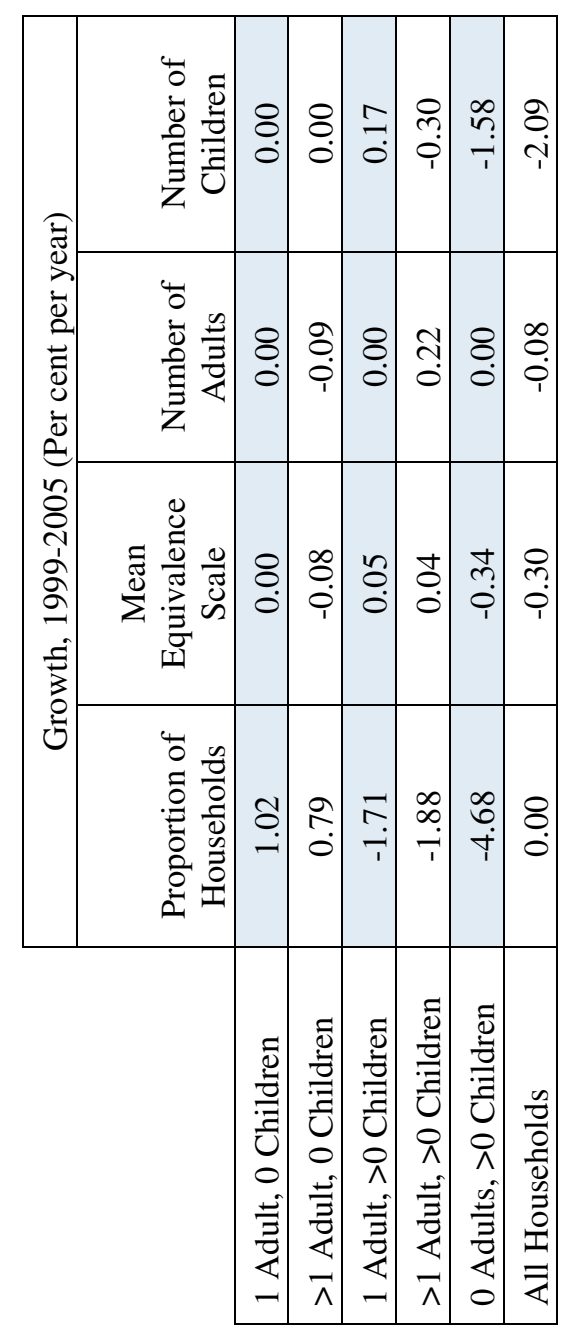




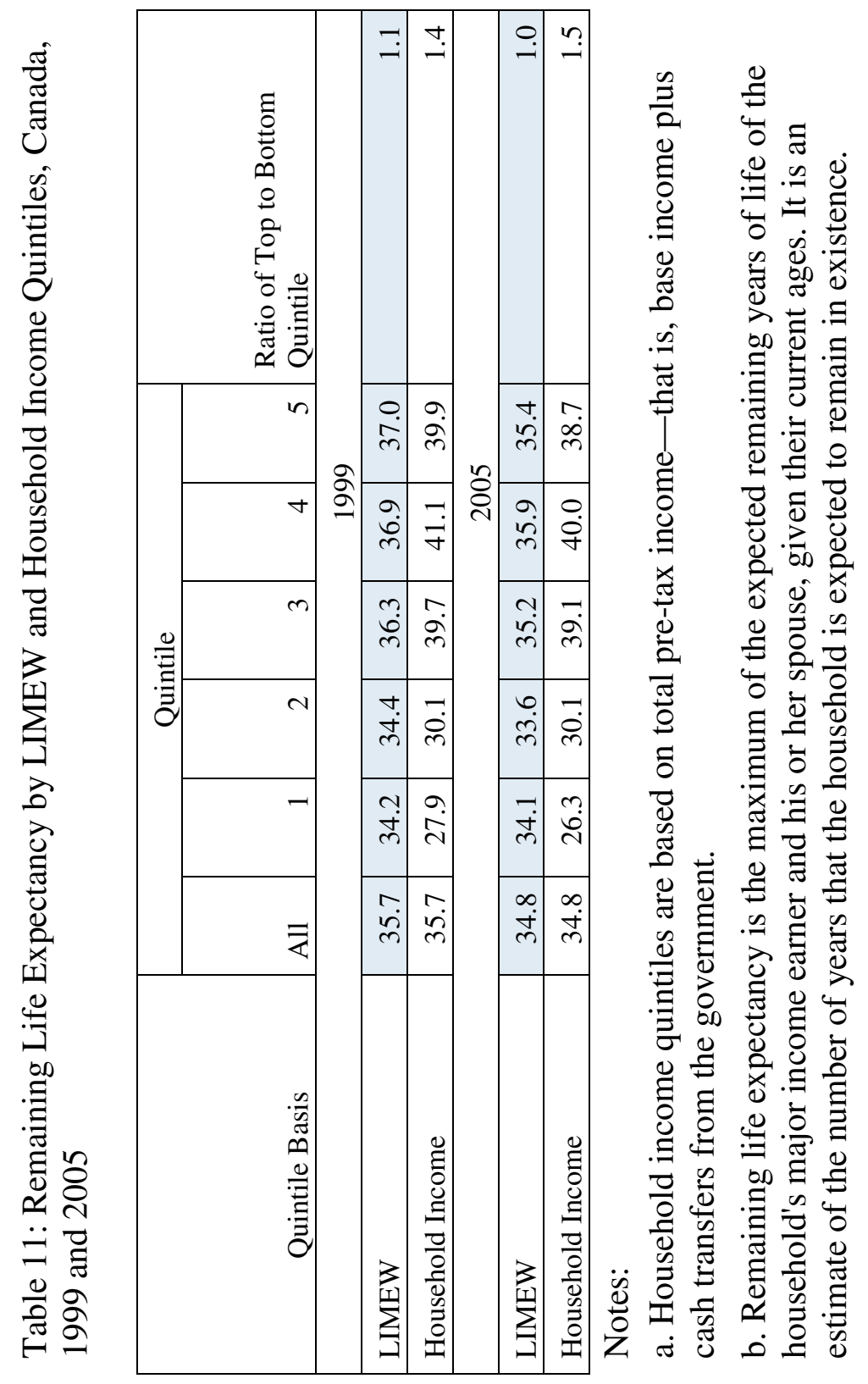


Table 12: Mean household Non-home Assets Holdings by LIMEW and Household Income Quintiles, Canada, 1999 and 2005

\begin{tabular}{|c|c|c|c|c|c|c|c|}
\hline \multirow[b]{2}{*}{ Asset Type } & \multirow[b]{2}{*}{ Real Interest Rate } & \multicolumn{6}{|c|}{ LIMEW Quintiles } \\
\hline & & All & 1 & 2 & 3 & 4 & 5 \\
\hline & & \multicolumn{6}{|c|}{1999} \\
\hline Real Estate and Business & 2.20 & 44,196 & 6,868 & 13,776 & 22,139 & 36,074 & 142,134 \\
\hline Liquid Assets & 0.03 & 12,743 & 4,728 & 9,790 & 11,516 & 13,511 & 24,170 \\
\hline Financial Assets & 2.68 & 19,881 & 3,470 & 7,583 & 9,402 & 14,134 & 64,823 \\
\hline Pension Assets & 2.68 & 90,373 & 17,532 & 41,716 & 65,154 & 105,337 & 222,147 \\
\hline Non-mortgage Debt & -4.12 & 12,034 & 6,225 & 7,814 & 10,942 & 13,568 & 21,623 \\
\hline \multicolumn{8}{|c|}{2005} \\
\hline Real Estate and Business & 2.20 & 81,152 & 9,234 & 16,241 & 26,989 & 44,456 & 308,842 \\
\hline Liquid Assets & 0.03 & 17,050 & 5,068 & 11,122 & 13,652 & 18,570 & 36,839 \\
\hline ;Financial Assets & 2.68 & 26,802 & 2,650 & 5,924 & 11,971 & 18,651 & 94,814 \\
\hline Pension Assets & 2.68 & 118,796 & 18,241 & 48,654 & 80,268 & 142,273 & 304,547 \\
\hline Non-mortgage Debt & -4.12 & 19,884 & 9,347 & 12,082 & 16,655 & 21,560 & 39,779 \\
\hline
\end{tabular}

\begin{tabular}{|c|c|c|c|c|c|c|c|}
\hline \multirow[b]{2}{*}{ Asset Type } & \multirow[b]{2}{*}{ Real Interest Rate } & \multicolumn{6}{|c|}{ Household Income Quintiles } \\
\hline & & All & 1 & 2 & 3 & 4 & 5 \\
\hline & & \multicolumn{6}{|c|}{1999} \\
\hline Real Estate and Business & 2.20 & 44,196 & 18,902 & 26,947 & 34,293 & 53,546 & 87,357 \\
\hline Liquid Assets & 0.03 & 12,743 & 13,053 & 14,970 & 9,207 & 9,849 & 16,646 \\
\hline Financial Assets & 2.68 & 19,881 & 15,239 & 17,959 & 9,355 & 13,617 & 43,289 \\
\hline Pension Assets & 2.68 & 90,373 & 45,427 & 71,958 & 57,360 & 92,936 & 184,354 \\
\hline Non-mortgage Debt & -4.12 & 12,034 & 5,104 & 6,357 & 11,083 & 15,780 & 21,858 \\
\hline \multicolumn{8}{|c|}{2005} \\
\hline Real Estate and Business & 2.20 & 81,152 & 33,139 & 61,713 & 56,322 & 62,963 & 191,728 \\
\hline Liquid Assets & 0.03 & 17,050 & 16,120 & 24,543 & 12,810 & 12,484 & 19,313 \\
\hline Financial Assets & 2.68 & 26,802 & 12,704 & 21,182 & 18,344 & 18,944 & 62,866 \\
\hline Pension Assets & 2.68 & 118,796 & 59,335 & 99,187 & 81,209 & 122,232 & 232,150 \\
\hline Non-mortgage Debt & -4.12 & 19,884 & 8,460 & 11,411 & 17,127 & 22,899 & 39,539 \\
\hline
\end{tabular}

Notes:

a. Household income quintiles are based on total pre-tax income - that is, base income plus cash transfers from the government. 
Table 12a: Composition of Household Non-home Assets Holdings by LIMEW and Household Income Quintiles, Canada, Per cent, 1999 and 2005

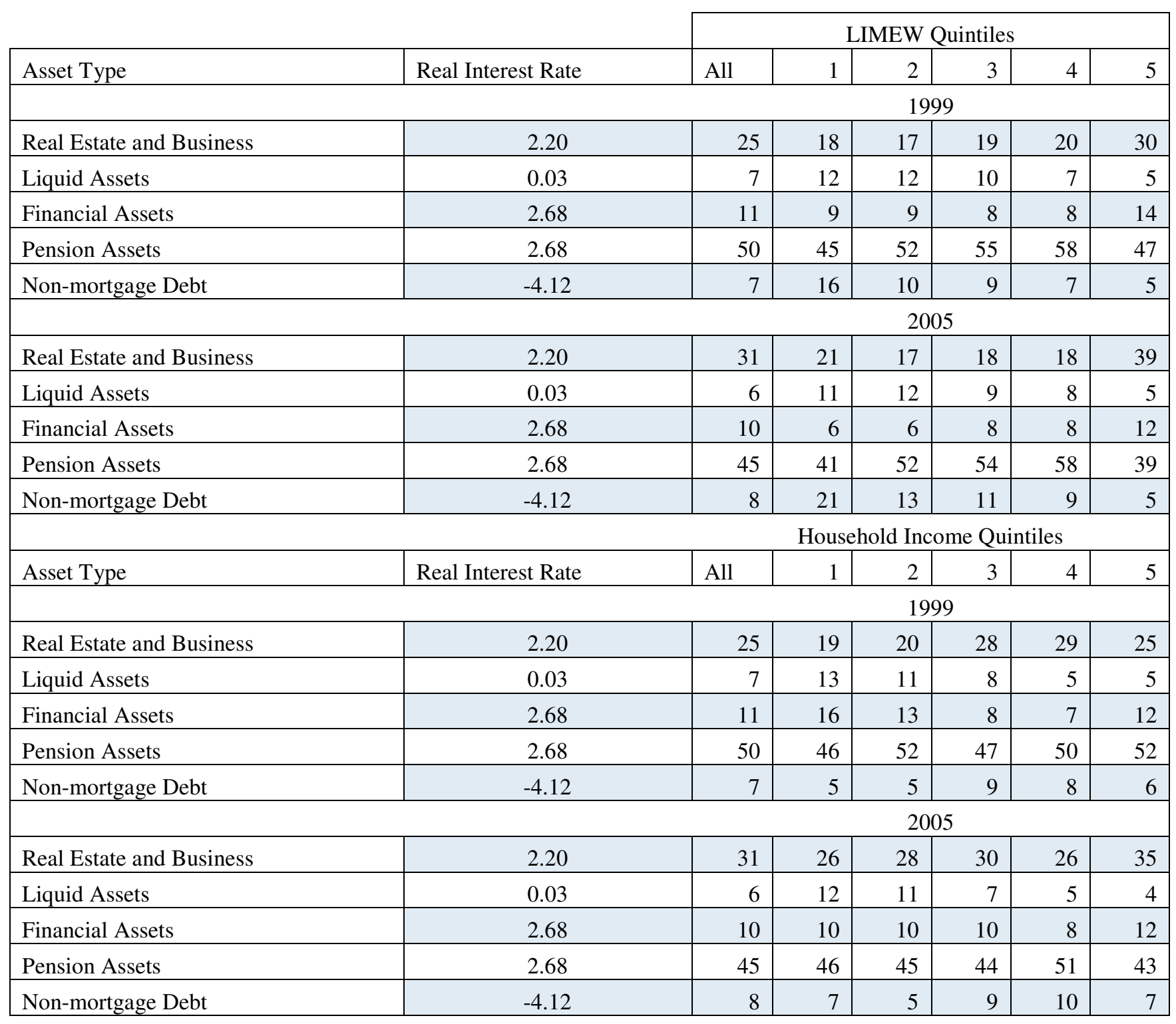

Notes:

a. Household income quintiles are based on total pre-tax income-that is, base income plus cash transfers from the government. 
Table 13: Mean Annual Hours of Household Production by LIMEW and Household Income Quintiles, Canada, 1999 and 2005

\begin{tabular}{|c|c|c|c|c|c|c|c|}
\hline \multirow[b]{2}{*}{ Quintile Basis } & \multicolumn{6}{|c|}{ Quintile } & \multirow[b]{2}{*}{$\begin{array}{l}\text { Ratio of Top to Bottom } \\
\text { Quintile }\end{array}$} \\
\hline & All & 1 & 2 & 3 & 4 & 5 & \\
\hline & \multicolumn{7}{|c|}{1999} \\
\hline LIMEW & 2,387 & 732 & 1,552 & 2,419 & 3,172 & 4,060 & 5.5 \\
\hline Household Income & 2,387 & 1,452 & 2,319 & 2,472 & 2,668 & 3,026 & 2.1 \\
\hline & \multicolumn{7}{|c|}{2005} \\
\hline LIMEW & 2,251 & 601 & 1,398 & 2,226 & 3,044 & 3,986 & 6.6 \\
\hline Household Income & 2,251 & 1,373 & 2,188 & 2,202 & 2,565 & 2,929 & 2.1 \\
\hline
\end{tabular}

Note: Household income quintiles are based on total pre-tax income - that is, base income plus cash transfers from the government.

Table 13a: Mean Annual Hours of Household Production Per Adult by LIMEW and Household Income Quintiles, Canada, 1999 and 2005

\begin{tabular}{|c|c|c|c|c|c|c|c|}
\hline \multirow[b]{2}{*}{ Quintile Basis } & \multicolumn{6}{|c|}{ Quintile } & \multirow[b]{2}{*}{$\begin{array}{l}\text { Ratio of Top to Bottom } \\
\text { Quintile }\end{array}$} \\
\hline & All & 1 & 2 & 3 & 4 & 5 & \\
\hline & \multicolumn{7}{|c|}{1999} \\
\hline LIMEW & 1,226 & 630 & 981 & 1,216 & 1,391 & 1,492 & 2.4 \\
\hline Household Income & 1,226 & 1,097 & 1,258 & 1,143 & 1,163 & 1,142 & 1.0 \\
\hline & \multicolumn{7}{|c|}{2005} \\
\hline LIMEW & 1,162 & 523 & 888 & 1,123 & 1,340 & 1,470 & 2.8 \\
\hline Household Income & 1,162 & 1,097 & 1,258 & 1,143 & 1,163 & 1,142 & 1.0 \\
\hline
\end{tabular}

Note: Household income quintiles are based on total pre-tax income - that is, base income plus cash transfers from the government. 
Table 14: Mean Number of Adults per Household by LIMEW and Household Income Quintiles, Canada, 1999 and 2005

\begin{tabular}{|c|c|c|c|c|c|c|c|}
\hline \multirow[b]{2}{*}{ Quintile Basis } & \multicolumn{6}{|c|}{ Quintile } & \multirow[b]{2}{*}{ Ratio of Top to Bottom Quintile } \\
\hline & All & 1 & 2 & 3 & 4 & 5 & \\
\hline & \multicolumn{7}{|c|}{1999} \\
\hline LIMEW & 1.9 & 1.2 & 1.6 & 2.0 & 2.3 & 2.7 & 2.3 \\
\hline Household Income & 1.9 & 1.2 & 1.8 & 2.0 & 2.2 & 2.6 & 2.1 \\
\hline & \multicolumn{7}{|c|}{2005} \\
\hline LIMEW & 1.9 & 1.1 & 1.6 & 2.0 & 2.3 & 2.7 & 2.4 \\
\hline Household Income & 1.9 & 1.3 & 1.7 & 1.9 & 2.2 & 2.6 & 2.0 \\
\hline
\end{tabular}

Note: Household income quintiles are based on total pre-tax income - that is, base income plus cash transfers from the government. 
Table 15: Mean Hourly Value of Household Production by LIMEW and Household Income Quintile, Canada, 1999 and 2005

\begin{tabular}{|c|c|c|c|c|c|c|c|}
\hline \multirow[b]{2}{*}{ Quintile Basis } & \multicolumn{6}{|c|}{ Quintile } & \multirow[b]{2}{*}{$\begin{array}{l}\text { Ratio of Top to Bottom } \\
\text { Quintile }\end{array}$} \\
\hline & All & 1 & 2 & 3 & 4 & 5 & \\
\hline & \multicolumn{7}{|c|}{1999} \\
\hline LIMEW & 9.81 & 7.46 & 7.83 & 8.26 & 9.18 & 12.41 & 1.7 \\
\hline Household Income & 9.81 & 8.89 & 8.87 & 8.46 & 9.26 & 12.56 & 1.4 \\
\hline & \multicolumn{7}{|c|}{2005} \\
\hline LIMEW & 9.51 & 7.56 & 7.67 & 8.10 & 8.99 & 11.62 & 1.5 \\
\hline Household Income & 9.51 & 8.68 & 8.72 & 8.35 & 8.92 & 11.86 & 1.4 \\
\hline
\end{tabular}

Note: Household income quintiles are based on total pre-tax income-that is, base income plus cash transfers from the government.

Table 15a: Impact of the Performance Index on Hourly Imputed Wage, Canada, Per cent, 1999 and 2005

\begin{tabular}{|l|r|r|r|r|r|r|}
\hline & \multicolumn{7}{|c|}{ Quintile } \\
\cline { 2 - 7 } \multicolumn{1}{|c|}{ Quintile Basis } & All & 1 & 2 & 3 & 4 & 5 \\
\hline & 6.8 & -18.8 & -14.8 & -10.1 & -0.1 & 35.1 \\
\hline LIMEW & 6.8 & -3.2 & -3.4 & -7.9 & 0.8 & 36.7 \\
\hline Household Income & 8.3 & -14.0 & -12.6 & -7.8 & 2.4 & 32.3 \\
\hline & 8.3 & -1.2 & -0.7 & -4.9 & 1.5 & 35.1 \\
\hline LIMEW & & & \multicolumn{7}{|c|}{1999} \\
\hline Household Income & &
\end{tabular}

Note: Household income quintiles are based on total pre-tax income-that is, base income plus cash transfers from the government. 
Table 16: Decomposition of the Change in Household Production over 1999-2005 Period, Canada

\begin{tabular}{|c|c|c|c|c|}
\hline & \multicolumn{2}{|c|}{ Levels } & \multirow{2}{*}{$\begin{array}{c}\begin{array}{c}\text { Growth Rates } \\
\text { (per cent per year) }\end{array} \\
1999-2005 \\
\end{array}$} & \multirow{2}{*}{$\begin{array}{c}\begin{array}{c}\text { Growth Contributior } \\
\text { (per cent of annual } \\
\text { growth rate) }\end{array} \\
1999-2005\end{array}$} \\
\hline & 1999 & 2005 & & \\
\hline Mean Value of Household Production & 23,415 & 21,397 & -1.49 & \\
\hline Hours & 2,387 & 2,251 & -0.97 & 65.30 \\
\hline Performance Index & 1.07 & 1.08 & 0.23 & -15.33 \\
\hline Base Wage & 9.19 & 8.78 & -0.75 & 50.26 \\
\hline
\end{tabular}




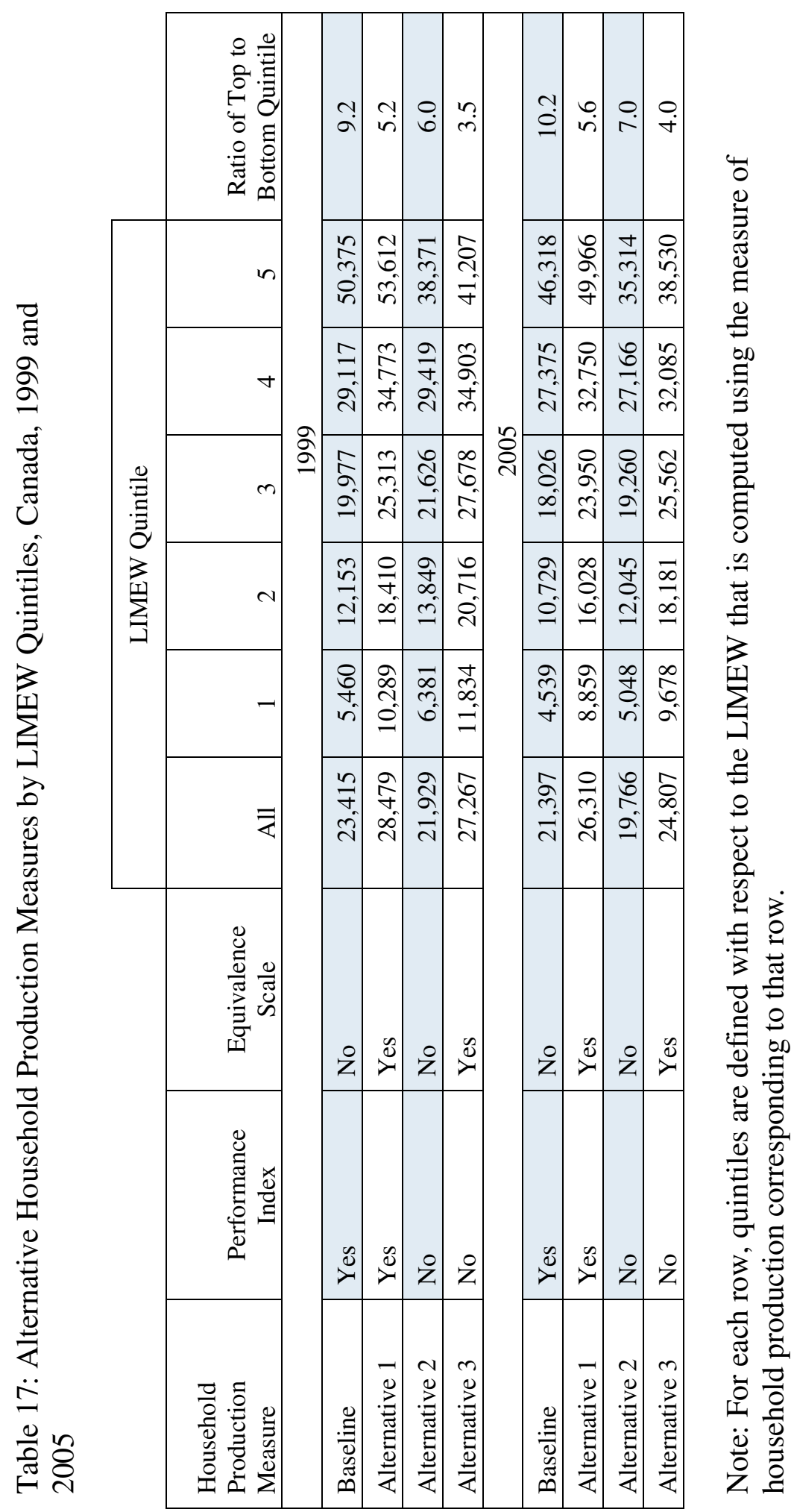




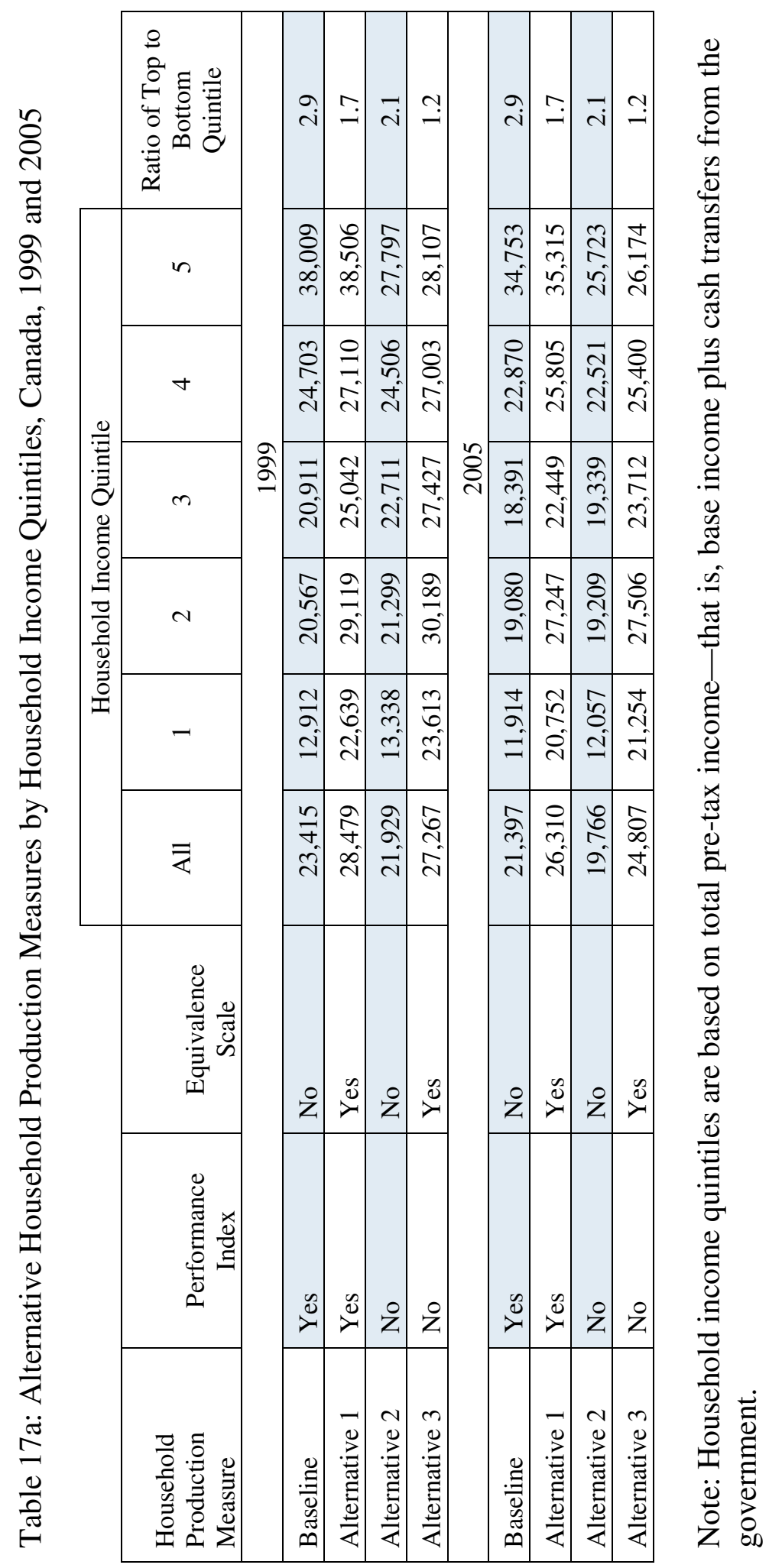




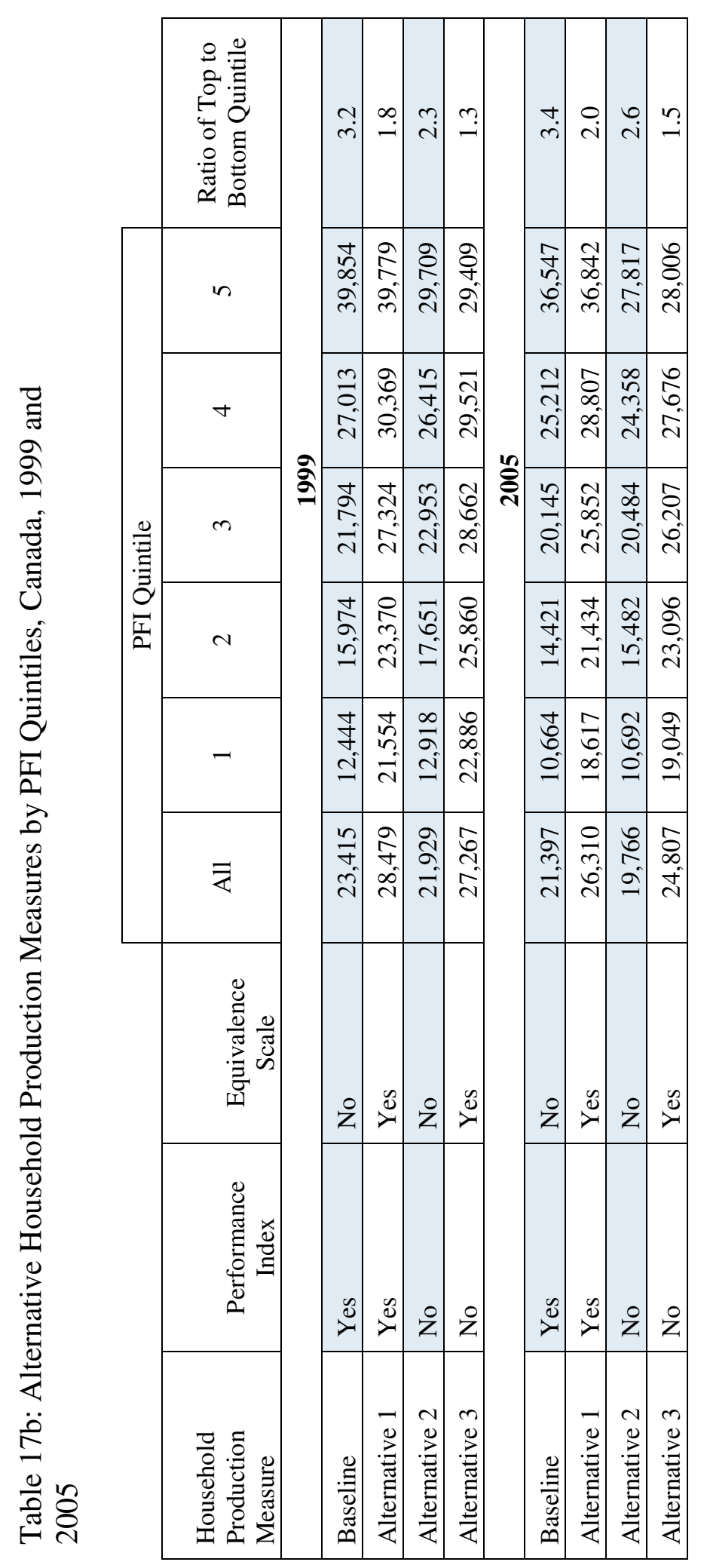




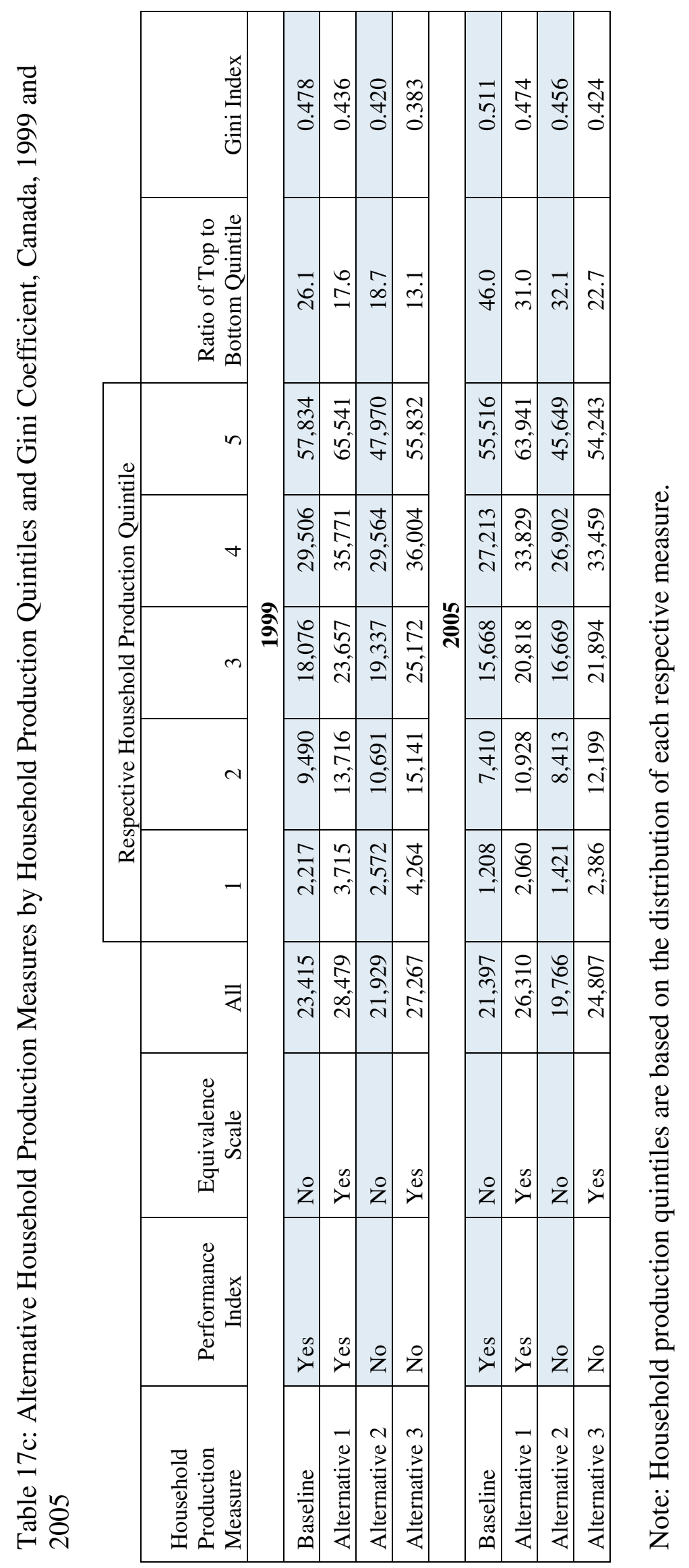


Table 18: Mean Equivalence Scale Value by LIMEW and Household Income Quintile, Canada, 1999 and 2005

\begin{tabular}{|c|c|c|c|c|c|c|c|}
\hline \multirow[b]{2}{*}{ Quintile Basis } & \multicolumn{6}{|c|}{ Quintile } & \multirow[b]{2}{*}{$\begin{array}{l}\text { Ratio of Top to Bottom } \\
\text { Quintile }\end{array}$} \\
\hline & All & 1 & 2 & 3 & 4 & 5 & \\
\hline & \multicolumn{7}{|c|}{1999} \\
\hline LIMEW & 0.77 & 0.51 & 0.64 & 0.79 & 0.90 & 1.03 & 2.0 \\
\hline Household Income & 0.77 & 0.54 & 0.68 & 0.80 & 0.88 & 0.97 & 1.8 \\
\hline \multicolumn{8}{|c|}{2005} \\
\hline LIMEW & 0.76 & 0.50 & 0.63 & 0.77 & 0.88 & 1.01 & 2.0 \\
\hline Household Income & 0.76 & 0.54 & 0.67 & 0.77 & 0.86 & 0.96 & 1.8 \\
\hline
\end{tabular}

Note: Household income quintiles are based on total pre-tax income-that is, base income plus cash transfers from the government. 
Table 19: Gini Coefficients for the Alternate LIMEW Estimates, LIMEW and Other Income Measures, Canada, 1999 and 2005

\begin{tabular}{|l|c|c|c|}
\cline { 2 - 4 } \multicolumn{1}{c|}{} & 1999 & 2005 & $\begin{array}{c}\text { Per Cent } \\
\text { Change }\end{array}$ \\
\hline Base Income & 0.546 & 0.550 & 0.82 \\
\hline After-tax Income & 0.496 & 0.490 & -1.19 \\
\hline CDI & 0.382 & 0.399 & 4.48 \\
\hline PFI & 0.345 & 0.365 & 5.80 \\
\hline LIMEW & 0.340 & 0.357 & 5.04 \\
\hline Alternative LIMEW 2 & 0.314 & 0.338 & 7.67 \\
\hline
\end{tabular}

\begin{tabular}{|l|c|c|c|}
\multicolumn{4}{|c|}{ Equivalence Scale Adjusted: } \\
\hline Base Income & 0.531 & 0.535 & 0.77 \\
\hline After-tax Income & 0.468 & 0.459 & -2.05 \\
\hline CDI & 0.345 & 0.360 & 4.45 \\
\hline PFI & 0.288 & 0.307 & 6.30 \\
\hline LIMEW (Alternative LIMEW 1) & 0.266 & 0.285 & 7.01 \\
\hline Alternative LIMEW 3 & 0.241 & 0.266 & 10.67 \\
\hline
\end{tabular}

Note: For each variable, there is a small proportion of households with negative values. The Gini coefficient may overstate the degree of inequality when negative income values are present in the data (indeed, negative values can lead to Gini coefficients greater than one). Although the number of households having negative values is relatively small, the Gini coefficients reported in this table should be interpreted with some caution.

Alternative LIMEW 1 employs Alternative 1 for Household Production Valuation from Table 17

Alternative LIMEW 2 employs Alternative 2 for Household Production Valuation from Table 17

Alternative LIMEW 3 employs Alternative 3 for Household Production Valuation from Table 17 
Appendix Table 1: Net Government Expenditure on Goods and Services, Canada, Millions of Current Dollars, 1999/2000

Column

Level of government

Total expenditures

General gov't services

Labor

Protection

National defence

Courts of law

Correction services

Policing

Firefighting

Regulatory measures

Other

Transportation and comm.

Air transport

Road transport

Public transit

Rail transport

Water transport

Telecommunications

Other

Health

Hospital care

Medical care

Preventive care

Other health services

Social services

Education

Elementary and secondary education

Postsecondary education

Special retraining services

Other education

Conservation \& Industry

Agriculture

Fish and game

Oil and gas

Forestry
Less Intergov't$$
\begin{array}{r}
\text { Fed } \\
173 \\
5 \\
2 \\
18 \\
1 \\
1 \\
2
\end{array}
$$

Baseline Spending

\begin{tabular}{cc|}
1 & 2 \\
Federal & $\mathrm{L} \& \mathrm{P} / \mathrm{T}$
\end{tabular}

$173,337 \quad 257,078$

$\begin{array}{cc}2,447 & 862 \\ 18,448 & 14,178\end{array}$

11,869

309

1,684

2,362

766

$\begin{array}{ll}7,457 & 306 \\ 1,720 & 103\end{array}$

$1,720 \quad 16,658$

$374 \quad 62$

$260 \quad 11,988$

2,616

$\begin{array}{cc}232 & 5 \\ 441 & 2,370\end{array}$

$167 \quad 384$

$246 \quad 344$

$1,730 \quad 63,059$

$67 \quad 21,097$

$333 \quad 27,441$

$439 \quad 2,246$

$891 \quad 12,275$

$50,386 \quad 39,115$

$4,917 \quad 57,268$

$941 \quad 33,700$

$1,584 \quad 20,631$

$1,658 \quad 2,488$

$734 \quad 449$

$5,779 \quad 9,564$

$2,199 \quad 3,639$

413

86

131
Transfers

\begin{tabular}{cc|}
\multicolumn{2}{c}{ Transfers } \\
3 & 4 \\
Federal & $\mathrm{L} \& \mathrm{P} / \mathrm{T}$
\end{tabular}

Federal $\quad \mathrm{L} \& \mathrm{P} / \mathrm{T}$

$144,442 \quad 257,078$

$5,630 \quad 8,122$

$2,089 \quad 862$

$17,571 \quad 14,178$

11,305

294

1,604

2,250

730

1,388

1,459

317

221

197

374

142

209

1,258

63

277

377

541

65,929

3,189

613

1,271

820

485

4,790

1,823

342

71

109

6,395

2,133

306

103

16,658

62

11,988

2,616

5

2,370

384

344

63,059

21,097

27,441

2,246

12,275

39,115

57,268

33,700

20,631

2,488

449

9,564

3,639

683

142

217
Less Transfers to

Persons

$\begin{array}{lll}5 & 6\end{array}$

Federal $\quad$ L \& P/T

$92,867 \quad 226,918$

17,571

11,305
5,630

2,089

294

1,604

2,250

8,122

862

14,178

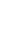

(2n)

6,395

2,133

730

1,388

1,459

317

221

197

374

142

209

1,258

63

277

377

541

14,354

3,189

613

1,271

820

485

4,790

1,823

342

71

109
306

103

16,658

62

11,988

2,616

5

2,370

384

344

63,059

21,097

27,441

2,246

12,275

8,955

57,268

33,700

20,631

2,488

449

9,564

3,639

683

142

217
Less Gov't Sales of Goods and Services

$\begin{array}{ll}7 & 8\end{array}$

Federal $\quad \mathrm{L} \& \mathrm{P} / \mathrm{T}$

$89,820 \quad 197,748$

$5,445 \quad 7,078$

$2,020 \quad 751$

$16,994 \quad 12,355$

10,934

285

1,551

2,176

5,573

1,859

706

1,342

267

1,411

90

$307 \quad 54$

$213 \quad 10,447$

2,280

190

5

362

2,065

137

335

$202 \quad 300$

$1,217 \quad 54,953$

$61 \quad 18,385$

$268 \quad 23,913$

$365 \quad 1,957$

523

10,697

$13,883 \quad 7,804$

$3,189 \quad 57,268$

$613 \quad 33,700$

$1,271 \quad 20,631$

$820 \quad 2,488$

$485 \quad 449$

$4,633 \quad 8,335$

$1,763 \quad 3,171$

$331 \quad 596$

$69 \quad 124$

105 


\begin{tabular}{l|cc|cc|cc|cc} 
Mining & 149 & 247 & 124 & 247 & 124 & 247 & 119 & 215 \\
Water power & 0 & 0 & 0 & 0 & 0 & 0 & 0 & 0 \\
Tourism promotion & 63 & 104 & 52 & 104 & 52 & 104 & 51 & 91 \\
Trade and industry & 1,820 & 3,012 & 1,509 & 3,012 & 1,509 & 3,012 & 1,459 & 2,625 \\
Other & 918 & 1,519 & 761 & 1,519 & 761 & 1,519 & 736 & 1,324 \\
Environment & 1,362 & 7,386 & 1,286 & 7,386 & 1,286 & 7,386 & 1,244 & 6,437 \\
Water & 627 & 3,400 & 592 & 3,400 & 592 & 3,400 & 573 & 2,963 \\
Pollution control & 155 & 841 & 146 & 841 & 146 & 841 & 142 & 732 \\
Other & 580 & 3,145 & 548 & 3,145 & 548 & 3,145 & 530 & 2,741 \\
Recreation and culture & 3,159 & 6,792 & 3,117 & 6,792 & 3,117 & 6,792 & 3,015 & 5,919 \\
Housing & 1,928 & 2,807 & 712 & 2,807 & 712 & 2,807 & 689 & 2,446 \\
Foreign affairs & 4,309 & 0 & 4,291 & 0 & 4,291 & 0 & 4,150 & 0 \\
Regional development & 377 & 1,422 & 340 & 1,422 & 340 & 1,422 & 329 & 1,239 \\
Research establishments & 1,872 & 244 & 1,707 & 244 & 1,707 & 244 & 1,651 & 213 \\
Transfers & 24,797 & & 0 & & 0 & & 0 & 24,953 \\
Debt charges & 44,140 & 28,634 & 31,539 & 28,634 & 31,539 & 28,634 & 30,504 & 243 \\
Other expenditures & 34 & 393 & 108 & 393 & 108 & 393 & 104 & 342 \\
\hline
\end{tabular}

Notes:

1. Data are for the fiscal year beginning in April 1999. Statistics Canada does not offer public expenditure data on a calendar year basis broken down by detailed expenditure category.

2. Baseline federal spending data are from CANSIM Table 385-0002. Baseline provincial and local data are from CANSIM Table 385-0001.

3. Federal expenditures net of intergovernmental transfers are calculated by subtracting provincial and local spending from consolidated federal/provincial/local government spending (CANSIM Table 3850001). It is assumed that no intergovernmental transfers occur at the provincial/local levels.

4. Transfers to persons are from CANSIM Table 384-0009 and are attributed entirely to the Social Services category of spending.

5. Data on government sales of goods and services are from CANSIM Table 385-0001. Sales are allocated across spending categories according to categories' shares of total government expenditures net of intergovernmental and personal transfers. 
Appendix Table 2: Net Government Expenditure on Goods and Services, Canada, Millions of Current Dollars, 2005/2006

Column

Level of government

Total expenditures

General gov't services

Labor

Protection

National defense

Courts of law

Correction services

Policing

Firefighting

Regulatory measures

Other

Transportation and comm.

Air transport

Road transport

Public transit

Rail transport

Water transport

Telecommunications

Other

Health

Hospital care

Medical care

Preventive care

Other health services

Social services

Education

Elementary and secondary education

Postsecondary education

Special retraining services

Other education

Conservation \& Industry

Agriculture

Fish and game

Oil and gas

Forestry
Government

Expenditure

$$
\text { Fe }
$$

\begin{tabular}{cc|cc|}
1 & 2 & 3 & 4
\end{tabular}

Federal L \& P/T

\begin{tabular}{ll|ll}
215,205 & 351,068 & 165,601 & 351,068
\end{tabular}

\begin{tabular}{ll|ll}
8,891 & 11,458 & 8,616 & 11,458
\end{tabular}

$1,976 \quad 904$

$25,485 \quad 19,149$

15,075

515

2,078

3,512$$
1,2
$$

\begin{tabular}{cc|cc} 
& 3,094 & & 3,094 \\
1,296 & 435 & 1,228 & 435 \\
3,009 & 228 & 2,851 & 228 \\
3,096 & 22,662 & 2,176 & 22,662
\end{tabular}

3,096

370

434

552

248

607

393

492

22,662

$21,823 \quad 95,244$

$89 \quad 32,844$

$699 \quad 41,647$

1,071

2,990

19,964

17,764

$65,211 \quad 51,980$

$5,385 \quad 81,362$

1,110

46,421

1,634

31,647

1,765

2,833

876

459

9,815

11,931

3,744

4,594

471

758

271
930

333
2,176

260

305

388

174

427

276

346

4,287

Less Intergov't Transfers Persons

81

642

1,054

2,509

79,606

3,398

713

1,240

765

681

7,829

2,986

376

605

216

5

Federal

8,616

1,576

24, 150

14,285

488

1,969

3,328

1,228

1,228

2,851

2,176

260

305

388

174

427

276

346

4,287

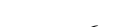

6

$\mathrm{L} \& \mathrm{P} / \mathrm{T}$

315,015

11,458

904

19,149

19,149

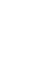$$
9,28
$$$$
\text { 3,094 }
$$$$
435
$$$$
228
$$$$
22,662
$$$$
91
$$

15,782

3,346

23

291

2,367

649

95,244

32,844

41,647

2,990

17,764

51,980

81,362

81

642

95,244

32,844

41,647

1,054

2,509

2,990

17,764

11,783

15,927

3,398

81,362

713

46,421

31,647

2,833

459

11,931

4,594

578

930

333
1,240

765

681

7,829

2,986

376

605

216
46,421

31,647

2,833

459

11,931

4,594

578

930

333
Less Gov't Sales of Goods and Services 78 Federal L \& P/T $93,883 \quad 275,534$ $8,273 \quad 10,022$ $1,513 \quad 791$ $23,188 \quad 16,749$

8,119 2,706 $1,179 \quad 380$

$2,738 \quad 199$

$2,089 \quad 19,822$

$250 \quad 79$

293

13,804

$373 \quad 2,927$

$167 \quad 20$

$410 \quad 254$

$265 \quad 2,070$

$332 \quad 568$

$4,116 \quad 83,307$

$78 \quad 28,728$

$616 \quad 36,427$

$1,012 \quad 2,615$

$2,409 \quad 15,538$

$11,314 \quad 13,931$

$3,263 \quad 71,165$

$685 \quad 40,603$

$1,191 \quad 27,681$

$735 \quad 2,478$

$654 \quad 401$

$7,517 \quad 10,436$

$2,867 \quad 4,018$

$361 \quad 505$

$581 \quad 813$

208

291 


\begin{tabular}{l|cc|cc|cc|cc} 
Mining & 70 & 86 & 56 & 86 & 56 & 86 & 54 & 75 \\
Water power & 1 & 1 & 1 & 1 & 1 & 1 & 1 & 1 \\
Tourism promotion & 100 & 123 & 80 & 123 & 80 & 123 & 77 & 107 \\
Trade and industry & 3,094 & 3,796 & 2,468 & 3,796 & 2,468 & 3,796 & 2,370 & 3,321 \\
Other & 1,306 & 1,602 & 1,042 & 1,602 & 1,042 & 1,602 & 1,000 & 1,402 \\
Environment & 1,738 & 11,687 & 1,471 & 11,687 & 1,471 & 11,687 & 1,412 & 10,222 \\
Water & 627 & 4,216 & 531 & 4,216 & 531 & 4,216 & 510 & 3,688 \\
Pollution control & 624 & 4,196 & 528 & 4,196 & 528 & 4,196 & 507 & 3,670 \\
Other & 487 & 3,275 & 412 & 3,275 & 412 & 3,275 & 396 & 2,864 \\
Recreation and culture & 4,169 & 10,288 & 3,980 & 10,288 & 3,980 & 10,288 & 3,821 & 8,999 \\
Housing & 2,119 & 3,847 & 680 & 3,847 & 680 & 3,847 & 653 & 3,365 \\
Foreign affairs & 5,586 & & 5,585 & & 5,585 & & 5,363 & \\
Regional development & 256 & 2,025 & 210 & 2,025 & 210 & 2,025 & 202 & 1,771 \\
Research & 3,222 & 609 & 1,250 & 609 & 1,250 & 609 & 1,200 & 533 \\
Transfers & 24,328 & & 0 & & 0 & & 0 & 21,456 \\
Debt charges & 32,076 & 25,513 & 21,456 & 25,513 & 21,456 & 25,513 & 25,513 \\
Other expenditures & 101 & 1,713 & 25 & 1,713 & 25 & 1,713 & 25 & 1,713 \\
\hline
\end{tabular}

Notes:

1. Data are for the fiscal year beginning in April 2005. Statistics Canada does not offer public expenditure data on a calendar year basis broken down by detailed expenditure category.

2. Baseline federal spending data are from CANSIM Table 385-0002. Baseline provincial and local data are from CANSIM Table 385-0001.

3. Federal expenditures net of intergovernmental transfers are calculated by subtracting provincial and local spending from consolidated federal/provincial/local government spending (CANSIM Table 385-0001). It is assumed that no intergovernmental transfers occur at the provincial/local levels.

4. Transfers to persons are from CANSIM Table 384-0009 and are attributed entirely to the Social Services category of spending.

5. Data on government sales of goods and services are from CANSIM Table 385-0001. Sales are allocated across spending categories according to categories' shares of total government expenditures net of intergovernmental and personal transfers. 


\section{Appendix Table 3: Allocation and Distribution of Public Consumption, LIMEW for the United States}

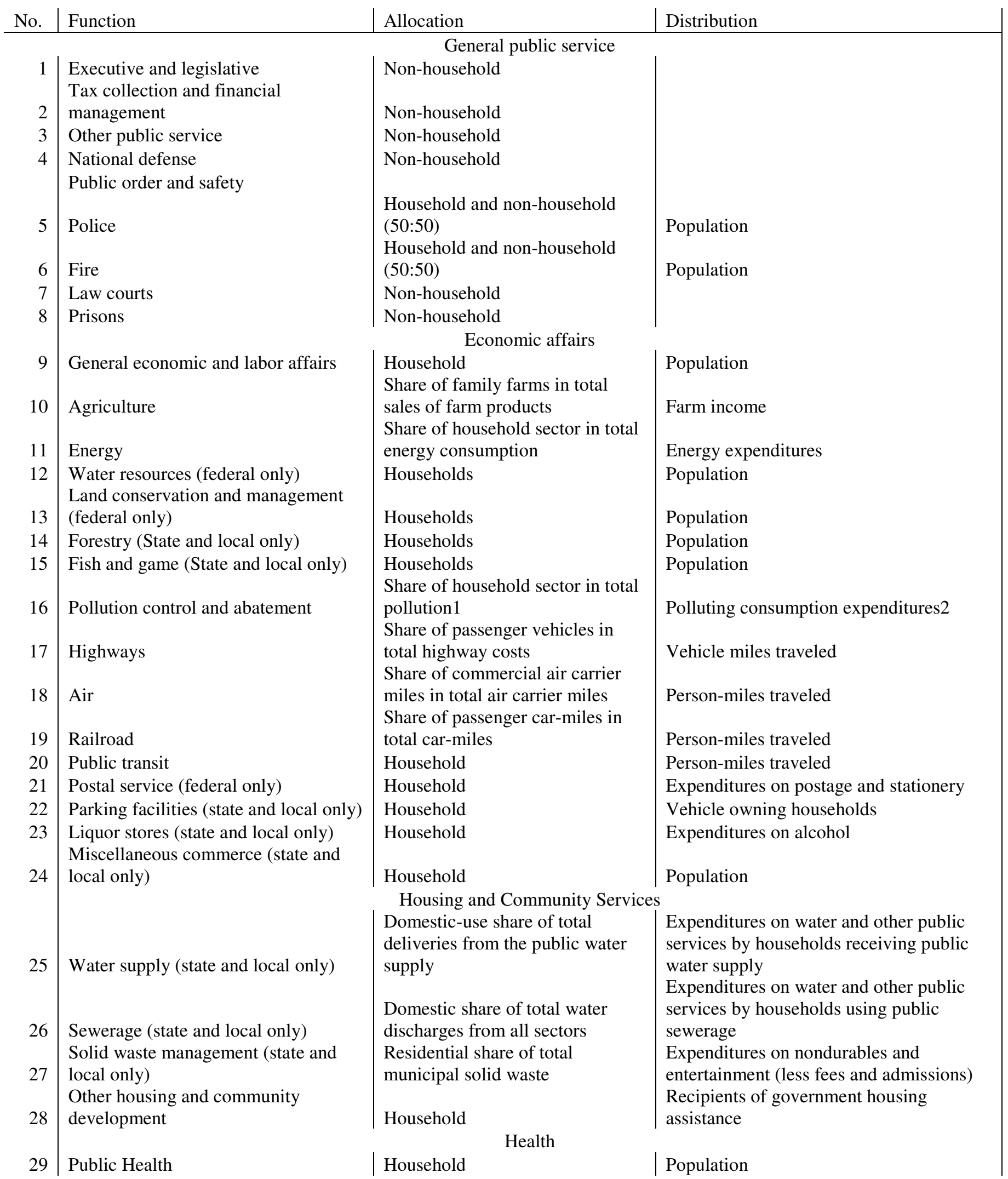


30 Public hospitals

31 Occupational safety and health

32 Administrative costs of Medicare

Medical and related services for

33 veterans

34 Recreation and culture 44 only)

Household
Household
Household
Household
Household Education
Household
Household and non-household
Household
Household Income Security
Household
Household
Household
Household
Household
Household

Population

Employed

Medicare recipients

Veterans

Population

Elementary and secondary public-school students

Higher education students residing in households

Population

Population

Recipients of public disability assistance Recipients of Social Security

Recipients of means-tested public assistance

Recipients of unemployment insurance Recipients of means-tested public assistance

Population 
Appendix Table 4: Allocation and Distribution of Public Consumption, LIMEW for the Canada

\begin{tabular}{|c|c|c|}
\hline Function & Allocation & Distribution \\
\hline General gov't services & Non-household & \\
\hline Labor & Household & Population \\
\hline $\begin{array}{l}\text { Protection } \\
\text { National defense } \\
\text { Courts of law } \\
\text { Correction services } \\
\text { Policing } \\
\text { Firefighting } \\
\text { Regulatory measures } \\
\text { Other }\end{array}$ & $\begin{array}{l}\text { Non-household } \\
\text { Non-household } \\
\text { Non-household } \\
50: 50 \\
50: 50 \\
50: 50 \\
50: 50\end{array}$ & $\begin{array}{l}\text { Population } \\
\text { Population } \\
\text { Population } \\
\text { Population }\end{array}$ \\
\hline \multicolumn{3}{|l|}{ Transportation and comm. } \\
\hline $\begin{array}{l}\text { Air transport } \\
\text { Road transport }\end{array}$ & $\begin{array}{l}1 / 3 \\
\text { Share of road costs }\end{array}$ & $\begin{array}{l}\text { Personal expenditure on air, by decile and } \\
\text { province } \\
\text { Personal expenditure on gasoline, by decile } \\
\text { and province }\end{array}$ \\
\hline Public transit & Household & $\begin{array}{l}\text { Personal expenditure on transit, by decile } \\
\text { and province }\end{array}$ \\
\hline Rail transport & Passenger Car Share & $\begin{array}{l}\text { Personal expenditure on rail, by decile and } \\
\text { province }\end{array}$ \\
\hline Water transport & Non-Household & \\
\hline Telecommunications & Non-household & \\
\hline Other & Non-household & \\
\hline Health & Household & $\begin{array}{l}\text { Health Costs by Age and Sex, Health } \\
\text { Canada }\end{array}$ \\
\hline Social services & Household & $\begin{array}{l}\text { Household's share of aggregate government } \\
\text { transfers to households }\end{array}$ \\
\hline $\begin{array}{l}\text { Education } \\
\text { Elementary and secondary } \\
\text { education } \\
\text { Postsecondary education } \\
\text { Special retraining services } \\
\text { Other education } \\
\end{array}$ & Household & $\begin{array}{l}\text { School aged Child in HH, SLID } \\
\text { Member of HH enrolled in PS, SLID }\end{array}$ \\
\hline \multicolumn{3}{|l|}{ Conservation \& Industry } \\
\hline Agriculture & Share of agr. Programs & Proportional to farm income \\
\hline Fish and game & Household & Population \\
\hline Oil and gas & Share of energy consumption & $\begin{array}{l}\text { Household energy Consumption, by income } \\
\text { deciles by province }\end{array}$ \\
\hline Forestry & Household & Population \\
\hline Mining & Non-Household & \\
\hline
\end{tabular}




\begin{tabular}{|c|c|c|}
\hline $\begin{array}{l}\text { Water power } \\
\text { Tourism promotion } \\
\text { Trade and industry } \\
\text { Other }\end{array}$ & $\begin{array}{l}\text { Share of energy consumption } \\
\text { Non-household } \\
\text { Non-household } \\
\text { Non-household }\end{array}$ & $\begin{array}{l}\text { Household energy consumption, by income } \\
\text { deciles by province }\end{array}$ \\
\hline $\begin{array}{l}\text { Environment } \\
\text { Water } \\
\text { Pollution control } \\
\text { Other } \\
\end{array}$ & $\begin{array}{l}\text { Water use } \\
\text { Share of GHG emission } \\
\text { Share of Waste Disposal }\end{array}$ & Ecological footprint by decile, CCPA \\
\hline Recreation and culture & Household & $\begin{array}{l}\text { By household personal expenditure on } \\
\text { Recreation, SHS: RE module }\end{array}$ \\
\hline Housing & Household & Receiving Gov't Reduced Rent \\
\hline Foreign affairs & Non-household & \\
\hline Regional development & Non-household & \\
\hline Research establishments & Non-household & \\
\hline \multicolumn{3}{|l|}{ Transfers } \\
\hline Debt charges & $\mathrm{n} / \mathrm{a}$ & \\
\hline Other expenditures & Non-household & \\
\hline
\end{tabular}


ลิ

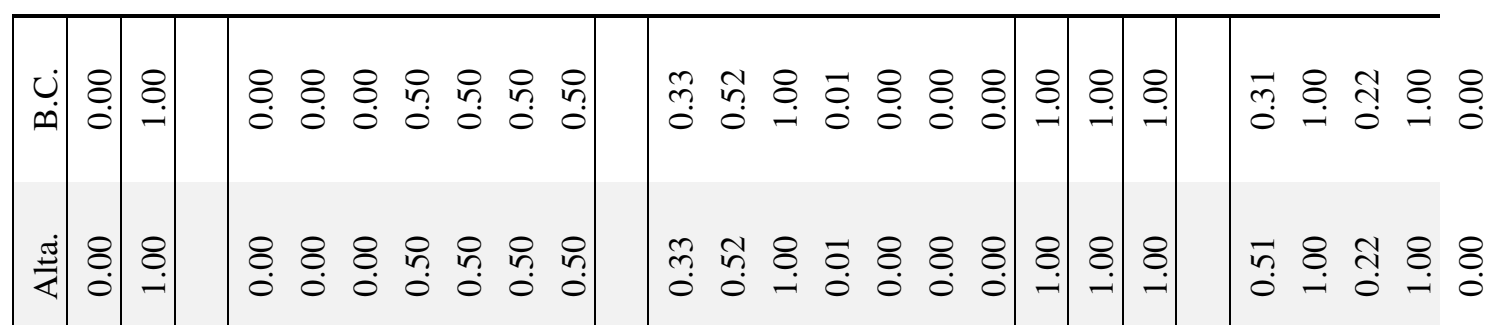

\section{ลे}

\begin{tabular}{|c|c|c|}
\hline & 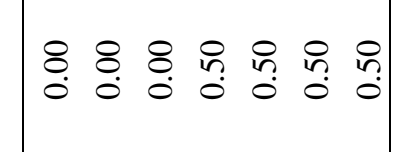 & 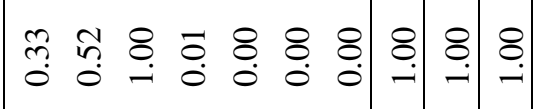 \\
\hline
\end{tabular}

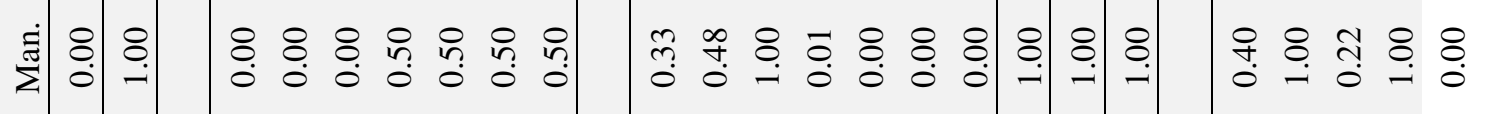

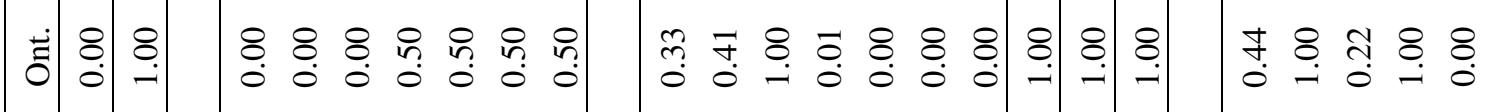

岁

:

मे.

武

司

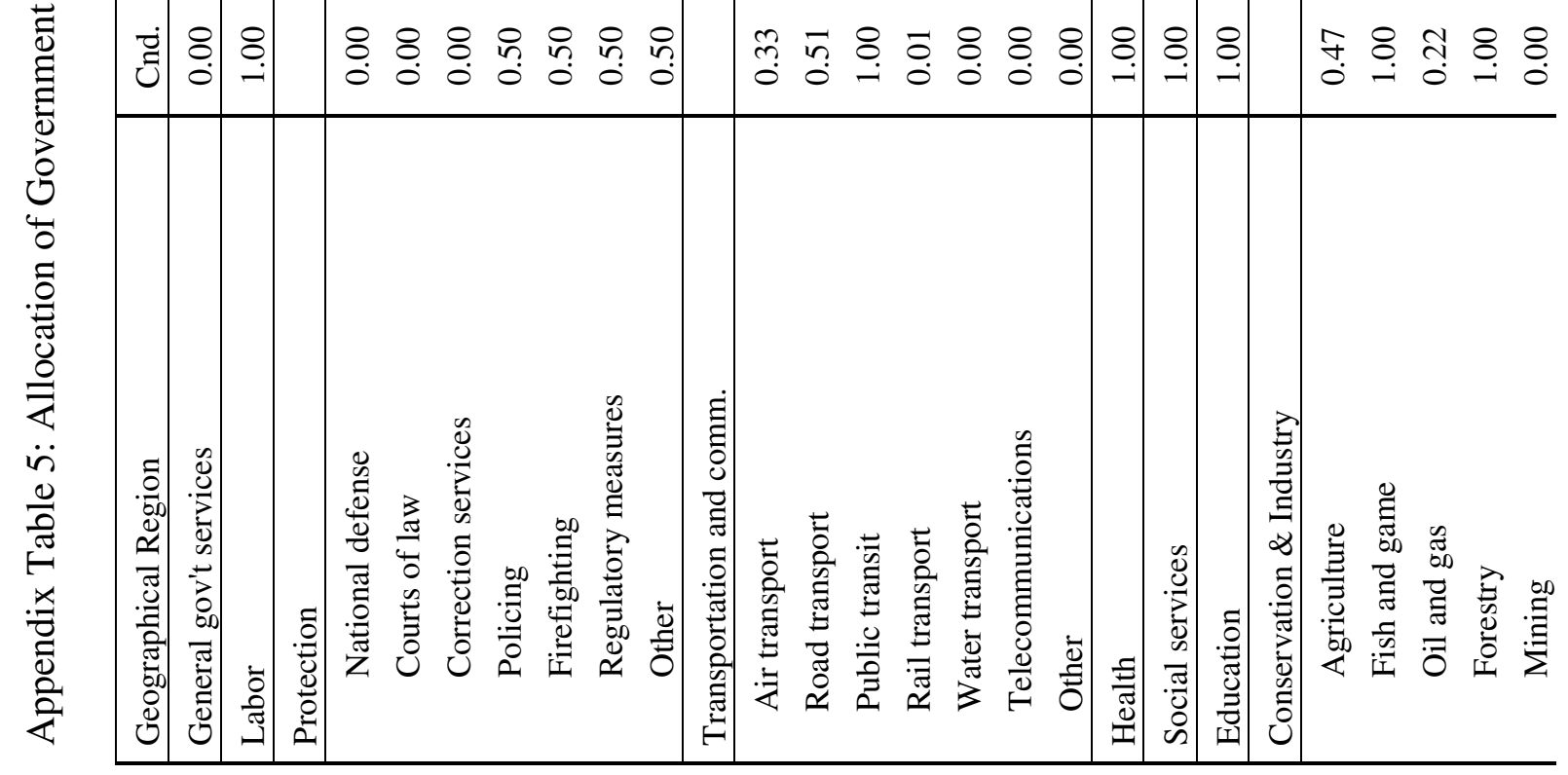




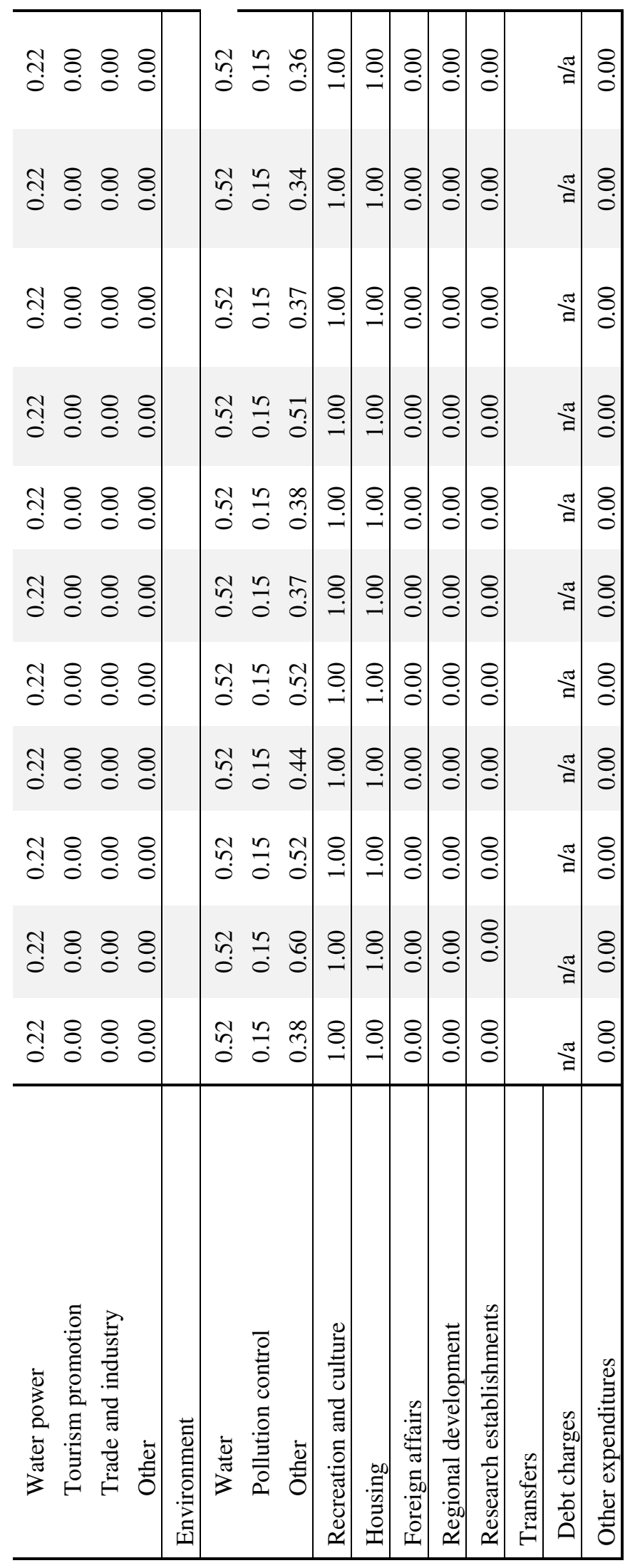




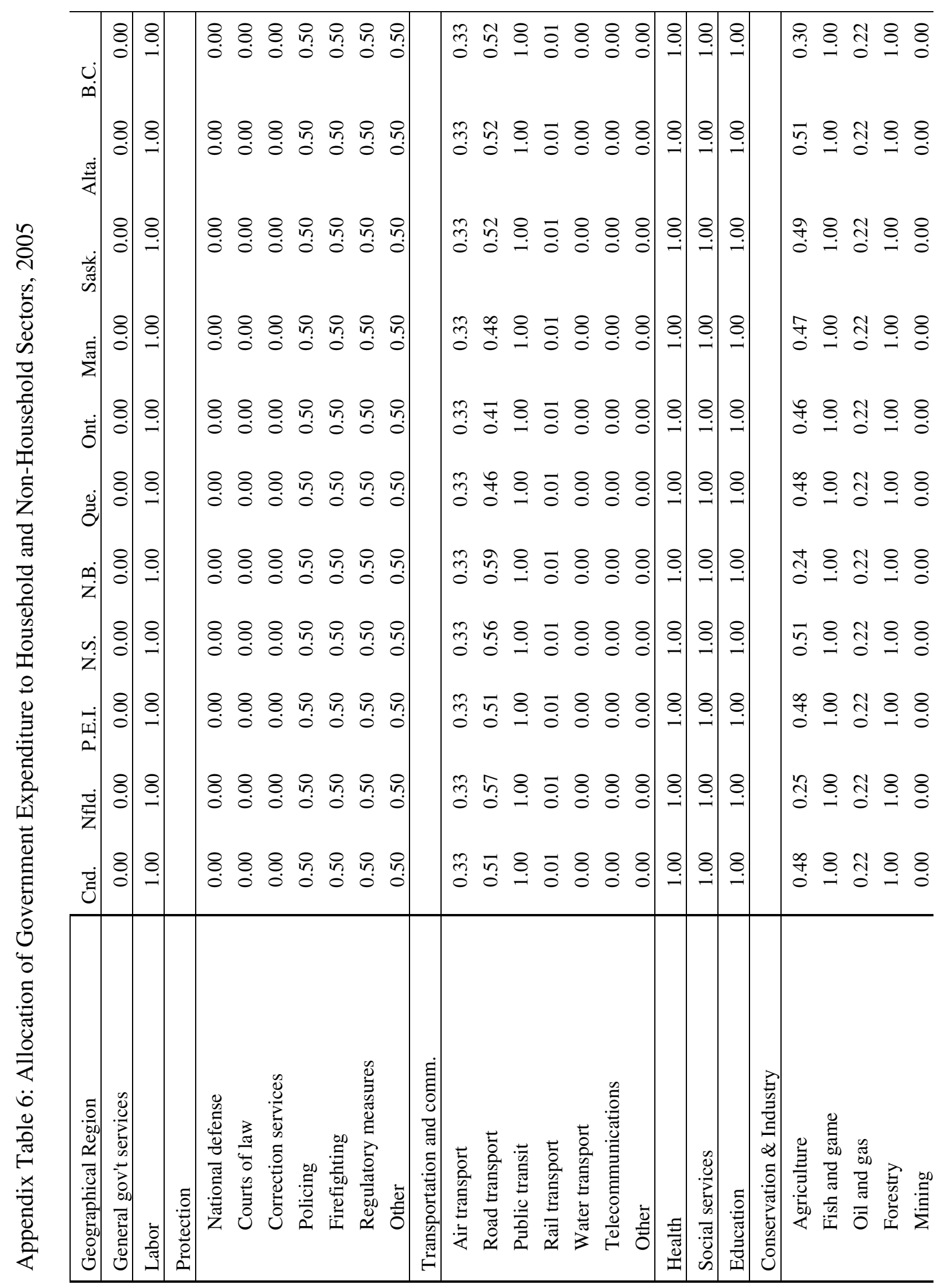




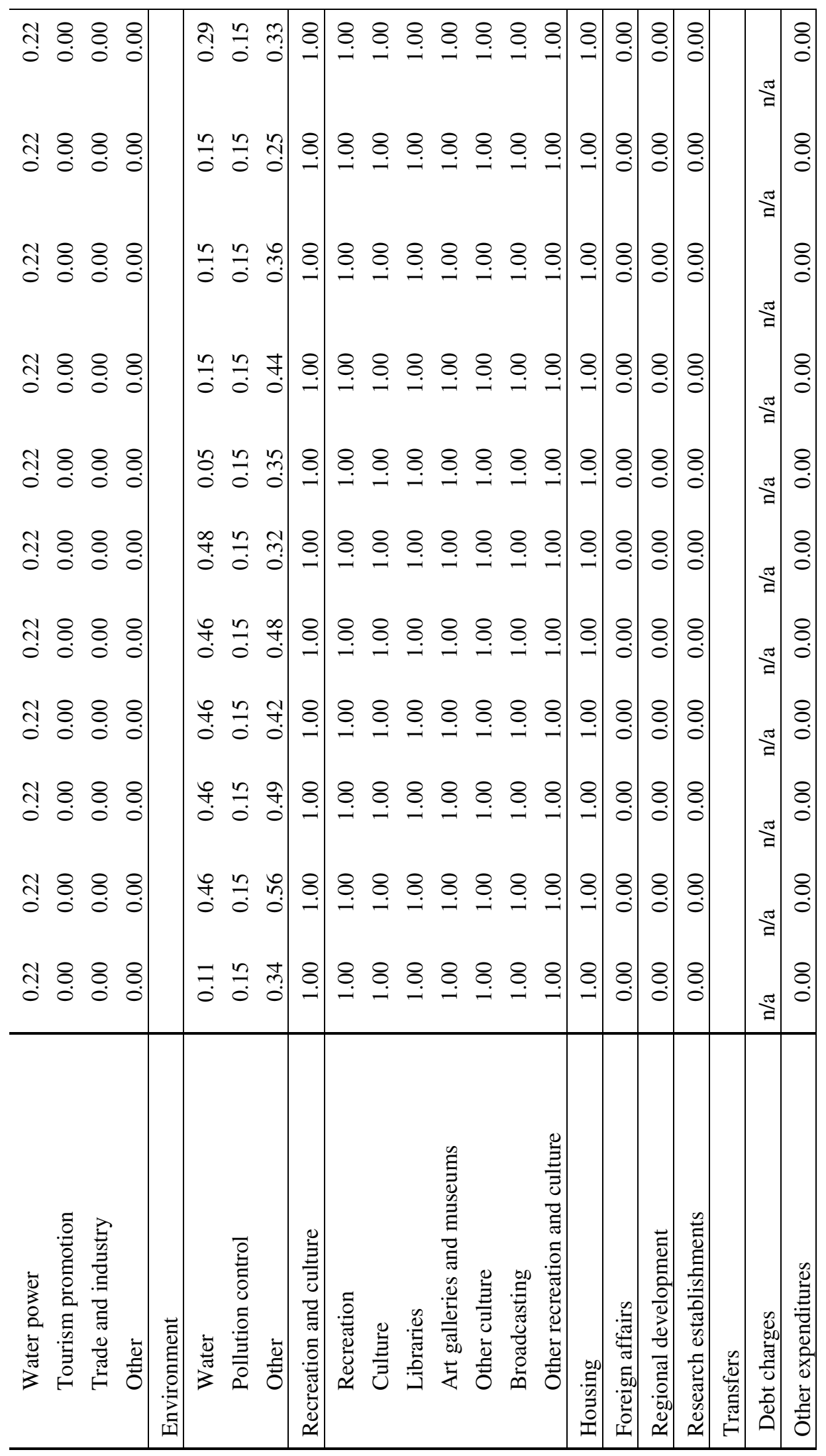


Appendix Table 7: Rates of Return for Assets, Canada, Per Cent per Year, 1999 and 2005

Real Estate and Business

Liquid Assets

Financial Assets

Pension Assets

Mortgage Debt

Other Debt

$\begin{array}{cc}\text { Nominal } & \text { Real } \\ 6.59 & 2.20 \\ 4.32 & 0.03 \\ 7.09 & 2.68 \\ 7.09 & 2.68 \\ 0.00 & -4.12 \\ 0.00 & -4.12\end{array}$

The rates of return are computed as follows:

Real Estate and Business: The method used in the US LIMEW could not be replicated in Canada due to the unavailability of data. We therefore estimate the rate of return by scaling the return on financial assets (see below) by 0.93 , which is the ratio of the return on real estate and business assets to the return on financial assets in the US LIMEW.

Liquid Assets: Equal to the mean of monthly year-over-year interest rates on non-checkable savings deposits with chartered banks, 1960-2009 (CANSIM series v122493).

Financial Assets: A weighted sum of the following:

- Canada treasury bills (2 month), 1960-2009 (CANSIM series v122554)

- Prime corporate paper rate (1 month), Canada, 1960-2009 (CANSIM series v122509)

- Conventional mortgage (5 year) with a chartered bank, 1973-2009 (CANSIM series v122521)

- Unweighted average of returns on 1-3, 3-5, 5-10 and 10+ year Government of Canada marketable bonds, 1960-2009 (CANSIM series v122485, v122486, v122487 and v122558)

- Combined time series on provincial bond yields:

-- 1960-1979: McLeod, Young and Weir bond yield average (provincials) (CANSIM series v122488)

-- 1980-2007: Scotia Capital Inc. average weighted yield, provincials (long-term)

(CANSIM series v122517)

- McLeod, Young and Weir bond yield average (municipals), 1960-1988 (CANSIM series v122489)

- Scotia Capital Ltd. Average weighted yield, all corporations (long-term) (CANSIM series v122518)

- Year-over-year growth in the Toronto Stock Exchange index (1960-2007) (CANSIM series v7668)

- Year-over-year growth in the S\&P 500 index, 1960-2007

(http://www.gpoaccess.gov/eop/tables09.html)

The weights are based on the shares of each asset type in their combined total.

Pension Assets: Assumed equal to the return on financial assets (see above). 